Portland State University

PDXScholar

$1-1-2011$

\title{
Identifying Regional Centers in Washington County, Oregon
}

Kevin Christopher Rancik

Portland State University

Follow this and additional works at: https://pdxscholar.library.pdx.edu/open_access_etds Let us know how access to this document benefits you.

Recommended Citation

Rancik, Kevin Christopher, "Identifying Regional Centers in Washington County, Oregon" (2011).

Dissertations and Theses. Paper 636.

https://doi.org/10.15760/etd.636

This Thesis is brought to you for free and open access. It has been accepted for inclusion in Dissertations and Theses by an authorized administrator of PDXScholar. Please contact us if we can make this document more accessible: pdxscholar@pdx.edu. 
Identifying Regional Centers in Washington County, Oregon

by

Kevin Christopher Rancik

A thesis submitted in partial fulfillment of the requirements for the degree of

\author{
Master of Science \\ in \\ Geography
}

Thesis Committee:

Thomas Harvey, Chair

Teresa Bulman

Hunter Shobe

Portland State University

(C)2011 


\begin{abstract}
An increasing national focus on problems related to urban sprawl has fueled debate on the best way for urban areas to accommodate increasing populations. Portland, Oregon has attracted international attention for its growth policies, which are among the most stringent in the United States. Metro, the area's regional government in charge of long-range planning, has designated certain locations as regional centers where increased density and development are to occur. A logical question is whether or not these centers are developing as intended; do Metro's plans match reality on the ground? This study of Washington County, Oregon analyzes land value, building volume, road intersection density, and public transportation availability using ArcGIS to locate potential regional centers in the county to answer that question. Subjective criteria are used during field visits to these locations to determine whether potential centers identified in the ArcGIS analysis are truly regional centers. Change over time is analyzed from 2000 to 2010 to see if the variables mentioned above contribute to regional center development. This study's results show Metro's designated regional centers are, in fact, regional centers or emerging regional centers using the above criteria, meaning this aspect of Metro's plans do match reality on the ground. Commercial land value tends to be the strongest indicator of regional centeredness. This study's findings aid in the understanding of urban areas. They help urban planners in their efforts to create viable plans that accommodate population growth and future development.
\end{abstract}




\section{Contents}

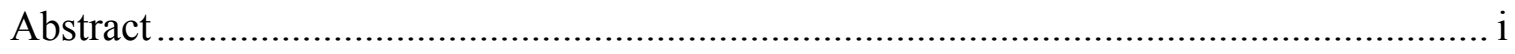

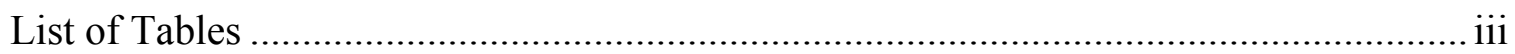

List of Figures and Maps …………….............................................................. iv

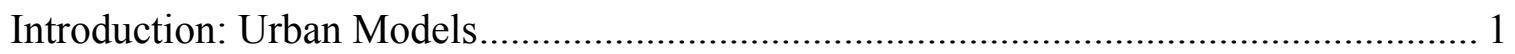

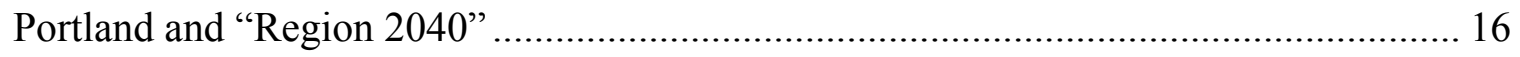

Data

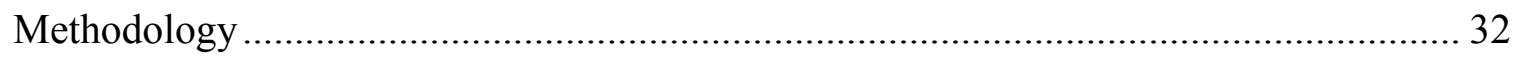

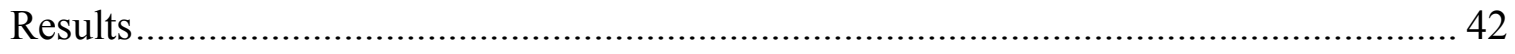

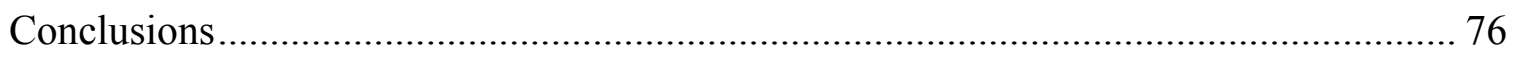

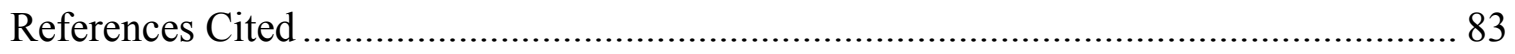

Appendices
A. Region 2040 Growth Concept Maps.............................................................. 91
B. Complete ArcGIS Analysis Model ................................................................. 94

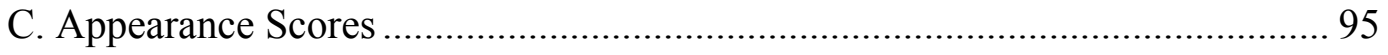

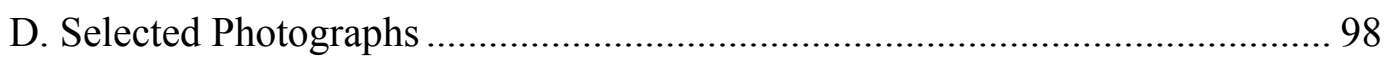




\section{List of Tables}

1. Field observation sheet template.......................................... 40

2. Field observation scores................................................... 59

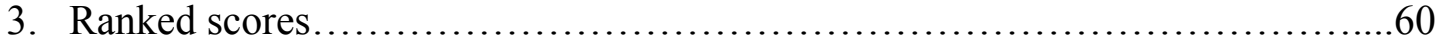

4. Metro-designated centers and results from each portion of the analysis..........62

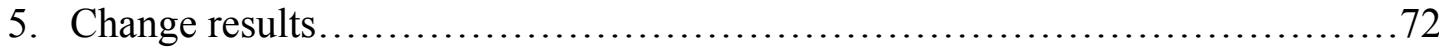

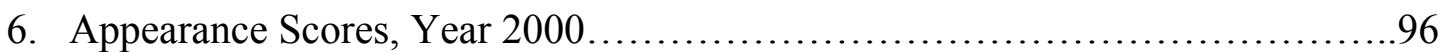

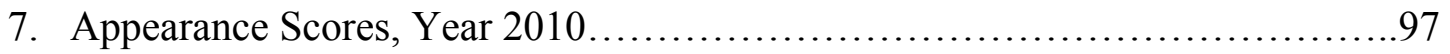




\section{List of Figures and Maps}

1. Burgess' concentric ring model..........................................

2. Hoyt's sector model................................................6

3. Multiple-nuclei model................................................ 9

4. Vance's urban realms model...............................................11

5. Urban realms model applied to the Los Angeles, California metropolitan

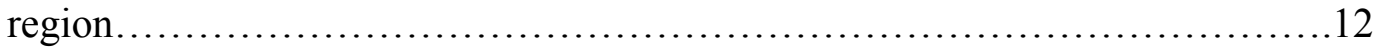

6. White's model of the twentieth-century city ............................... 13

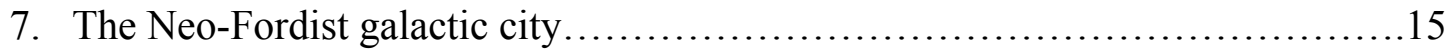

8. Portland metropolitan area in context of the Pacific Northwest................. 17

9. Close-up of Portland metropolitan region................................ 17

10. Throop's 1948 diagram of the Portland metropolitan region...................21

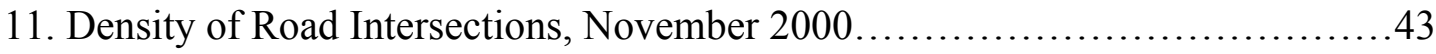

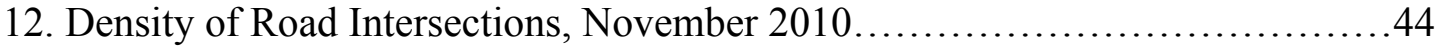

13. Density of TriMet Public Transportation, November $2000 \ldots \ldots \ldots \ldots \ldots \ldots \ldots . \ldots 45$

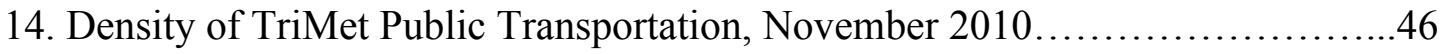

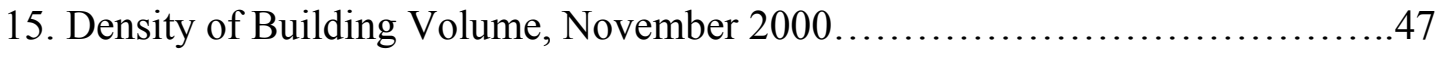

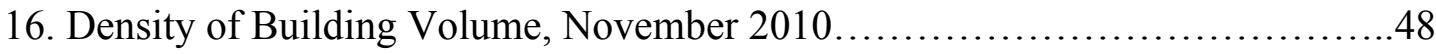

17. Density of Total Value of Commercial Taxlots, November $2000 \ldots \ldots \ldots \ldots \ldots . . .49$

18. Density of Total Value of Commercial Taxlots, November $2010 \ldots \ldots \ldots \ldots \ldots \ldots . .50$

19. Density of Total Value of Multi-Family Residential Taxlots, November 2000...51

20. Density of Total Value of Multi-Family Residential Taxlots, November 2010...52

21. Density of Value per Square Foot of Commercial Taxlots, November 2000.....53 
22. Density of Value per Square Foot of Commercial Taxlots, November 2010

23. Density of Value per Square Foot of Multi-Family Residential Taxlots, November 2000

24. Density of Value per Square Foot of Multi-Family Residential Taxlots, November 2010 .56

25. Study Results....................................................64

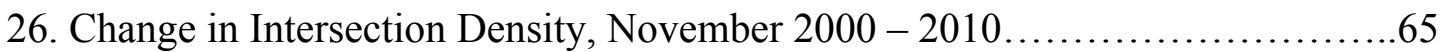

27. Change in Public Transportation Density, November 2000 - 2010.............66

28. Change in Building Volume Density, November $2000-2010 \ldots \ldots \ldots \ldots \ldots \ldots . \ldots 6$

29. Change in Commercial Density Using Total Taxlot Value, November 2000 -

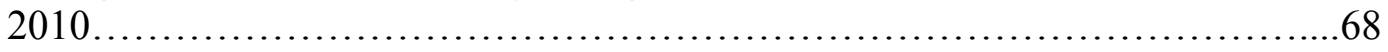

30. Change in Multi-Family Residential Density Using Total Taxlot Value, November $2000-2010$.

31. Change in Commercial Density Using Value per Square Foot, November 2000 2010 .70

32. Change in Multi-Family Residential Density Using Value per Square Foot, November $2000-2010$. .71

33. Early version of the Region 2040 concept map..........................91

34. 2005 update of the Februrary 2003 Region 2040 concept map..................92

35. 2011 update of the Region 2040 concept map............................93 


\section{Introduction: Urban Models}

Throughout human history cities have been dynamic centers of culture and innovation (Mumford 1961). They have been centers of government and centers of economic activity. Cities are where transportation routes converge and where various goods and services can be obtained and where people can indulge in entertainment. Cities, once a rarity, are now where half the world's population lives (UN 2002). By the year 2000, the United States was $80 \%$ urban (Alig et al. 2004). The United States has experienced rapid growth in its cities, primarily in suburbs. Suburban low-density development outside older cities and urban areas was home to half of the American population in the year 2000 (Nicolaides et al. 2006). The shift toward low-density suburban growth has changed the form, and to an extent the functions, of American cities. Various social ills such as heavy traffic, a rise in obesity, and isolation have all been attributed to the growth of suburbs, and remedies such as New Urbanism which call for a return to more "traditional" development patterns have been proposed to fix these ills (Hagerman 2007). The state of Oregon mandates the use of urban growth boundaries in an effort to contain urban growth and preserve agricultural and natural land (Kline 2005). Metro, the regional government of Portland, the largest city and metropolitan area in Oregon, is in charge of the region's growth planning and has adopted Region 2040. This plan directs growth towards centers and aims to create a vibrant urban region (Metro 2009). Regional centers are larger centers expected to develop into high-density locations with a multitude of services and transportation options. Portland's urban growth boundary and elected regional government are together unique in the United 
States (Moore 2008). Portland may be experiencing trends and growth patterns different from other cities in the country, and this study explores Washington County in an effort to determine whether the plan's regional centers are coming to fruition and what may be contributing to their growth. This discussion begins with an overview of urban models and their attempt to explain the growth of urban areas in the United States.

A variety of urban models have been set forth to explain the distribution of land uses in cities, particularly in the Western world. The authors of these models sought to explain why, for example, higher-income residents would choose to live in the location they did or why factories would congregate in a certain part of a city. Early in the 1900s at the University of Chicago, a school of thought developed that attempted to explain the city of Chicago in a scientific manner (Simpson and Kelly 2008). The early urban models came out of the Chicago school, inspired by the concept of human ecology (Pacione 2005). In this school of thought the city was viewed as akin to a living organism. Different parts of the city comprise different ecological units with defining characteristics (Knox et al. 2005). The biological concepts of invasion and succession play a large role in the early models. Social interaction is placed in the context of competition for living space; as different cohorts of society gain wealth compared to others, and as immigrants with little power or organization arrive, groups of people move into and out of certain areas.

Ernest Burgess' concentric ring model was the first of the Chicago school. His essay The Growth of the City was built on a number of theories popular at the time, including the ideas that society progresses linearly from traditional to modern states and that cities have centers which unify their hinterlands into a whole unit (Fyfe et al. 2005). 
Expansion of the city is a process based strongly upon the invasion and succession concepts mentioned above (Burgess 1925). In Burgess' model the center of a city is its central business district (CBD), shown as the "loop" in Figure 1 below. Government services, high-density neighborhoods with skyscrapers, and cultural amenities such as theaters create the city's "center." The center has the greatest access to transportation and the highest land values, a point later reiterated by Harris and Ullman in their 1945 article The Nature of Cities. Transportation has a direct impact on the higher land values in the center. The city's roads, rails, and public transportation converge on the CBD. This, combined with the services and jobs that attract people from the region, attracts the greatest number of customers and provides businesses with the greatest amount of visibility. Commercial land uses outbid all others for land here.

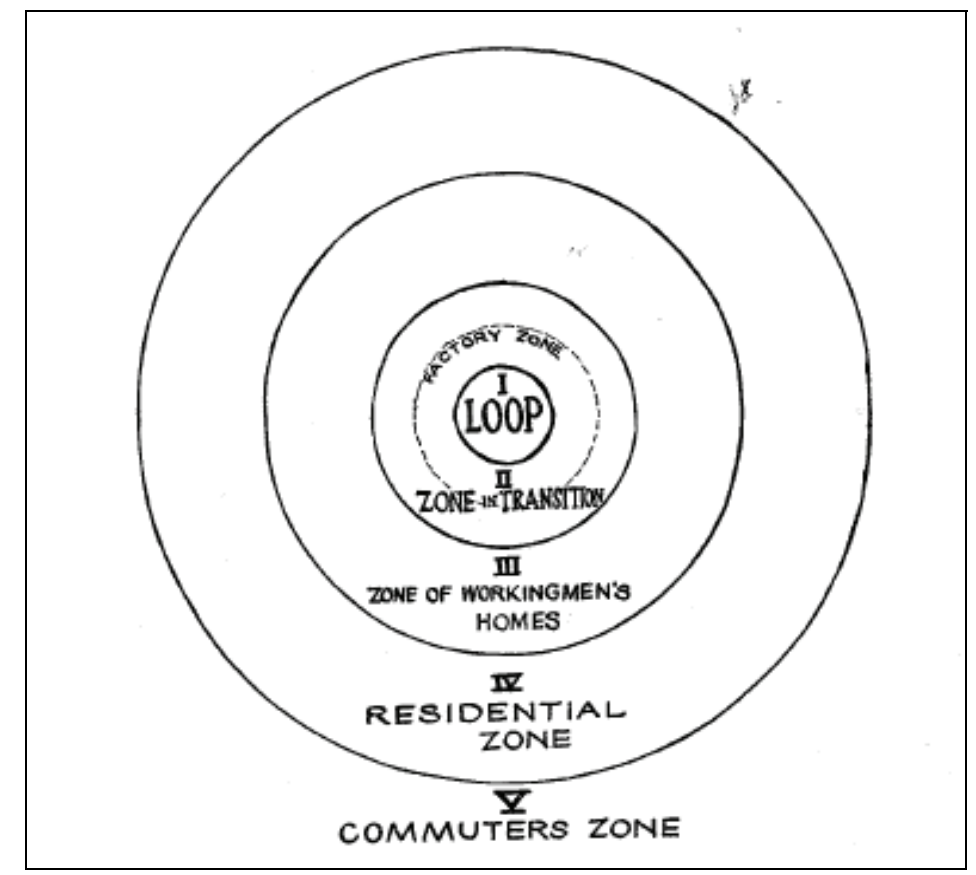

Figure 1

Burgess' concentric ring model (Burgess 1925) 
Surrounding the CBD is what Burgess calls a zone in transition. Businesses gradually move outward as the city, and the CBD, grow and expand. Manufacturing and light industry exist here as well, taking advantage of the transportation routes which allow them to easily and more cheaply receive and export goods.

Where the residential and industrial zones converge is a "zone of deterioration." In other words, these two types of land uses are fairly incompatible. Industrial functions, especially during the era during which Burgess lived, generate a great deal of pollution and noise. These nearby locations create undesirable conditions which gradually push residents away and farther from the city center, leaving an abandoned and deteriorating residential area in their wake. Beyond the zones in transition and deterioration are the residents of the city. Each zone of residents consists of a different group of people generally separated by income. The inner-most residential zone includes the lowestincome residents of the city. This first zone is beyond the zone of deterioration; these residents have "escaped" that area but are still within easy access of their jobs closer to the core. The next zone includes residents of higher income and more exclusive neighborhoods, and still farther beyond this is the commuter zone. The commuter zone includes satellite cities that are largely dependent on their parent city; most residents here continue to do business and work in the city. Because Burgess' model consists of numerous rings it has also become known as the concentric ring model. A critical concept of the model is that each of the rings expands by slowly moving outward and subsuming locations formerly occupied by a different ring. Each land use invades a new area and succeeds the previous one. 
Burgess' model was, and still is, seen by some as oversimplified. In addition to being an overly simple explanation of the complexities of a city, his concentric ring model was built solely on observations and work performed in Chicago. Among the more influential alternatives to Burgess' model was Homer Hoyt's sector model of the city. Whereas Burgess was concerned with the social organization of a city, Hoyt was more concerned with suburban locations and affluence (Fyfe 2005). Hoyt's research is based on data from more than 140 cities across the United States and was performed for the Federal Housing Administration (Knox et al. 2005). Hoyt's analysis involves the mapping of rent values for every residential block in a city (Pacione 2005). Hoyt's conclusions incorporate transportation and are directly related to the locations of affluent neighborhoods.

In Hoyt's model, seen in Figure 2, the central business district remains the center of the metropolitan region. Though concentric rings of land use and residential wealth segregation still exist, they exhibit differences from those of Burgess' model. Hoyt posited the wealthiest residents have the greatest choice in where they live. They occupy more desirable, pricier locations as a result. These locations are far from noisy and polluted industrial centers. Fast transportation options such as commuter rail or major roads guide high-wealth growth (Hoyt 1939). Open spaces with natural attractions such as forests or areas at higher elevations and less prone to flooding also attract high-wealth residents. 


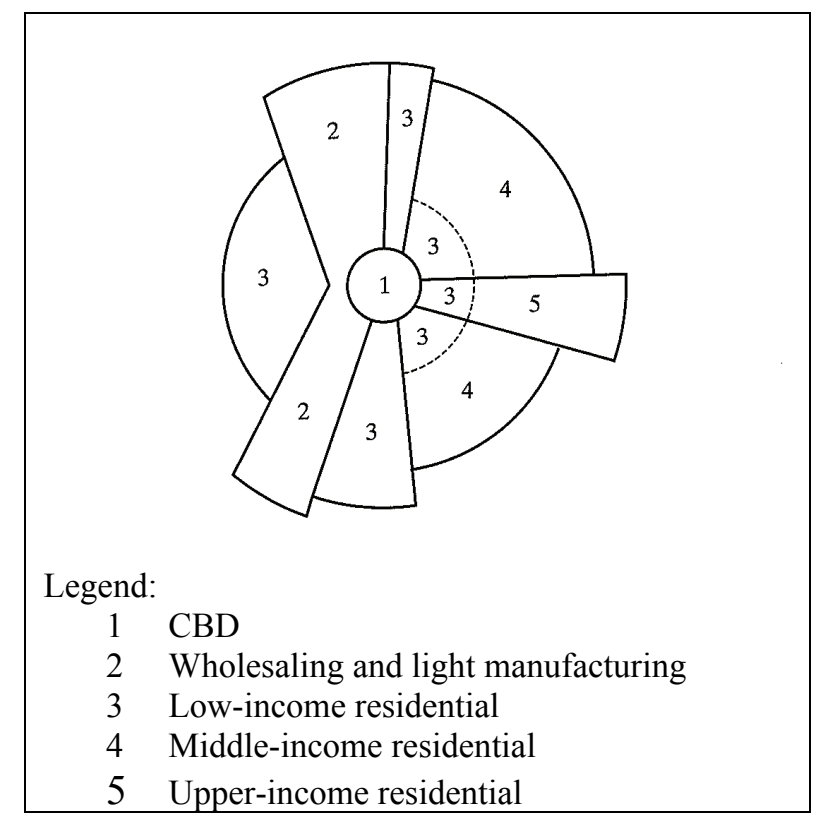

\section{Figure 2}

Hoyt's sector model (Knox et al. 2005)

As high-wealth residents move outward from the city center they leave behind vacant homes. These homes "filter" down to the next income level. As middle-income residents move in to these newly vacated homes they also leave behind vacant homes. Lower-income residents then move in to what was once a middle-income neighborhood. This filtering of households from one income group down to the next theoretically continues until the lowest value homes are in such poor shape that nobody is willing to buy them (Hoyt 1939, Knox et al. 2005, Pacione 2005). High-end commercial services also follow this trend, but they follow the high-wealth residents rather than attract them in the first place. In other words those services are followers, not leaders.

These ideas are shown in the visualization of the sector model (Figure 2). The high-wealth residential zone radiates outward from the CBD in a straight line along some sort of transportation corridor with easy access to the CBD. The industrial zone, located 
on the opposite end of the city from the high-wealth residential zone, also radiates out from the CBD. Industrial areas are also located along transportation corridors but instead along rails and roads more suited for freight rather than commuters. Lower-income residents occupy the zones alongside the industrial areas as those locations are less desirable and have been vacated by those of higher socioeconomic status. In some cases, including the development of shantytowns, high-income residents may have never lived in some of the low-income areas to begin with (Hoyt 1939). Middle-income residents predictably fill in the middle spaces between the low and high wealth residential areas. These locations are essentially in the middle of their life cycles as the high-income earners have left but the area remains unaffordable to those at the bottom of the socioeconomic ladder.

Despite a more thorough explanation of patterns in a city, Hoyt's model also received criticism. Although Hoyt observed that the widespread popularity of the automobile may have begun to change the patterns seen in American cities, he continued to defend his work (Fyfe et al. 2005). The automobile allowed residents more freedom of movement and opened new locations to development (Dieleman et al. 2004). Land use became less restricted. Even though his model attempted to address some of the shortcomings of the concentric ring model, Hoyt's sector model was also seen as overly simple (Pacione 2005). In 1945 Chauncy Harris and Edward Ullman published an article called The Nature of Cities. In it they set forth their multiple-nuclei model. Rather than being arranged in specific layout, different land uses are located in certain areas based upon their relationships with other nearby uses (Knox et al. 2005). Harris and Ullman did not believe cities formed around a single CBD, but that instead urban areas that 
developed around separated nuclei gradually integrate together (Pacione 2005). Cities and their suburbs specialize in certain activities based on the resources and demand in their vicinity. Harris and Ullman (1945) point out Miami, with its beaches and pleasant climate, specializes as a resort town. Suburbs can also specialize in certain functions. Hamilton (1987) noted that Portland's western suburbs of Beaverton and Hillsboro are part of the "Silicon Forest," specializing in high-tech industry.

Figure 3 shows a generalized diagram of the multiple-nuclei model. The CBD remains the largest and most visible center in the region. As in both the concentric ring and sector models, manufacturing areas are adjacent to or somewhere near the CBD and are surrounded by low-income residential areas. Even with adoption of the automobile and changes in America's transportation network during this era, locations near polluting factories and industrial zones remain the least desirable places for residents. Also similar to the concentric ring and sector models are the locations of the middle and high-income residents. The high-income residential zone lies in the contiguous urban area farthest away from the CBD and is at the opposite end of the urban area from industrial land uses. Separating the high-income area from the low-income and CBD zones is a large swatch of middle-income residents. Land uses attract others like themselves while repelling others (Knox et al. 2005). 


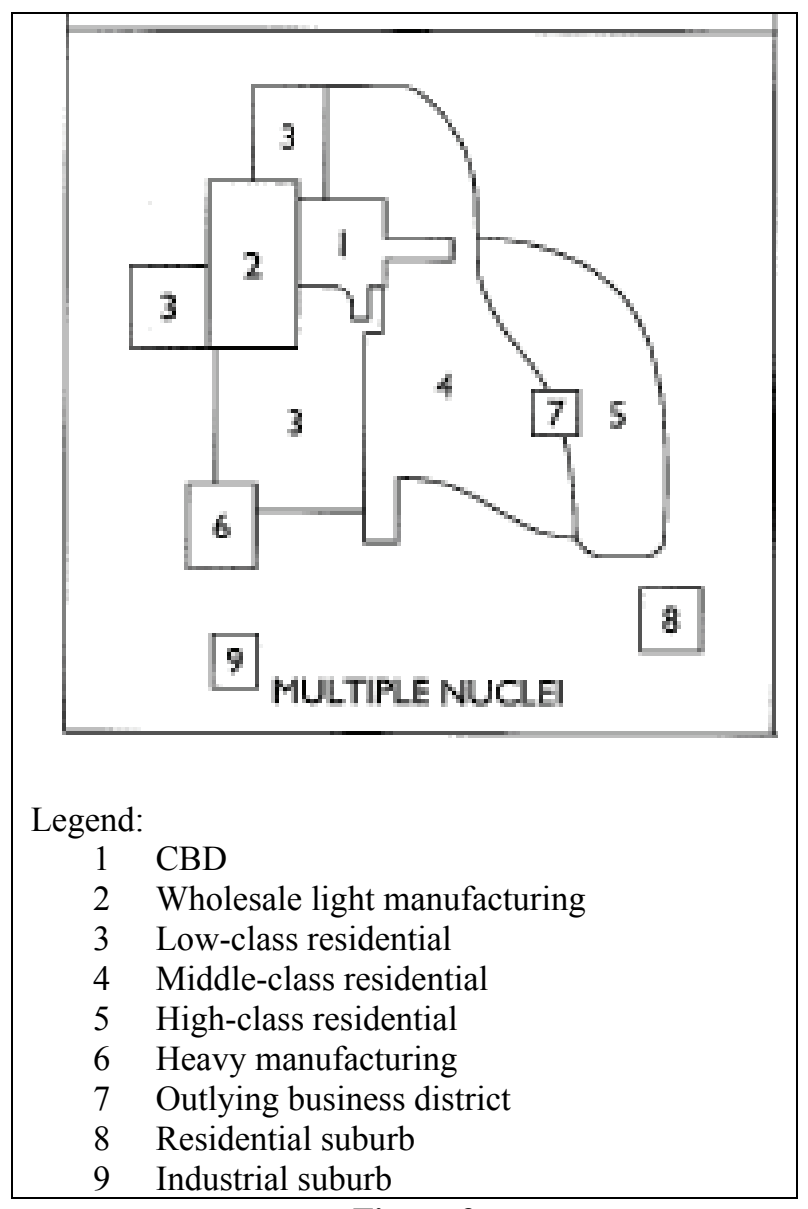

Figure 3

Multiple-nuclei model (Harris et al. 1945)

Hoyt posited that the CBD would gradually move toward and "follow" the highwealth residents as they moved outward. Unlike the older models, the multiple-nuclei model includes one or more outlying business districts. Here the CBD remains in place. Instead the business district catering to these residents lies along the boundary between middle and high-wealth residential areas. These "secondary downtowns" (Garreau 1992) may duplicate enough functions of the original CBD that some residents may never visit the original (Knox et al. 2005). These do not necessarily appear spontaneously, but are 
generally anchored by a mall, highway intersection, university, or some other function of importance (Garreau 1992, Harris et al. 1945).

Specialized suburbs also exist in this model. In the diagram are a residential suburb and an industrial suburb. Commuting to the main urban area from these suburbs may be limited despite their economic connections to that nearby urban area.

Improvement of rail lines and use of automobiles contributes to suburbanization in these locations which may be miles away from the CBD (Harris et al. 1945). Though growth in locations far from the CBD seems normal today, at the time it was a fairly new phenomenon.

The multiple-nuclei model contains many elements of today's cities. Still, this model met criticism. This one, along with the two that came before it (together known as the "classic" models), were seen as favoring economic over cultural influences in urban land use (Pacione 2005). The dramatic expansion of suburbs in following World War II consumed hundreds of square miles with new housing construction (Knox et al. 2005) which adjusted urban form. Descriptions of urban form have generally grown more complex, and terms used in these subsequent descriptions have come to be so numerous that Lang (2003) identifies over two-hundred in current use.

Among the more notable post-classic models is James Vance's urban realms model, a 1964 extension of the multiple-nuclei shown in Figure 4 (Pacione 2005). 


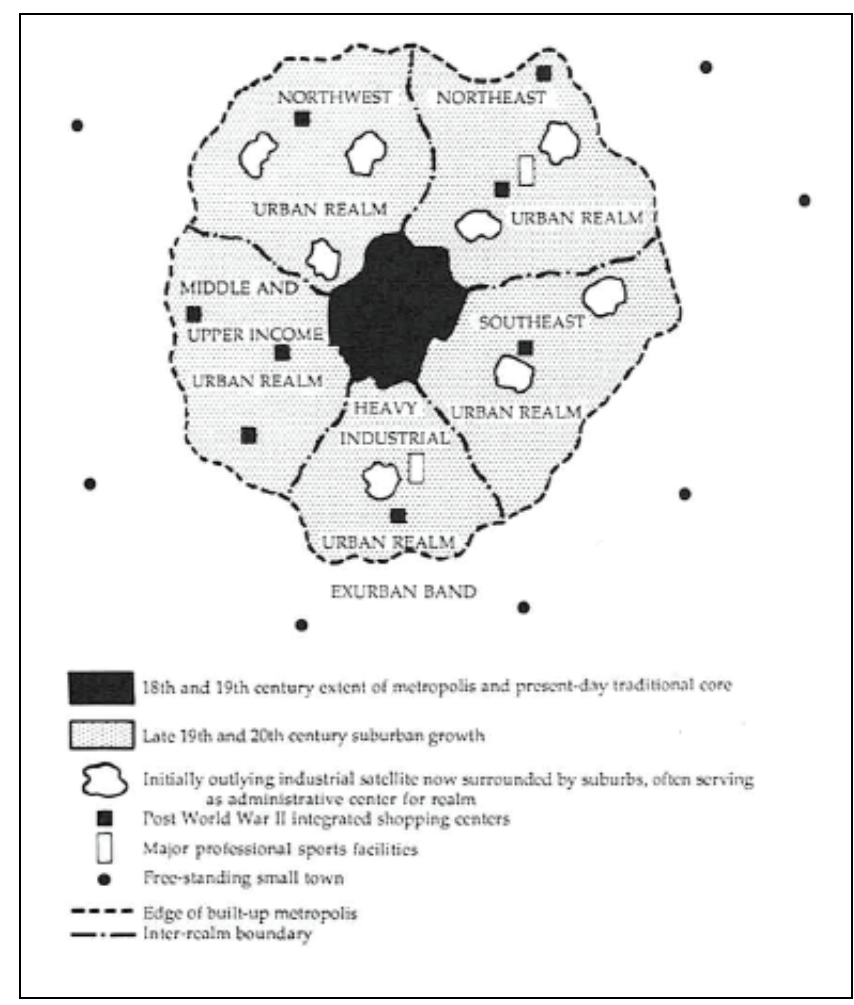

Figure 4

Vance's urban realms model (Vance 1990)

In it the secondary downtowns and business districts of the multiple-nuclei model have reached a point where they anchor an urban "realm" of their own. These realms offer nearly all of the services as the original CBD and have populations of up to a quarter-million (Knox et al. 2005). They include residential, commercial, and industrial areas. In essence each realm functions as a separate urban region, anchored upon its own CBD. In his research Vance noted the original, traditional CBD of San Francisco was becoming more specialized in financial services and that employment there was increasing at a slower rate than elsewhere in the Bay Area (Vance 1964). It can be surmised the original CBD will, in a sense, devolve into a specialized urban realm, mostly separated from the locations which once called it their anchor. Some realms are specialized, as in the case of the heavy industrial realm. Each realm has its own shopping 
centers, and each includes a former satellite of the original CBD which now anchors its own realm. Though Vance based his research on San Francisco, Brian Godfrey (1995) studied socioeconomic of the New York area and came to the conclusion the urban realms model applies there. Carl Abbott (2006) later came to the same conclusion and noted the model also applies to Chicago. Figure 5 illustrates the urban realms concept applied to Los Angeles, California.

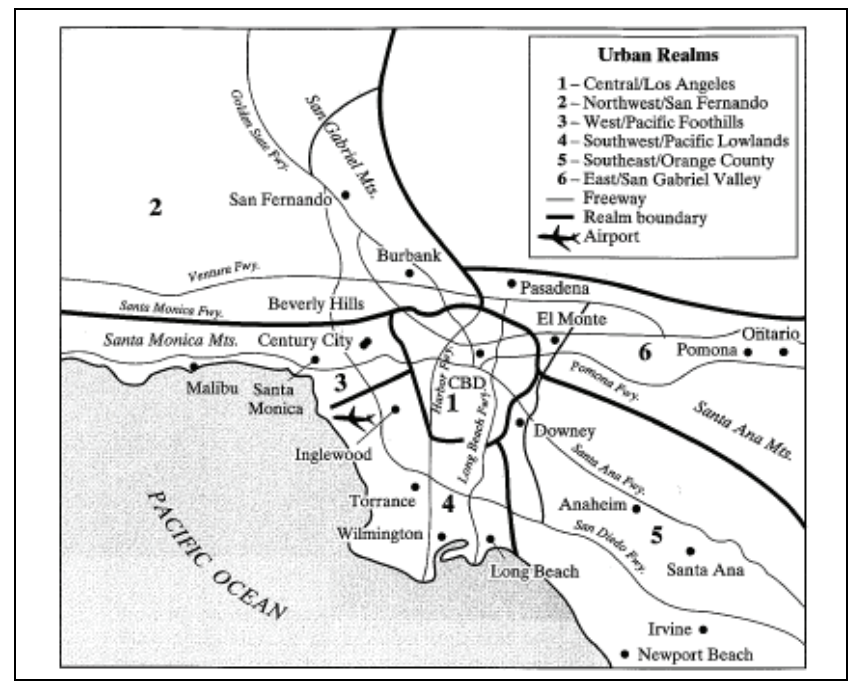

Figure 5

Urban realms model applied to the Los Angeles, California metropolitan region (Knox et al. 2005)

In 1987 Michael White revisited and revised the Burgess model to incorporate modern cultural and technological trends (Pacione 2005). Among such trends were deindustrialization, the rise of a service economy, the move from automobile dominance to dependence, reduced family sizes, and continued low-density residential development. Figure 6 shows White's model. The CBD, or "Core" in the figure, remains the focus of the region. Images of its skyline represent the region. Large corporations call it their home. Redevelopment of downtowns has begun and often includes a residential component. 


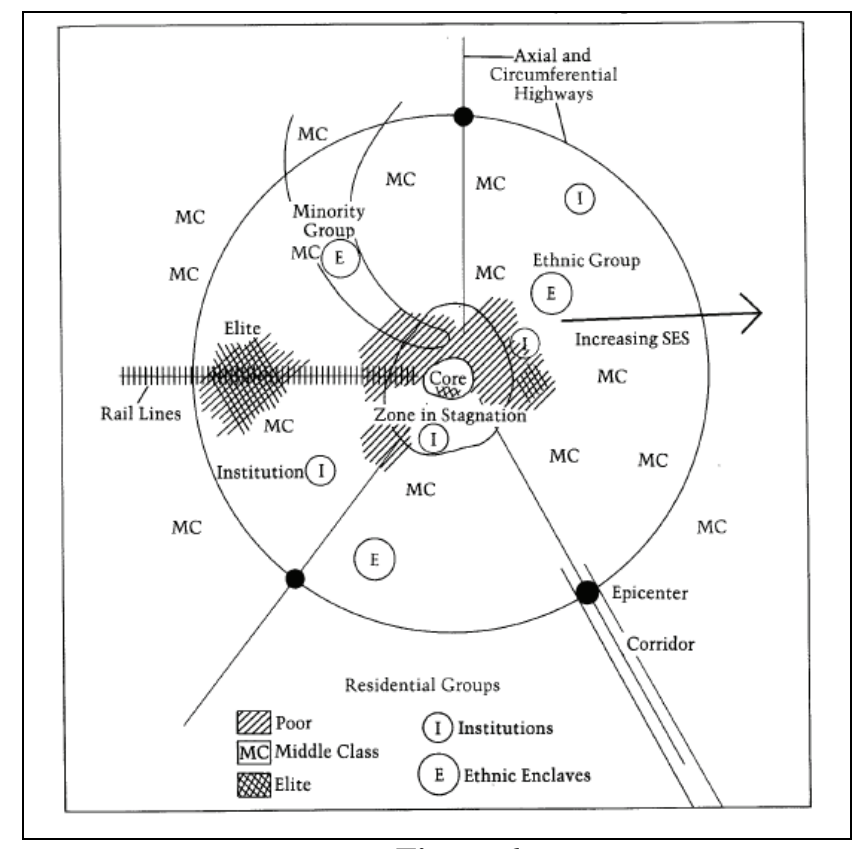

Figure 6

White's model of the twentieth-century city (White 1987)

Burgess' zone in transition has not been enveloped by CBDs because the CBDs have grown upward rather than outward with advances in construction technology. Residential projects there have instead been torn down. Highways have been built through those locations, and vacant land is relatively abundant there. In this general location are "pockets of poverty" (White 1987). Residents at the bottom of the socioeconomic ladder, including homeless, inhabit this area. Housing is likely to be in poor condition. This zone may not be limited to the central city; some older suburbs may also have a zone in stagnation (Pacione 2005). Upper-income elite areas tend to congregate at the suburban fringe in formerly-rural or agricultural areas. Middle-income residents, as in the other models, occupy the areas between the lower and upper income residents. 
Missing from the earlier models but present here are the "ethnic enclaves" and racial components of social geography. Segregation may officially be gone but congregation remains. In some cases it may be by choice; people want to live near others like themselves. In other cases this may be due to the relative position of the group in American society; for instance, recent immigrants may occupy low-income areas which have always been low-income and in general cannot leave the area. The legacy of segregation may also be a cause. People who lived in formerly segregated areas may simply have chosen not to leave. Garreau (1992) notes these aspects in his research, particularly in regards to his visits to Atlanta suburbs. Though class has become a more important aspect to new arrivals in Atlanta, large swaths of the city and its suburbs remain highly segregated racially. Garreau points out Hunter Hill, an affluent suburb, is nearly all black. Other suburbs feature a nearly all white population. White's model acknowledges these ethnic enclaves and the fact they, in addition to class concerns, influence peoples' behavior.

Institutions such as universities, hospitals, and large business parks also influence the land uses around them. A university for instance, may be physically located in an area that otherwise makes up the zone of stagnation. However, administrators and city officials are unlikely to let the immediate area around the university decline. Infrastructure may be better maintained in that area than in others of the city (Pacione 2005). Police may increase patrols in the area, and this may create a pocket of low crime and relative safety (White 1987). An institution in a wealthier suburb may serve as the anchor for an edge city or secondary downtown, and thus influence land use in that location as well. These edge cities, or epicenters as White calls them, also tend to form at 
major highway intersections, and these highway corridors have functionally replaced Main Streets. Sometimes these edge cities become so large they even overshadow the original CBD (Knox et al. 2005).

Figure 7 illustrates the Neo-Fordist galactic city. The galactic city can be seen as an amalgamation of concepts applied in the models already discussed.

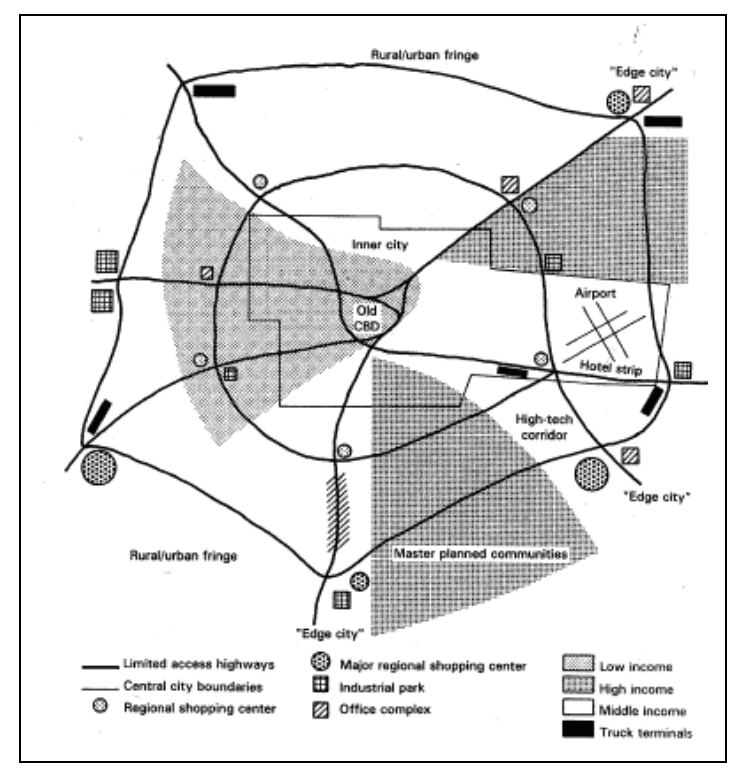

Figure 7

The Neo-Fordist galactic city (Knox et al. 2005)

Edge cities and employment areas occur at highway intersections. Residents of different incomes occupy different locations in the city, with low-income residents clustered around the $\mathrm{CBD}$ and inner city and high-income residents choosing to locate near their jobs in the high-tech corridor and adjacent areas. Master-planned communities represent the large swaths of land converted into single-family subdivisions. The inclusion of an airport and nearby hotels in close proximity to the high-tech corridor are evidence of the increased importance air travel has in that industry and in today's economy in general. 


\section{Portland and "Region 2040"}

Portland, Oregon is served by an elected regional government known as Metro. Metro looks after the region's land use planning and growth (Gibson et al. 2002). The agency has adopted a growth concept known as Region 2040, an attempt at planning the Portland area's growth until the year 2040. Understanding the urban models previously described provides a generalized background on urban growth and urban structure which helps in the analysis of Metro's growth plans.

Portland is the largest city in Oregon (Census 2010). The urban area as a whole shares this distinction in the state. Four counties make up the core of this region: Multnomah, Clackamas, and Washington in Oregon, and Clark in Washington (note that Clark County does not fall under Metro's jurisdiction). The west-flowing Columbia River divides the Washington and Oregon portions of the region while the north-flowing Willamette River divides the western and eastern portions on the Oregon side. To the south of the urban area is the Willamette Valley, an agricultural region that also includes Salem, the state capital. In the United States' Pacific Northwest, Portland is outranked in population only by the Seattle metropolitan area. 


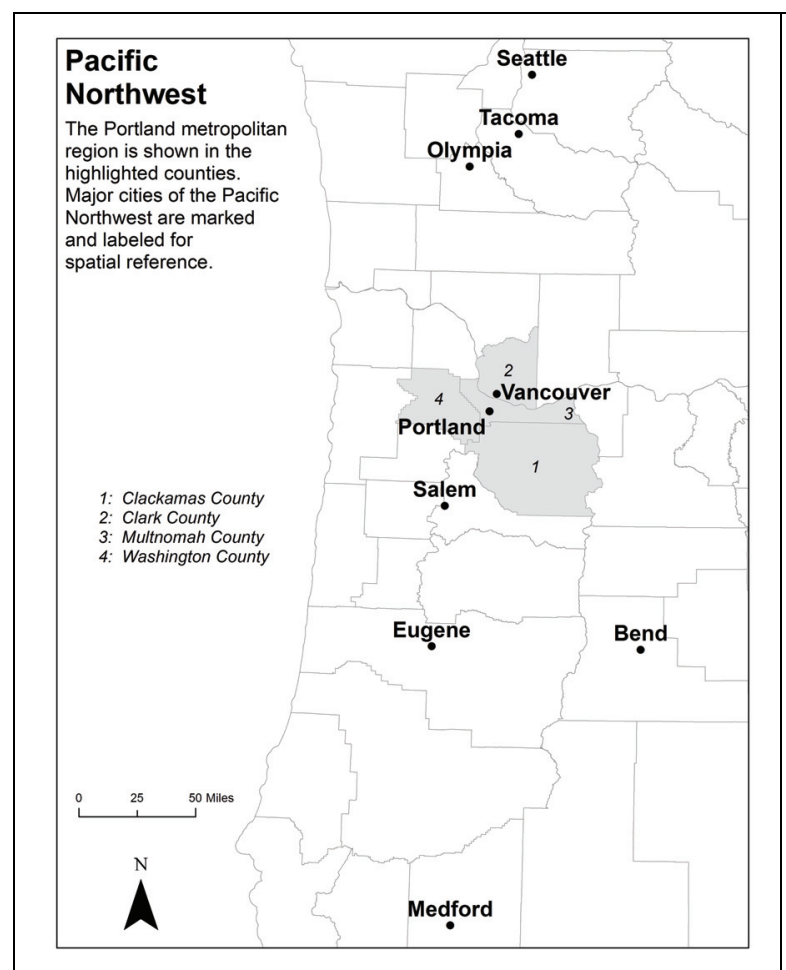

Figure 8

Portland metropolitan area in context of the Pacific Northwest. GIS data accessed from http://gis.oregon.gov/.

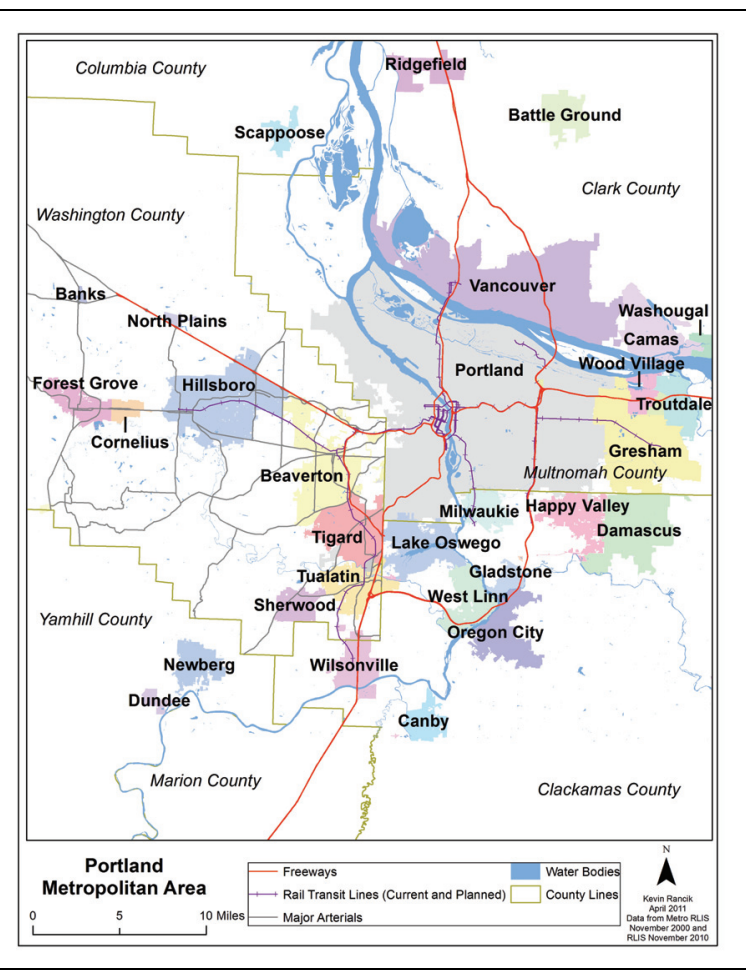

Figure 9

Close-up of Portland metropolitan region; incorporated cities highlighted in colors. Physically larger cities are labeled.

Forestry and agriculture were historically the major players in the region's economy, but as early as the 1940s the economy was diversifying (Throop 1948). Though both of those sectors remain important, high-technology firms, services, and manufacturing have driven much of the region's economic growth over the past few decades (Mayer et al. 2004). High-tech, much of which is located in Washington County, has become so prominent in the region that it has earned the nickname "Silicon Forest" (Hamilton 1987). Trade, especially of imported automobiles from Asia, has been and continues to be important as well (Gibson et al. 2002).

Portland has also been recognized as one of the greenest cities in America (Shandas et al. 2008), and many have lauded the region's overall quality of life (Yang 
2008). Sustainability is a major goal of Metro and the governments in its jurisdiction, particularly in the city of Portland itself. The region's public transportation system has one the highest ridership rates of commuters in the country, with some of the largest growth in that rate from 1990-2000 (Jun 2008). Green energy initiatives such as Beaverton's solar program (Fong 2011), the rising prominence of ecoroofs (Spolek 2008), and large number of LEED-certified buildings (Allen et al. 2008) contribute to the region's green image. Forest Park functions as something of a greenbelt with minimal development, beginning just west of Downtown Portland and stretching to the northwest beyond the urbanized area. The Urban Growth Boundary (UGB), enacted as part of a statewide program in the 1970s (Crowe 2011), clearly demarcates where urban growth can occur. It separates rural from urban land uses. Among its major goals are the protection of farmland and natural resources such as forests. Increasingly it has also been used as a method of urban sprawl prevention and for the protection of the region's natural beauty (Wheeler 2003). Portland's overall planning system is one of the most wellknown and recognized in the United States (Aurand 2010).

Metro's Region 2040 Growth Concept, the map for which is shown in Appendix A, has also earned the region a great deal of attention with it already being hailed as part of the region's growth management success (Chapman et al. 2004). Enacted in the 1990s (Song et al. 2004), the plan guides growth of the region to accommodate the one million more residents expected to move to the area (Redden 2009). Region 2040 calls for increased density and concentrated development, with the greatest growth directed toward locations identified as centers while keeping UGB expansions at a minimum. Transportation plays a key role in determining future growth as most of the growth is 
slated to occur along major transportation corridors (Adler et al. 2004). Metro divides centers into two types: regional centers and town centers (Metro 2011). The regional centers are intended to serve hundreds of thousands of people and include a variety of uses, such as commercial, civic, and cultural institutions. Building construction is expected to be in the range of two-to-four stories (Metro 2009). Seven regional centers were initially planned for the region (Metro 2000), but Metro has recently added the Tanasbourne/Amberglen area as a new regional center (Kane 2010). Eventually Metro intends for each of these regional centers to be connected to one another via rail service. Town centers will have some of the functions of regional centers but on a much smaller scale with a service area radius of two to three miles. Town center construction will be in the range of one-to-three story buildings with a lower density than in regional centers. Services will include those geared toward residents' every day needs (Metro 2009). Metro aims for each town center to have its own community identity as well as quality public transportation service. Unlike regional centers, each town center will not be interconnected to one another but will instead be channeled toward the local regional center. Ultimately the centers will be relatively self-sufficient with enough jobs, retail, and residents that most day to day business can be conducted within a matter of a few blocks (Metro 2010b). Downtown Portland and its environs (among them the South Waterfront and Lloyd Districts) will remain the focus of the entire region with the highest density and greatest concentration of civic and cultural services.

Outside of the centers are corridors, Main Streets, and station communities (Metro 2011). Corridors consist of major roads and transportation routes with high movement of people and freight. Main Streets have similar functions to town centers but 
are more linear and are more readily connected to the immediate vicinity. Public transportation is to be readily available on both corridors and Main Streets. Station communities are centered on light rail stops with small-scale retail stores and will be accessible to all types of transportation including cars, pedestrians, and bicyclists. The end result of the plan is a vibrant metropolitan region with a variety of transportation and housing options for residents and relatively increased density and compact urban form compared to other American cities. UGB expansion will be limited as the region is expected to grow up rather than grow out (Mayer et al. 2004).

The design of Region 2040 bears a striking resemblance to the multiple-nuclei and urban realms models discussed earlier. Despite the dominance of Portland's downtown in the region as a whole, the regional centers are expected to become dense enough and offer enough services that reasons to go to Portland may be diminished. Beaverton has expressed interest in building a stadium in its own downtown (Schmidt 2009) as well as in building its own performing arts center (Fong 2011b). Prior to the recent economic downturn, a 17-story tower was even on the books for downtown Beaverton (Schmidt 2009b). Hillsboro wants the Tanasbourne regional center within its city boundaries to become a district complete with high-rise, mixed-use towers, its own version of Portland's park blocks, and a light-rail extension (Hillsboro 2010). As these regional centers develop they will serve as the centers of their local urban realm with jobs, residents, entertainment, and government services.

This will dramatically change Portland's urban form. In 1948 Vincent Throop studied the region and determined it exhibited a concentric ring layout with extensions 
along highways that radiated out from the central city. A diagram of his findings is shown in Figure 10.

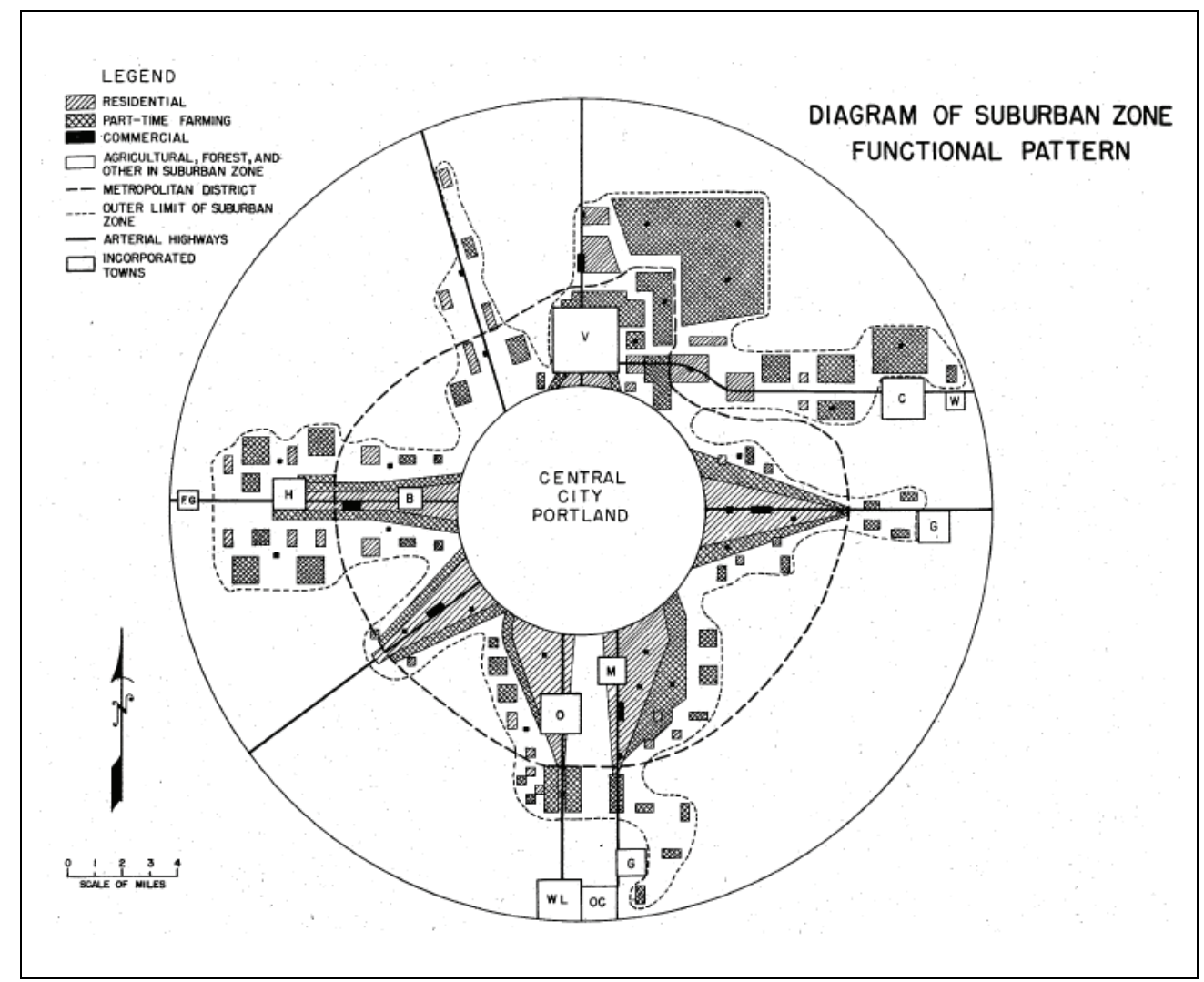

Figure 10

Throop's 1948 diagram of the Portland metropolitan region

Most local suburbs in existence today had populations far eclipsed by Portland itself; Gresham, which has over 100,000 residents today (Census 2010), had fewer than 2,000 at the time of Throop's study. Portland had more than 300,000, a level over 16 times as high as Vancouver, the region's second largest city at the time. The suburbs were noted to specialize in only one area, and Throop points out in many cases the suburbs had only a small economic area that combined commercial and industrial uses. Agriculture remained an important part of the region's economy in locations where today 
it no longer exists. The historic urban form Throop observed can no longer describe Portland as it will exist if the Region 2040 plans come to fruition.

It is important, however, to note Clark County, Washington's presence in the region. Metro's jurisdiction extends only to locales within the state of Oregon (Gibson et al. 2002). Land use laws in Washington differ from those in Oregon. Vancouver is the largest city in Clark County (Census 2010). It is the second largest jurisdiction in the metropolitan region following Portland and the fourth largest in all of Washington (Census 2010). Despite this, coordination with Metro is relatively limited. Coordination is increasing, however, particularly in regards to the Columbia River Project, an expansion of Interstate 5 over the Columbia River which is scheduled to include an extension of TriMet light rail from Portland into Vancouver's downtown core (CRC 2010). Metro also only has jurisdiction over the cities included within the greater Portland UGB. Neighboring cities in Oregon, including Canby, North Plains, and even the state capitol of Salem (within less than an hour's drive of Portland) have varied levels of coordination with Metro, ranging from none at all to close cooperation.

In Region 2040 Metro identifies Vancouver as a smaller central city with regional centers of its own, but Vancouver's website includes virtually no information on the growth concept. The city's own plans make only passing mention of Metro's designation. Instead Vancouver has identified fifteen centers and corridors of its own with a major focus on its downtown (City of Vancouver 2004). These locations, identified as urban activity centers, will feature compact mixed-use development, increased transportation options and accessibility, and investment in public facilities and amenities. Vancouver's 2007 monitoring report identifies two of the fifteen urban 
activity centers which now have developed and adopted plans (City of Vancouver 2007). The report notes the downtown Vancouver plan was highly successful with thousands of jobs and residents and a new hotel, conference center, and office building. That plan has been expanded to include more of the surrounding area. The report also notes though that the plan for the Fourth Plain Corridor Subarea is too new to "accurately measure its success." A 2011 plan update was scheduled, but the official website has not been updated since late 2009 (Vancouver 2011).

However, the growth concepts and plans called for by Metro and Vancouver do not always represent reality on the ground. In his book Shaping Suburbia, Paul Lewis identifies "major business centers" in the region (Lewis 1996). Washington Square and Clackamas Town Center appear on his map as well as on Metro's as regional centers. However, other locations Lewis identifies such as Jantzen Beach appear on Metro's map as only a small station community. Metro's map includes the downtowns of both Beaverton and Hillsboro as regional centers, though Lewis makes little mention of them. Lewis' work was published in 1996 at roughly the same time Region 2040 was developed, pointing to significant differences between on-the-ground observations and regional plans.

Others have also noticed these differences. In Edge City Garreau broadly defines the Sunset Corridor and Beaverton-Tigard-Tualatin as edge cities (Garreau 1992) but does not specifically identify locations within that corridor. Arthur Nelson however identifies Washington Square as an edge city using Garreau's criteria (Nelson 1993). The city of Hillsboro plans a large, mixed-use development in its Amberglen neighborhood south of the Streets of Tanasbourne shopping mall (Hillsboro 2010). The district, 
envisioned as a regional urban center complete with high-rise buildings and a possible MAX Red Line extension, was initially absent from Metro's Region 2040 plans. When the plan was created Tanasbourne began as a town center but has since been upgraded to a regional center. Lee (2007) studied the urban form of six U.S. metropolitan areas including Portland. His findings indicate that in Portland jobs both decentralized and dispersed between 1980 and 2000, creating an "edgeless city" contrary to Metro's goal of focusing growth in centers. He suspects Portland's planning regime has been more effective at promoting compact residential rather than commercial growth.

Wheeler (2003), while including the Region 2040 map in his analysis but making only passing mention of it specifically, points out New Urbanist projects such as Orenco Station in Hillsboro meet with limited success due to the fact they are surrounded by typical automobile-dependent suburbs. The Portland Urban Growth Boundary was initially set so far out from existing development that development within it was built as typical low-density sprawl. Reconciling differing urban forms poses a challenge for Metro despite mandates for maximum block sizes, minimum levels of street connectivity, and other amenities in new development.

Although specifics of Region 2040 may not exactly fit Metro's map, Dieleman et al. (2004) point out Portland has indeed grown in a more compact manner than other American cities. They attribute this difference largely to transportation and TransitOriented Development, a type of development focused on non-car-based transportation alternatives with concentrations of jobs, services, and residents at transit stops. In analyzing use of transit at such developments Dill (2008) discovered residents in such locations were using transit more than they had previously, but she acknowledged the 
possibility of response bias to her survey. She also noted residents who had free and easy access to parking at their school, workplace, or other destinations were less likely to use public transportation. This reinforces Wheeler's (2003) belief that Metro's goals are more difficult given existing land use in the region. Song et al. (2004) conducted an analysis of neighborhoods in Washington County and discovered neighborhoods are growing denser and better internally connected streetwise, suggesting the urban form is indeed undergoing slow change. Still, Jun (2008) asserts that analysis of specific growth policies aimed at reducing automobile dependence in the Portland area is limited, citing a significant gap in the literature.

Metro claims the best centers are intentional. They "don't just happen" (Metro 2010). Collaboration between different parties and continued investment combine to create these places. However, journalist Alex Marshall disagrees. By setting out to protect rural and undeveloped lands from urbanization through the strict land-use laws in effect today, Oregonians inadvertently set the stage for healthy and vibrant urban spaces (Marshall 2000). Growth boundaries and related policies forced development back inward toward downtown and intensified suburbs' relationships with Portland. This, combined with market forces, resulted in numerous active neighborhoods like Northwest $23^{\text {rd }}$ and the Hawthorne District. Considering this alongside discrepancies between Metro's plans and reality on the ground indicates planning might play less of a role than Metro believes.

Metro has conducted only limited analysis of progress towards meeting the 2040 plans, most of which has only occurred within the past five years. Only now is Metro shifting its focus towards the plan (Institute 2009). Current data and reports provide 
incomplete pictures of 2040 progress. In January 2009, the State of the Centers report was released which describes each center identified in Region 2040 and inventories the amenities available in each (Metro 2009). Examples of counted amenities include fast food restaurants, clothing stores, and wine bars. The related Urban Living Infrastructure Report identified various amenities as contributing to more active and vibrant locations, creating an "urban experience," and increasing local property values (Johnson-Gardner 2007). However, the State of the Centers report does little more than provide a numbered list of those amenities and other basic information, including population per acre and median household income. The report does not explicitly spell out connections between the counted amenities and Region 2040 centers. The problem is any large strip mall or shopping mall could fit the report's definition of a center, while locations exhibiting characteristics of Metro's desired built environment may not. This means a single-story shopping center with abundant parking, drive-thru restaurants, clothing stores, grocery stores, and a WalMart might be identified by Metro as a regional center using this criteria. However, a multi-story mixed-use development with easy public transportation access, high walkability, but fewer restaurants or stores might not be. Additionally, Metro analyses have focused almost exclusively on centers. Reports regarding corridors, Main Streets, and other categories identified in Region 2040 appears limited to sporadic information on individual projects.

A centers and corridors report was released in November 2009. It acknowledges development expected with the plan has not materialized as quickly as hoped. The report underscored the importance of the economy and market forces in paving the way for development and was written to generate recommendations and strategies for overcoming 
barriers to developing the region's centers and corridors (Institute 2009). Metro's 2004 Performance Measures Report also attempts to analyze progress toward Region 2040, but its analysis of centers is extremely limited. The report includes measurements such as academic performance and population change in the region's cities, but these measurements have little relevance in analyzing the centers' development progress. Variables such as employment or new construction are tracked for entire cities and counties, but data are not broken down to an individual center (Metro 2004).

Most maps in these reports and in others omit Vancouver and neighboring jurisdictions entirely. As part of the plan Metro does coordinate with neighboring municipalities to direct some growth to those locations, but it does not have jurisdiction over them. Nevertheless, the omission represents a significant gap in knowledge and coordination in achieving the Region 2040 plans. Metro's growing focus on its centers and corridors ignores locations outside the centers' boundaries, the area of which represents the majority of the region. The State of the Centers report acknowledges, for instance, that the Happy Valley town center does not exist on the ground yet (Metro 2009). While not identifying any local alternatives which could serve as a town center, in 2011 Metro did adopt Happy Valley's recommendation to move the designated center to a new location. Because of the lack of publicly released data and reports, the Portland metropolitan landscape may include centers and locations of high density which the Region 2040 plan does not acknowledge.

Placing a dot on a map where Metro wants a center may not accurately represent where a local center has actually begun to form and thus, where higher potential for the development Metro seeks already exists. Metro's late attempts to assemble data about its 
plan hint development potential was misidentified and market forces misunderstood when drafting the plan. This sentiment is echoed by Redden (2009) who believes the 2040 concept does not work and who quotes a Metro councilor as saying that putting "blobs" on a map does not make things happen.

This study focuses on Washington County. Much of the existing literature about the Portland region is based almost exclusively on the city of Portland with minimal acknowledgement of surrounding areas. It has been well-established that downtown Portland serves as the center of the metropolitan region. It continues to grow and serve as a major transportation and cultural hub, with all light-rail lines converging in downtown and attractions such as Jeld-Wen Park and the Portland Art Museum calling it home.

However, data from the 2010 Census show the suburban counties of Washington and Clackamas, Oregon together have a higher population than Multnomah County, home to Portland. Including Clark County, Washington puts the population of the suburban counties well beyond that of Portland (Census 2010). The faster growth of Portland's suburbs compared to the core city is not unique to the region; this phenomenon has been observed throughout the United States (Lang et al. 2007). Given that the suburban counties in the area generally have greater rates of growth as well as greater growth in absolute population numbers, a focus on these places instead of Portland seems a logical decision.

So why then, choose to study Washington County? Of the four-county metropolitan area, Washington County had the greatest increase in population between 2000 and 2010. The county is home to Nike World Headquarters. The term "Silicon 
Forest" is often applied to Washington County due to the prominence of many hightech industries in the area (Wollner 2011); Genentech, Intel, and SolarWorld are only a handful of the many companies with operations in the area. There are many major shopping malls such as Washington Square and the Streets of Tanasbourne. The region's highest concentration of Asians lives in the Bethany and western Beaverton neighborhoods (Hannah-Jones 2011), and overall diversity of the county's major cities (Hillsboro, Beaverton) surpasses that of Portland (Kost 2010). New Urbanism and smart growth have found a local audience with Orenco Station and planned development in Hillsboro (Parks 2011b) and Forest Grove (Parks 2011a). 


\section{Data}

A logical question to ask at this point is whether or not Region 2040 is indeed coming to fruition. Do Metro's plans match reality on the ground? What might explain those results? The first step is to determine what variables might contribute to a center's development and whether available data allow for those variables to be analyzed.

Based on the urban models explained earlier, CBDs have historically had the highest land values in a region. Regional centers, which should have the same type of development as CBDs but on a smaller scale, are likely to exhibit the same characteristic. Thus, land value is a key variable of interest. The models also show that these areas are located in places with easily accessible transportation, whether it be a freeway junction or a convergence of streetcar lines. Accessibility, then, is another variable of interest. Accessibility can be measured through public transportation and road network data. Public transportation data indicate the locations of bus and rail stops, while street-level data can be used to generate a map of street intersections. A larger number of intersections should indicate a more walkable environment. CBDs and other commercial nodes, plus the higher-density Metro calls for in its centers, indicate building volume should also be a variable. Clusters of larger buildings are likely to indicate the location of a center. Metro calls for its centers to include primarily residential and commercial land uses, so the above data would be narrowed down to those uses where necessary. Overall, the hypothesis of the study is that the variables listed below contribute to the growth of regional centers:

- Street intersections 
- Public transportation availability

- Building volume

- Land value

To determine the hypothesis' validity certain steps must be taken. The variables listed above must be mapped to locate potential regional centers. Data for these variables exist for the years 2000 and 2010; the locations of centers will be mapped for both years. Because the hypothesis states those variables contribute to centers' growth, the change in those variables over the ten year period will be mapped. If the change is greatest where the centers exist in 2010 , this will verify the hypothesis. If change occurred outside of those centers instead, this indicates that variables other than these ones contributed to the centers' growth. This methodology is explained in much greater detail later in this report.

Metro's regional centers in Washington County include downtown Hillsboro, downtown Beaverton, Tanasbourne/Amberglen, and Washington Square (Metro 2011b). Prior to the research it was believed Washington Square and Tanasbourne would be confirmed as centers. The office complexes at the Interstate 5 and Highway 217 interchange were expected to show up as well, as were the medical complexes at the intersections of Highway 26 and 217. Nike Headquarters, located between Beaverton and Tanasbourne was also expected to show up as a center in the GIS analysis due to its immense size and presumably very high land values. Beaverton and Hillsboro, without the major shopping malls or office complexes, were not expected to be confirmed as regional centers. 


\section{Methodology}

The central question of this research involves regional centers and what contributes to their development. Where are these centers, have they developed in the locations of Metro's choosing, and thus do the selected criteria form a good model of potential center location? In order to generate an answer it becomes necessary to break the research down into pieces which can then be further broken down into subsequent components, or steps, to follow. Overall there are two major pieces to the research: analysis using Geographic Information Systems (GIS) software and field visits to locations the GIS results identify as regional centers.

Critical to this study is the use of ArcGIS's kernel density tool. Kernel density was used by Thurstain-Goodwin et al. (2000) in their own study of centers in the London, England area. The tool was used to identify generalized town centers in the metropolitan region. High-resolution data, available for the Portland area, introduce a level of granularity and complexity that makes analysis of overall trends and patterns difficult. Kernel density, explained more thoroughly below, helps make the data more manageable and produces legible results.

Kernel density surfaces are raster, cell-based outputs in ArcMap used to represent the density of a given feature. The Kernel Density function in ArcMap can be used with either point or line features and may be weighted with a user-specified field. The function uses a user-specified search radius which tells the program how far from a point or line to look when calculating density. During the calculation each input feature is examined and its reach extended to the user-specified search radius distance. Once each 
feature has been extended in this manner the program counts the number of features appearing in each raster cell. If a weight field was specified, the program counts each feature based on the number found in the weight field (ESRI 2010).

In other words, imagine three apartment buildings standing 500 feet apart from each other. One building has ten people living in it. Another has twenty people living in it, and the third has thirty residents. A density tool could be used to map the population density of this hypothetical apartment complex. The three buildings would be the input points into a density tool. The number of residents would serve as the weight function. A user could specify a search radius of a quarter-mile for example. Assuming each raster cell, or pixel, on this map equaled an area of one square foot, the tool would look at each square foot and calculate the population density at that location. For instance, the building with ten residents would be counted ten times in every cell within a quarter-mile of the building. The second building would be counted twenty times and the third building thirty. For cells where the quarter-mile radius overlaps, the numbers would be added together. If all three population areas overlap in a central area, those cells will have a value of sixty residents. While the actual kernel density function is based on a quadratic equation (ESRI, 2010), the above example illustrates the concept behind it.

The GIS analysis was performed in ArcMap Version 10. To simplify and better organize the analysis the model shown in Appendix B was constructed and used. Data used in the analysis comes exclusively from Metro’s Regional Land Information System (RLIS) files. These data are updated and released quarterly (Metro 2011c). Portland State University (PSU) has a subscription to the RLIS data and downloads it onto its servers upon release. The RLIS files can be accessed for free by students or faculty of 
the university. Some, but not all, of the RLIS data are now available through Metro's website as well, but this service was not used during the course of this research.

Region 2040 was finalized in 1997 (Wheeler 2003). PSU does not have access to quarterly RLIS data prior to February 2002, however, there is an RLIS dataset from November 2000. A small amount of data from the year 1996 are also available, but the data are limited to taxlots and is not in an ArcMap-readable format, limiting their usefulness. The decision was made to use RLIS data from November 2000 and November 2010. This allows for an analysis of change in Washington County over the course of a ten-year period which in turn allows for an analysis of whether the selected variables did indeed contribute to the formation of centers.

Specific shapefiles of interest from the RLIS data include those for taxlots, public transportation, roads, and building volume. Each of these is available for both the 2000 and 2010 data with the exception of building volume, which is only available for 2010. The building volume data do, however, include the year of construction for many buildings. Because that information exists, buildings constructed after the year 2000 can be removed from the analysis to create a de-facto shapefile of building volume for the November 2000 data.

Kernel density surfaces were created for each of the four variables of interest using a variety of parameters. All kernel density operations were performed twice, once using a half-mile search radius and a second time using a one-mile radius. Performing the operation using the two distances allows the results to be compared to determine which radius is better suited to the analysis. All data were limited to Washington County by means of either clipping the data or by using the select by location tool. 
Determining the density of street intersections was perhaps the simplest operation. First, copies of the street layers from 2000 and 2010 were made. The Intersect tool was used to intersect the original layer and the copy together, resulting in a new shapefile consisting of points at the street intersections. These points were then used as inputs in the Kernel Density tool to generate the density surfaces.

Data for TriMet's bus and rail lines are available as well. Point data for the stops are used instead of data for the lines themselves because the mere presence of a line does not add to a city's transportation arsenal without a stop to pick up and drop off passengers. A new field was added to the transit shapefiles for the purpose of creating a weight to use in density analysis. Bus stops were provided with a weight of " 1 " while rail stops were given a "2." The rail stops were doubled in weight compared to bus stops because rail is seen as a more permanent investment in a region's infrastructure. Rail routes also tend to be easier to understand than bus routes, and many TriMet bus routes feed directly into the rail system, making the rail system a critical piece of the region's public transportation. The resulting stop points were used as inputs in the Kernel Density tool weighted based on the type of transit stop.

Building volume data and taxlot data are both more complex. The building volume data are only available in the November 2010 RLIS release, but it contains data for every building within Metro's jurisdiction. The data contains a "YEAR_BUILT" field for the date each building was constructed. To include this data for the year-2000 analysis, anything built after the year 2000 was removed from the data. The Select by Attribute tool was used to remove buildings without data (a value of zero) and those greater than 2000. The result served as a proxy for November 2000. The data were then 
converted into point format because the polygon format it comes in cannot be used with the kernel density tool. The points for the November 2000 data and for the original full dataset were used as inputs in the Kernel Density tool, weighted by the total building volume (the "VOLUME" field in the data).

Taxlot data include a field for each lot's designated land use. This allows the data to be separated into multiple categories through the use of the Select by Attribute tool. The first category was limited to multi-family residential (MFR) taxlots and the second to commercial (COM) taxlots. These two categories were created because of Metro's desire to include those types of land uses in its centers. In addition to land use, the taxlot data also include information on each lot's value. One field provides the lot's land value, a second the value of any buildings or improvements on the site, and a third the total value of those first two categories combined. After converting the taxlot shapefiles for the different types of land uses from polygon to point using the Feature to Point tool, the resulting points were used as inputs in the Kernel Density tool with the total value of the taxlots (TOTALVAL field) serving as the weight value. The entire process was repeated using different criteria, however. Because the data also include the area of each taxlot, a new field for the value per square foot was added. The Field Calculator was used to divide the total value of each taxlot by the respective taxlot's area. After this was completed, the steps described earlier in the paragraph were repeated. This time, however, the value-per-square-foot field served as the weight value in the Kernel Density tool. Performing the operation twice using the two different weight fields provides a comparison between two different methods of measuring land value. 
Generating the maps from the methods provided above concludes the first part of the GIS analysis. The second piece of the research involves field research to locations identified as potential centers in that analysis. All density surfaces were mapped using five-category equal intervals, ranging from no/very low density to very high density. To determine the locations to visit each map was examined, and all locations exhibiting the highest density category were tallied in a spreadsheet. Ultimately four equations were used to generate a list of center candidates. The one-mile surfaces were used due to the more generalized results they produced and larger areas they identified. The tallies for the public transportation, intersection, building volume, and taxlot values were added together to determine which locations appeared most often in the maps. Initially all appearances in the highest category were going to be tallied with a value of " 2 " and locations appearing in the second-highest category a "1." However, the latter tally was abandoned as the sheer number of locations in that category proved extremely high, and regional centers should theoretically show stronger results. Despite this all appearances in the top category were still given a value of " 2 " instead of " 1 " for greater legibility.

Tally Equations $(\mathrm{A}=$ Appearance in specified map):

- $2[$ A, 2000 $($ Transit + Intersection + Building Volume + MFR total value + COM total value) $]$

- $2[$ A, 2000 $($ Transit + Intersection + Building Volume + MFR value per square foot + COM value per square foot) ]

- $2\left[\mathrm{~A}, 2010_{(\text {Transit }+ \text { Intersection }+ \text { Building Volume }+ \text { MFR total value }+ \text { COM total value })}\right]$

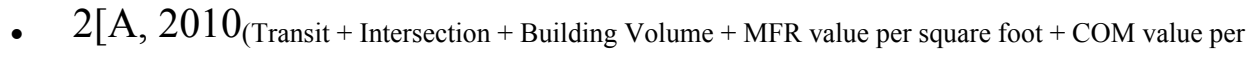
square foot) ] 
The tally methodology is an adaptation of that used by Ian McHarg in Design with Nature (1992). His studies, which took place prior to the advent of GIS, used maps printed on transparency sheets. To determine the suitability of a site for urbanization multiple criteria were mapped. Scenic values, floodplains, and soils are three of the many variables he used in his studies. Each was mapped on its own transparency with regards to urbanization suitability. For example, building in a floodplain was ill-advised in his criteria (and is frankly ill-advised in general), so the floodplain map could have two categories: suitable for construction or not suitable for construction. Unsuitable locations were mapped in a darker color. When placing each of the transparencies on top of one another, the most suitable locations for urban development would be lightest. The tally accomplishes the same result. Locations appearing on the maps will be symbolized using a darker color; if Location A is a center then Location A will be in a darker color. Marking how often each location appears in the darkest colors merely moves the results off the map and into a spreadsheet for clearer analysis. Each map, akin to each of McHarg's transparencies, has its results added together to create a final score, akin to McHarg's composite maps. This methodology is used for two major reasons. One is the difficulty of using transparency levels in ArcGIS software. Transparency levels for layers can be adjusted, but with multiple layers on top of one another some of the layers on the "bottom" become blocked from view. Thus, the transparency levels in the software do not show an actual composite map on the screen. Further, ArcGIS has a raster calculator function that can be used to add raster values such as those from the density maps generated here. Though the raw values can be summed together to create a new map, the new values are meaningless. In this case, a density map of road 
intersections added to a density map of building volume would create a map that simply doesn't provide real-world information. One intersection would have a raster value of one. A $\$ 150,000$ house adjacent to that intersection would have a raster value of 150,000 . Using the raster calculator, the local area would have a raster value of 150,001 . As a result, the raster calculator cannot provide meaningful information unless different data are in the same unit of measurement or can be normalized using a logarithmic function.

Field visits included two components: extensive photography of the area and field observation. Each location was visited once during the afternoon when activity was expected to be highest. Photography involved both driving and walking around the locations. Buildings, people, roads, and anything else of interest were photographed. Field observations involved rating aspects of the locations such as the level of pedestrian traffic, level of vehicle traffic, and how safe the area felt. Ratings ranged from "1" to "5," with a five being a higher amount of the variable in question. In other words a location with very low or nonexistent pedestrian traffic would receive a one while a location with a high level of such traffic would receive a five. On rare occasions a score of zero was given due to a complete lack of the variable in question. The template for the recording field observations is provided in Table 1. 


\begin{tabular}{|c|c|c|c|}
\hline \multicolumn{4}{|l|}{ Location } \\
\hline Date & Day of Week & Time & Weather \\
\hline \multicolumn{4}{|l|}{ Gathering place } \\
\hline \multicolumn{4}{|l|}{ Civic institutions } \\
\hline \multicolumn{4}{|l|}{ Perceived density } \\
\hline \multicolumn{4}{|l|}{ Perceived safety } \\
\hline \multicolumn{4}{|l|}{ Pedestrian traffic } \\
\hline \multicolumn{4}{|l|}{ Vehicle traffic } \\
\hline \multicolumn{4}{|l|}{ Ease of navigation } \\
\hline Feels like a "center" & & & \\
\hline
\end{tabular}

Other observations/comments on back of sheet

Table 1

Field observation sheet template

Because time-travel remains impossible the field observations were not conducted for the year 2000. Determination of which locations were regional centers in 2000 was made strictly based on the results of the initial GIS analysis. For 2010 the field visit ratings were entered into a spreadsheet, and final scores for each location visited were summed based on the scores for each variable. However, determination of these scores was purely subjective and features variability depending on the time the location was visited. Thus, a second chart was generated which ranks the locations compared to each other independent from the scores in the first chart. Each of the eight locations visited was ranked from one through eight, with lower scores being more indicative of a regional center. In this case, possible scores range from eight to sixty-four. Analyzing the visits in this manner helps remove some of the subjectivity; depending on the observer's mood, a score of " 3 " one day might earn a "2" on another day or at another location. Looking 
back on the visits after the fact allows the locations to be compared directly and ranked accordingly, thus avoiding some of the score problems.

After the final list of centers was compiled the last portion of analysis could ensue. ArcMap was again employed at this stage. At this point the density surfaces were re-examined. When calculating density surfaces ArcMap generates a value for each raster cell which makes it possible to perform mathematical operations on one or more such surface (ESRI 2010). The Raster Calculator function was used to subtract year2000 surfaces from 2010 results for each of the variables suspected of contributing to center formation. For example, the public transportation density surface for 2000 was subtracted from that of 2010 to create a third surface that shows the location of public transportation density change over time. By tallying the locations where change occurred it can be determined whether or not these particular variables contributed to the formation of observed regional centers. To confirm the hypothesis, the change in these variables should be greatest at locations where centers were observed in 2010 but not necessarily in 2000. Observing change in locations other than these disproves the hypothesis. 


\section{Results}

The first GIS analysis involved mapping the variables suspected of being indicators of a regional center. The following pages include these maps with interpretation. Only density maps generated using a one-mile search radius are included; the half-mile maps were very focused and did not yield a generalized surface that allowed for a center to be identified. Because of the nature of kernel density, the numerical values will not make much sense; they are calculated using the square foot as the unit of measurement. The maps show relative density, and thus the trend they show is more important than the specific values at any one point. Locations outside of the mapped area displayed negligible density results. 


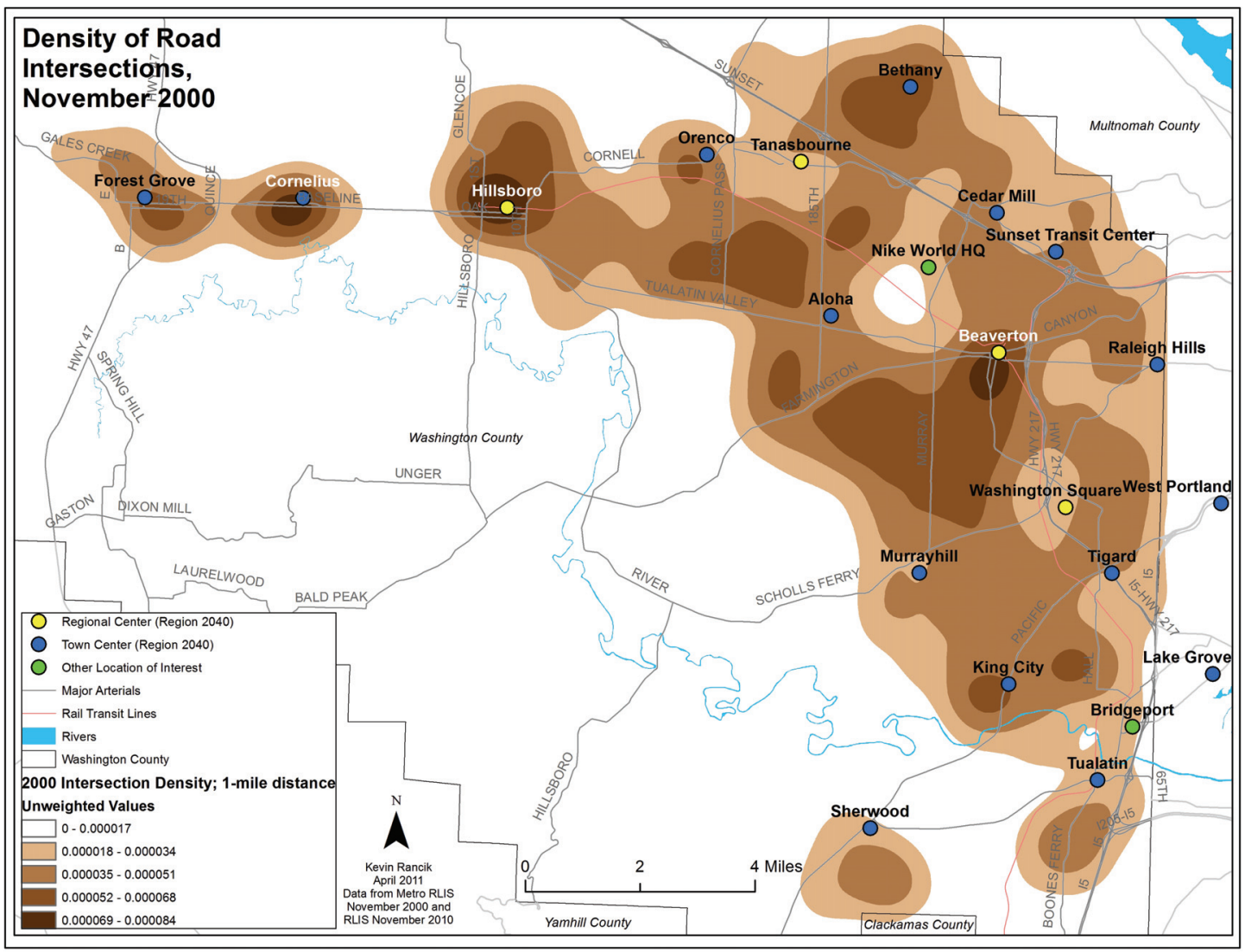

Figure 11

Density of Road Intersections, November 2000

The density of road intersections in the year 2000 was highest in central Beaverton, downtown Hillsboro, and Cornelius. Beaverton and Hillsboro are designated as regional centers by Metro, but Cornelius was only recently designated as a town center. Washington Square and Tanasbourne have relatively low intersection density, and Nike World Headquarters forms a notable hole in the density fabric. 


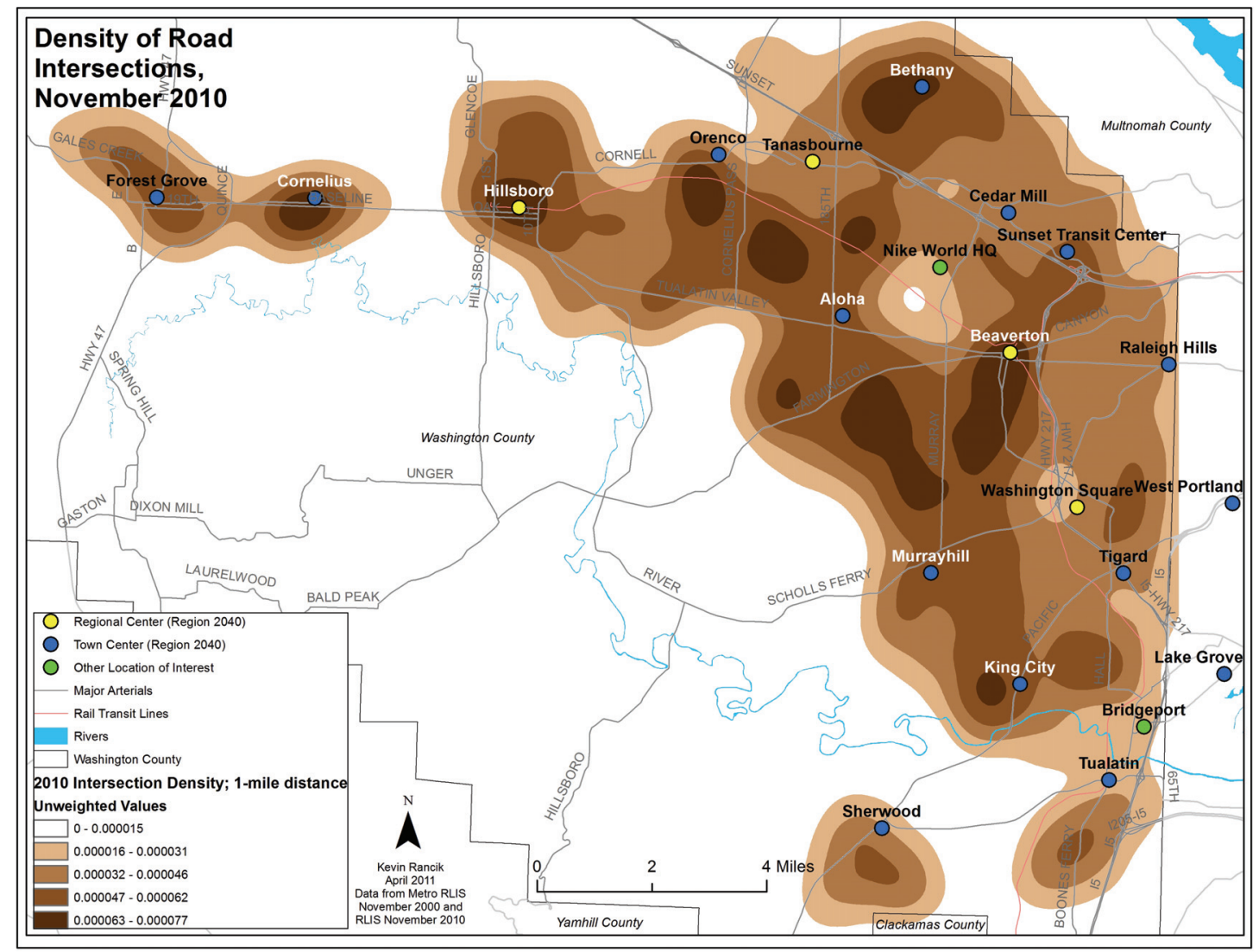

Figure 12

Density of Road Intersections, November 2010

Street intersection density appeared to increase between 2000 and 2010.

Beaverton, Hillsboro, and Cornelius continue to exhibit relatively high density, but their relative dominance is decreased in light of the fact many other locations join them in the highest density category. Among these locations are Bethany and Orenco, both classified as town centers by Metro. Washington Square and Nike World Headquarters continue to show pockets of relatively low density in the region. 


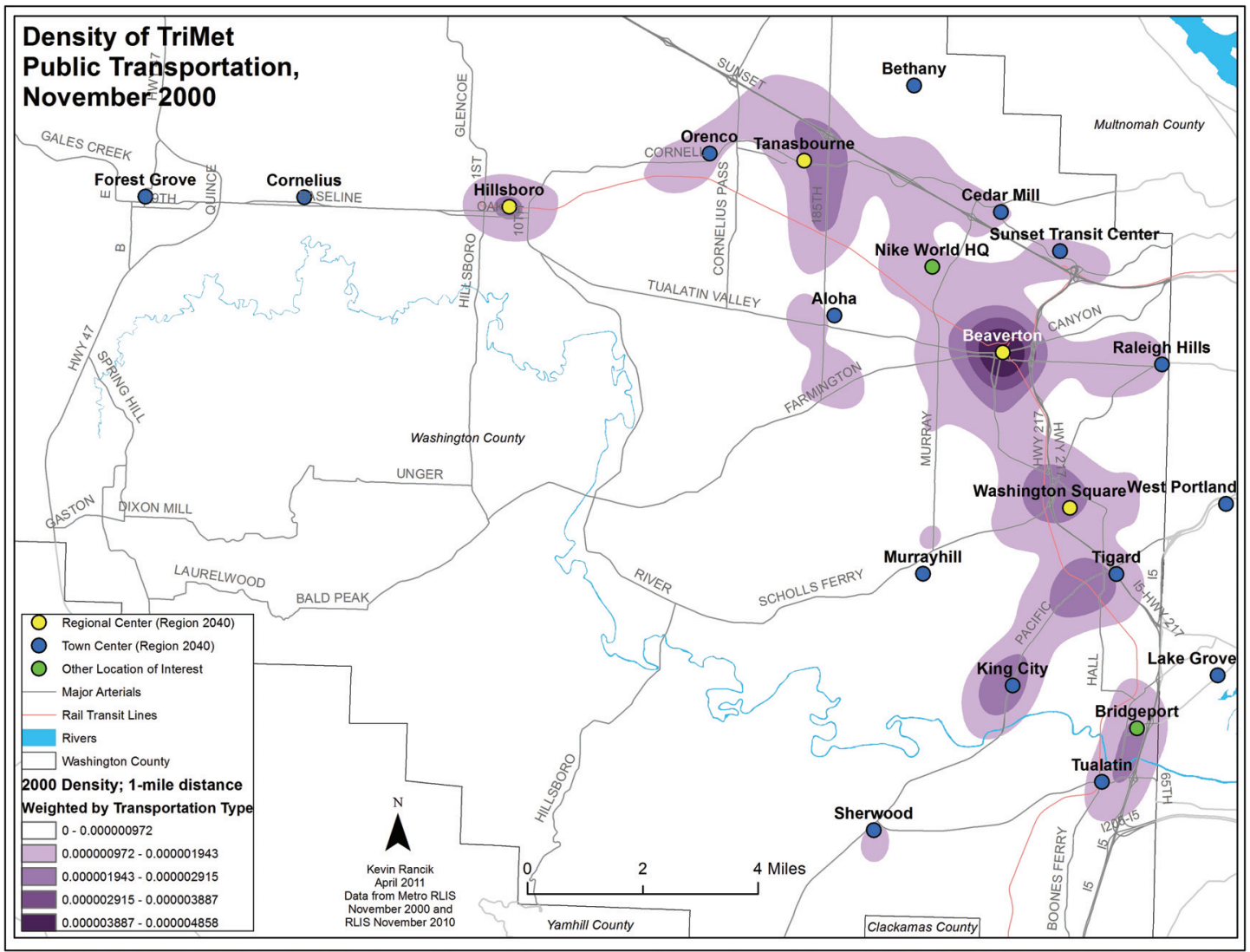

Figure 13

Density of TriMet Public Transportation, November 2000

Beaverton was a strong focus of public transportation in the year 2000. Its dominance in the county was unsurpassed by any other location; no other location appeared in either the top or second-highest density categories. 


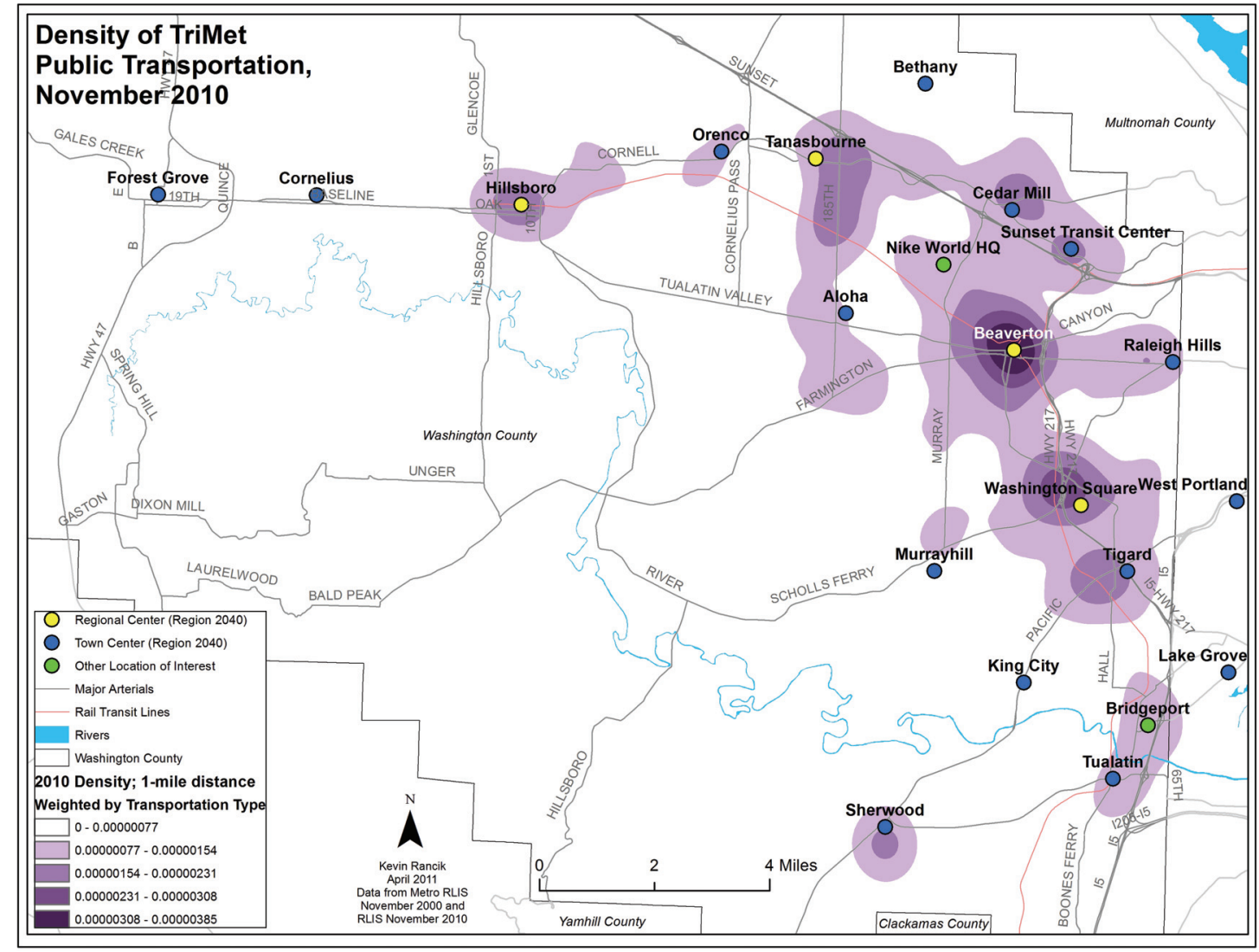

Figure 14

Density of TriMet Public Transportation, November 2010

Beaverton's dominance in public transportation continues to the present day.

Washington Square, another location designated by Metro as a regional center, has now reached the second-highest density category but still does not exhibit the level of transportation accessibility Beaverton does. 


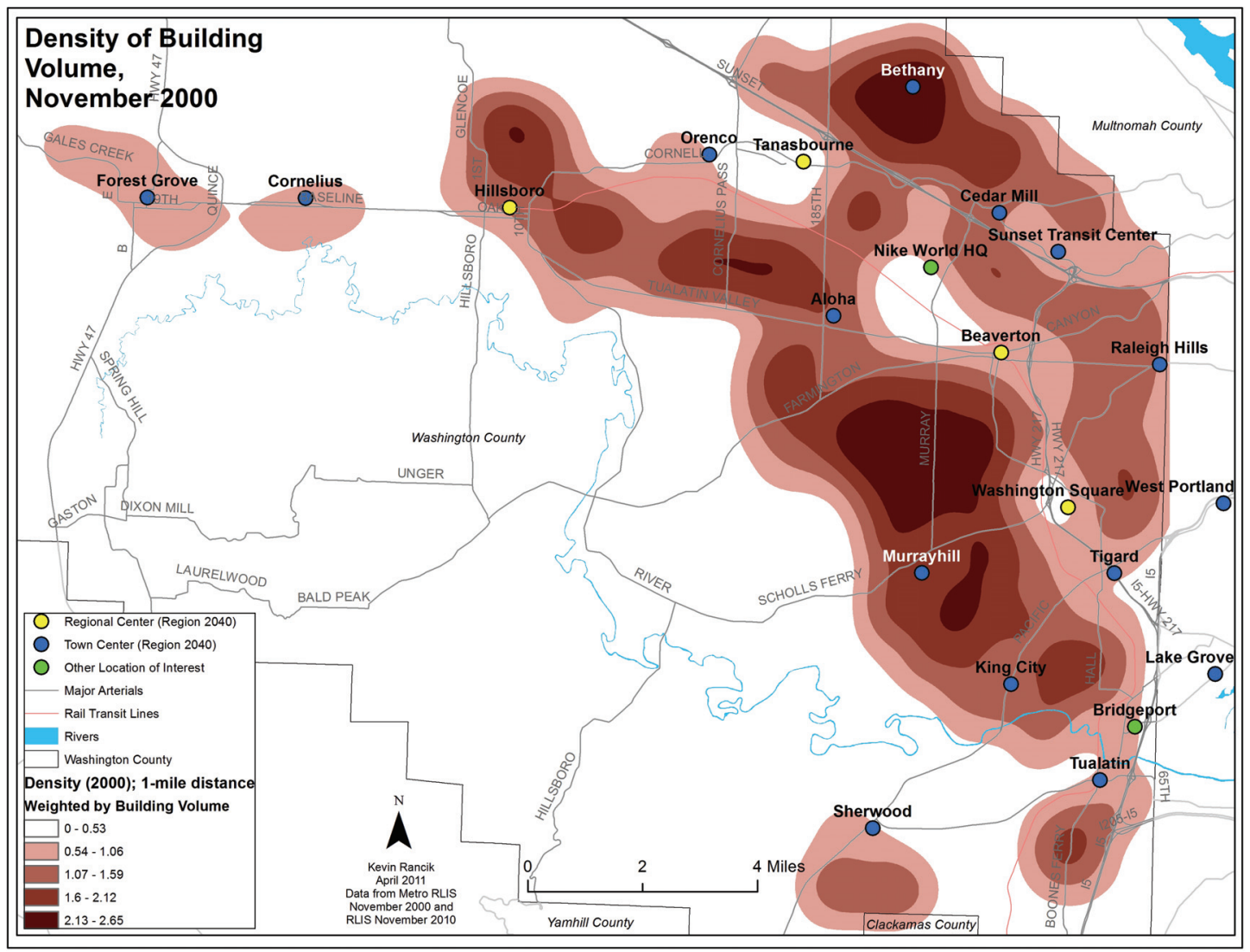

Figure 15

Density of Building Volume, November 2000

Using available data, the highest building volumes are concentrated in Bethany (designated a town center by Metro) and the southern Murray Road corridor. Two much smaller pockets in the highest density category exist at Jackson School Road in northern Hillsboro and along Rock Road in northwestern Aloha. No locations Metro considers regional centers appear in the highest category of this map. 


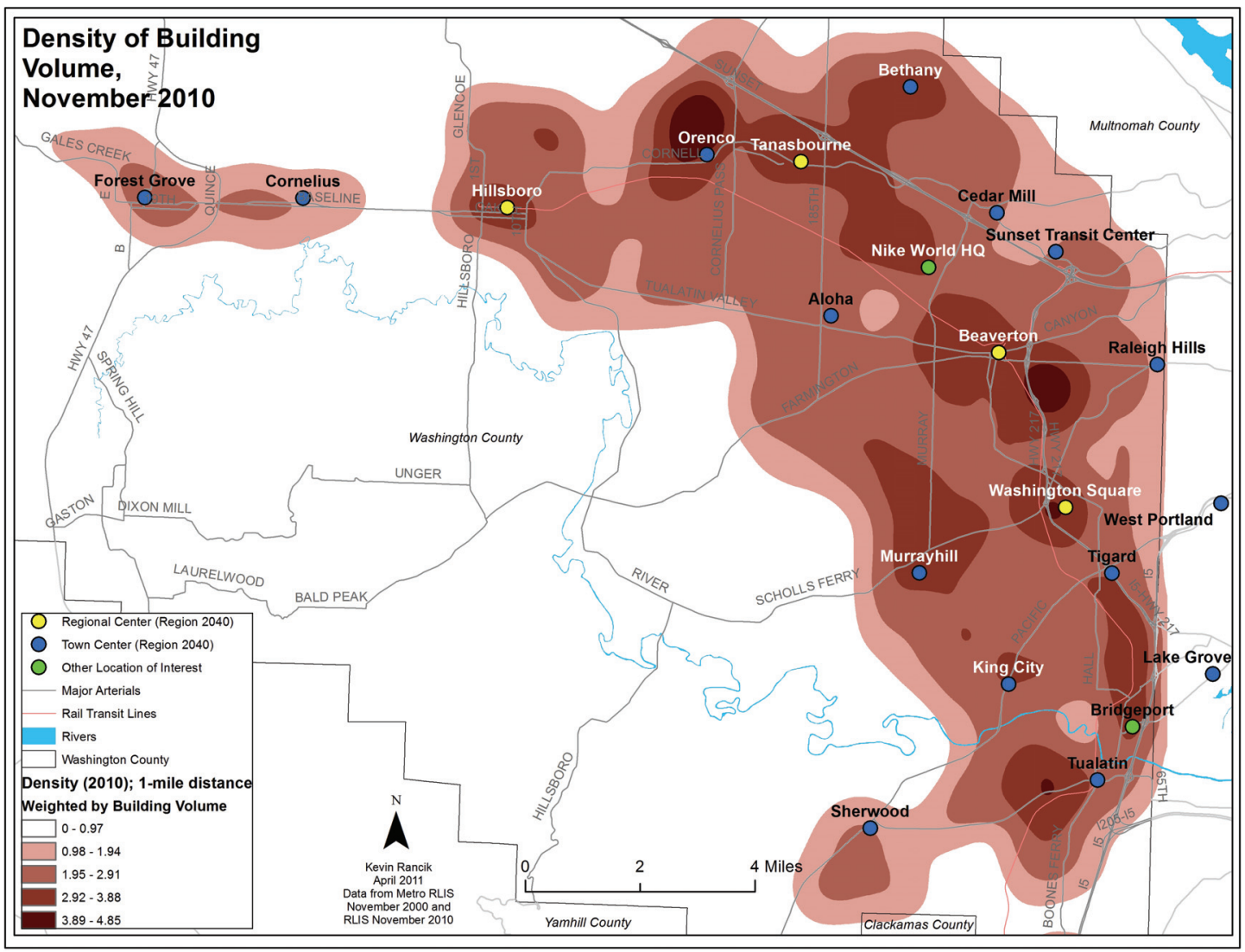

Figure 16

Density of Building Volume, November 2010

Washington Square most directly exhibits the highest density of building volume in 2010. An Intel plant north of Orenco and the general area southeast of downtown Beaverton also exhibit high density, as does a small area west of Tualatin. 


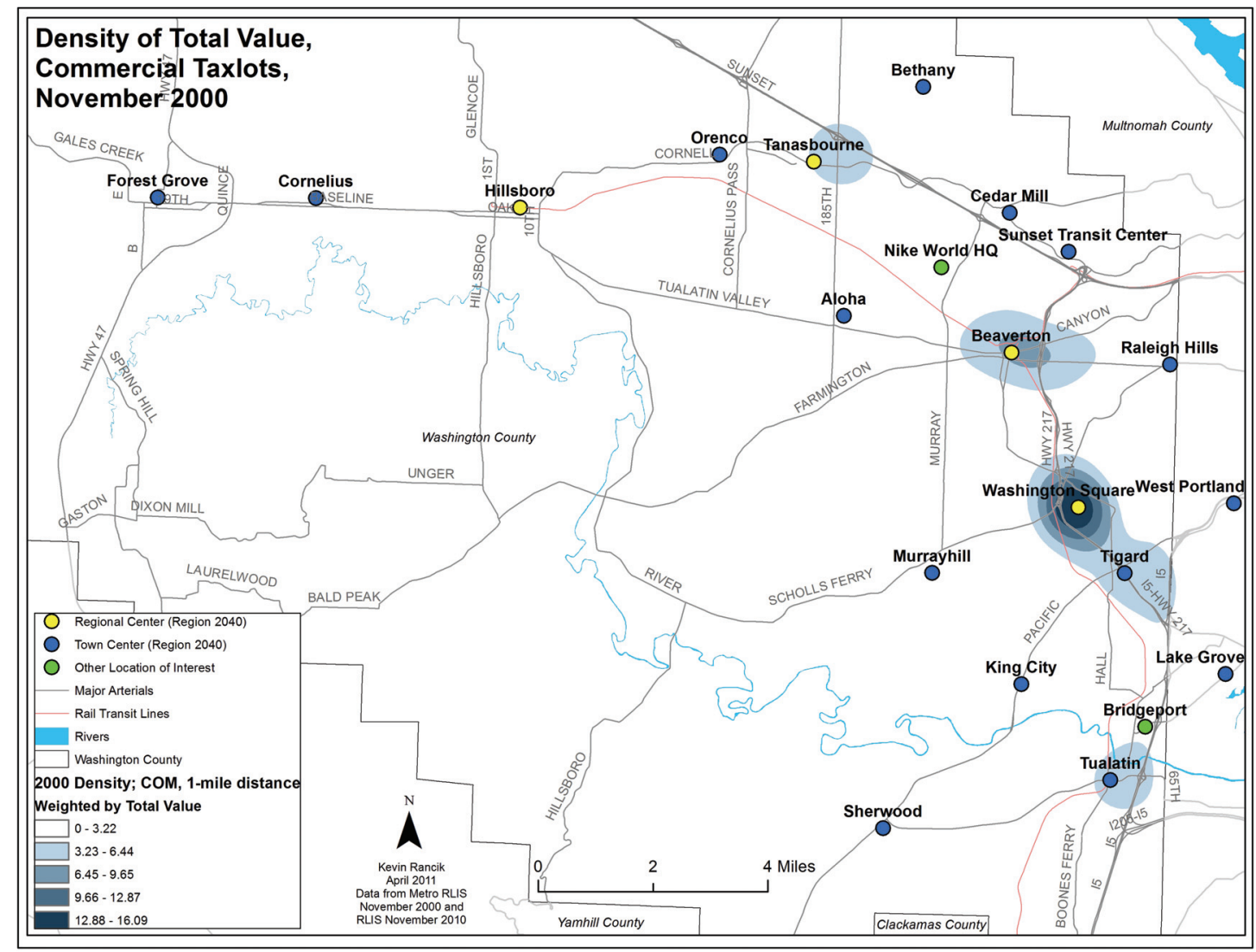

Figure 17

Density of Total Value of Commercial Taxlots, November 2000

Washington Square showed the highest density for commercial taxlot value in 2000. No other locations exhibited density in either the highest or second-highest density categories, and only Beaverton sits in the middle category. 


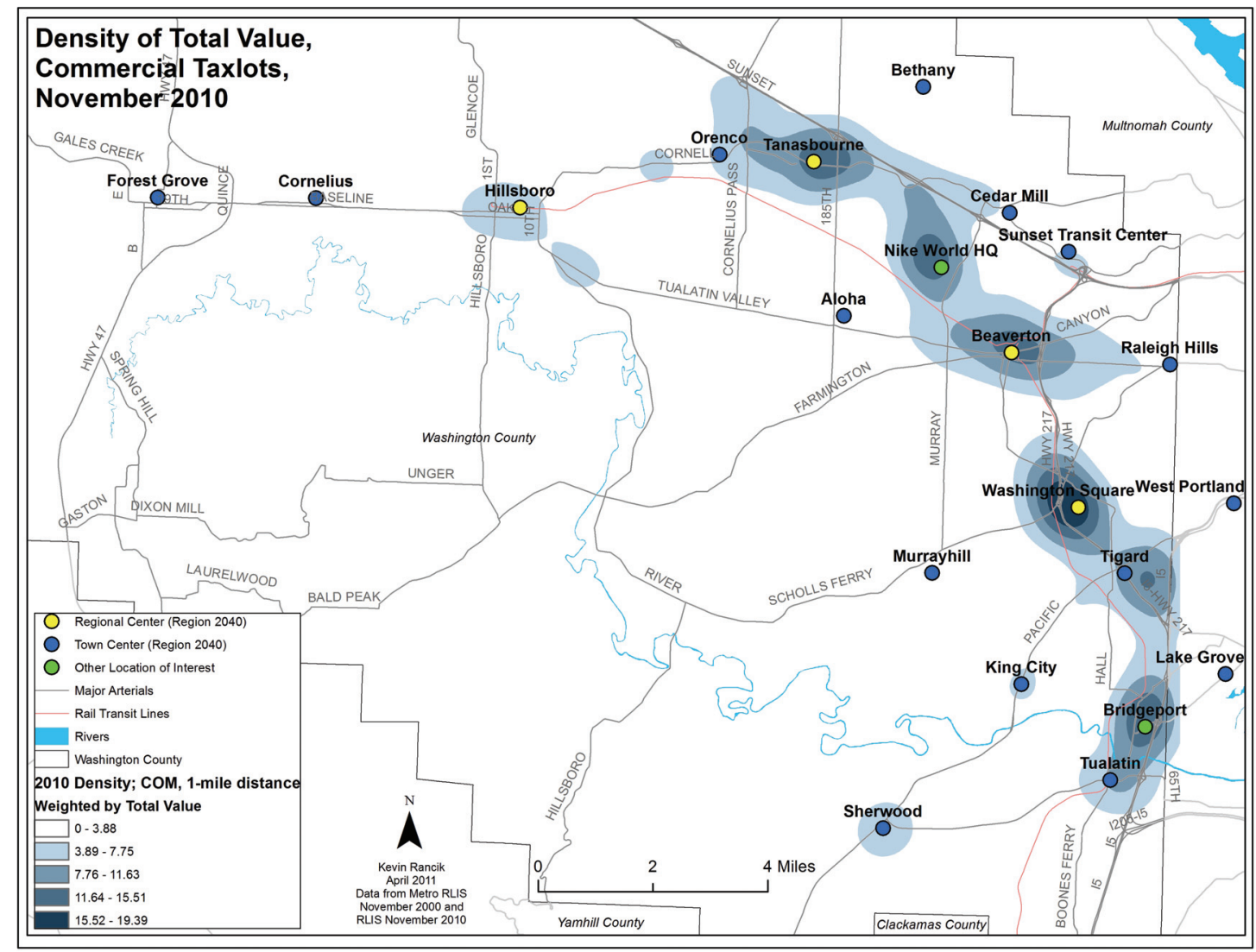

Figure 18

Density of Total Value of Commercial Taxlots, November 2010

When mapping the total value of commercial taxlots, Washington Square undeniably shows the highest density in the county. No other location shares its position in the highest density category, although unlike in 2000, a handful of locations are in the second-highest category. Beaverton, Bridgeport, Nike World Headquarters, and Tanasbourne may be emerging centers based on this criteria. 


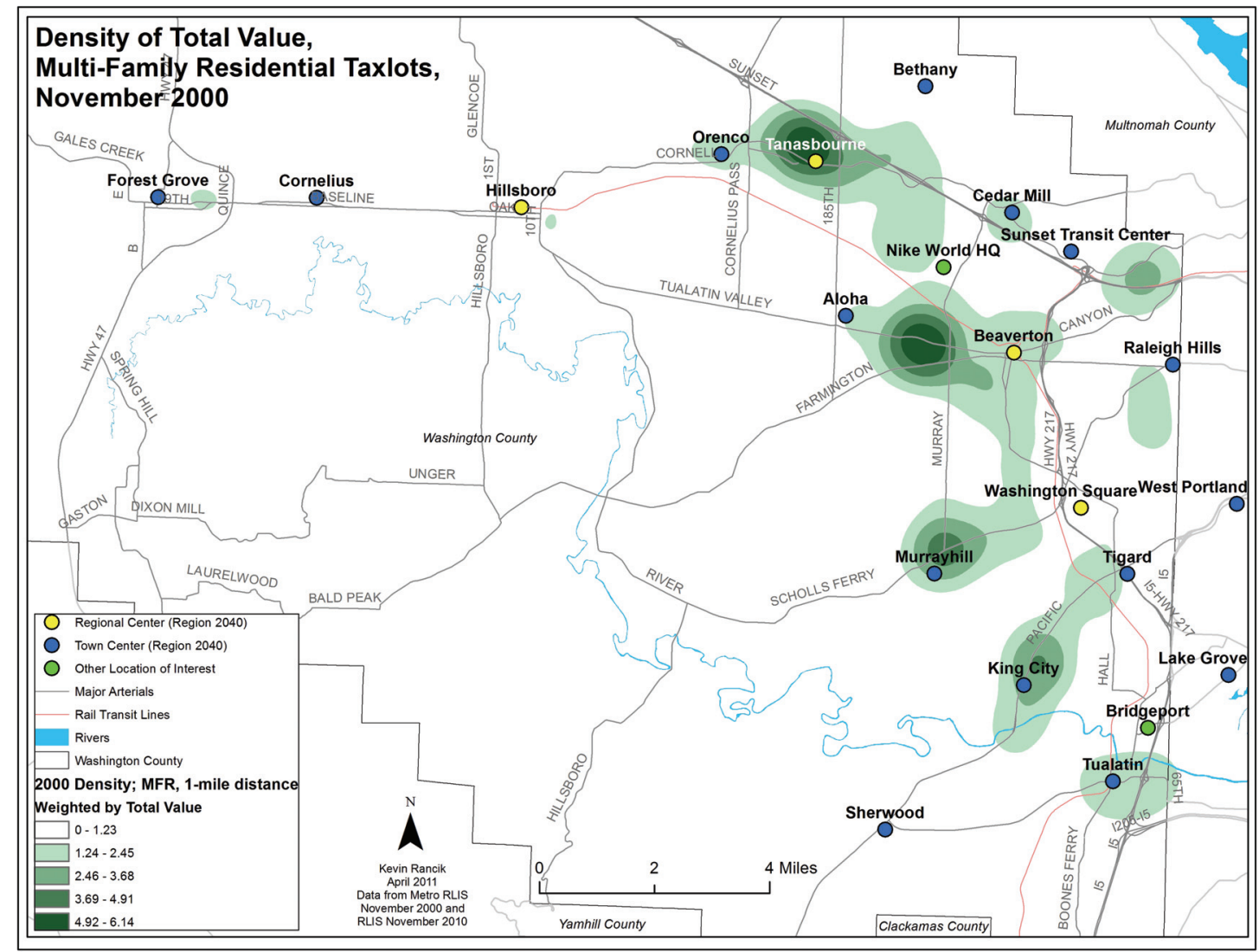

Figure 19

Density of Total Value of Multi-Family Residential Taxlots, November 2000

Density of multi-family residential taxlots in 2000 was concentrated in

Tanasbourne and the area between Aloha and Beaverton. Murrayhill and King City may have been emerging centers using this criteria. 


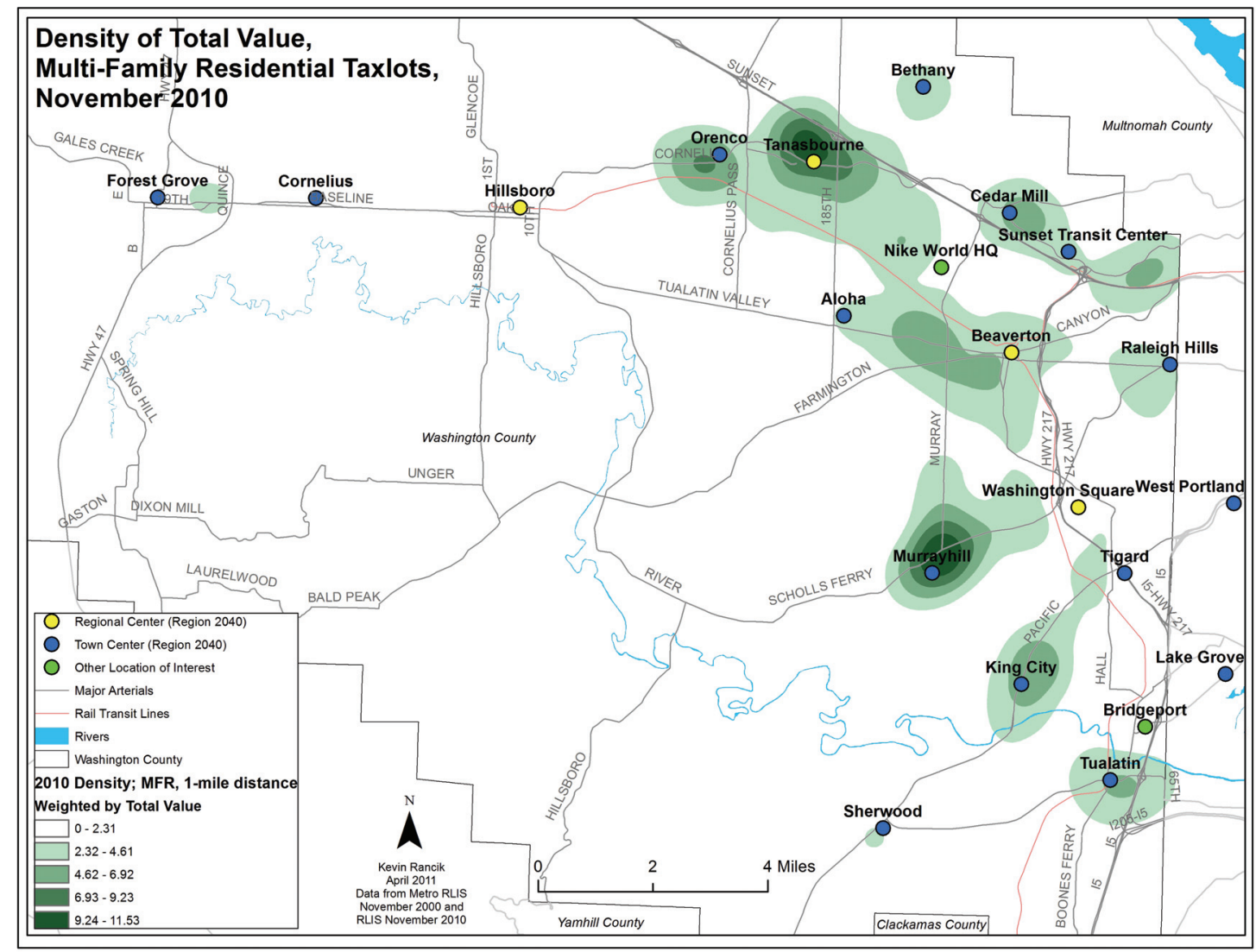

Figure 20

Density of Total Value of Multi-Family Residential Taxlots, November 2010

The 2010 map of multi-family residential taxlot value is generally similar to that of 2000 but has some significant differences. Tanasbourne continues to occupy the highest density category but is now joined by Murrayhill. The location between Aloha and Beaverton now shows much lower relative density. Orenco now sits in the secondhighest category, the only location to do so. 


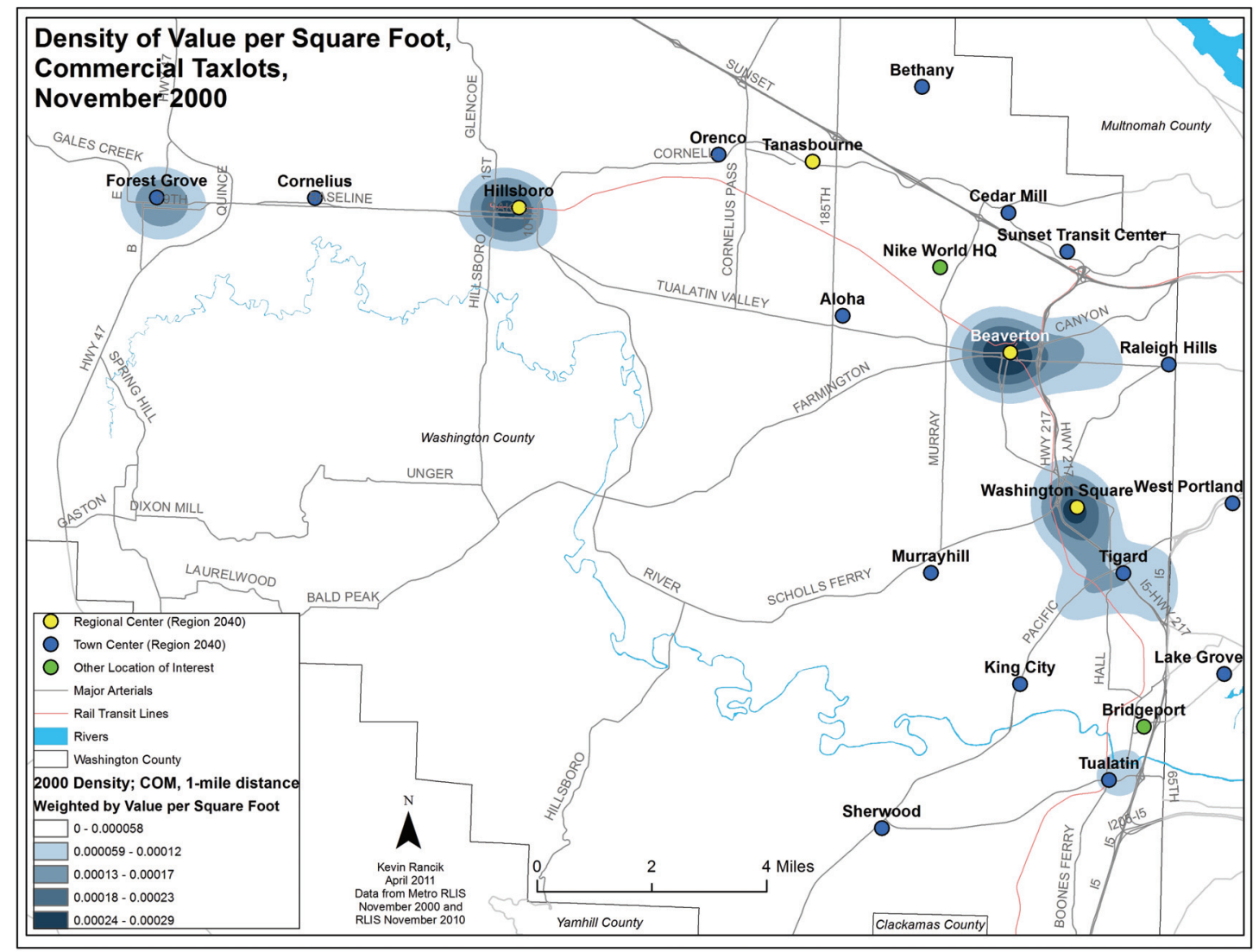

Figure 21

Density of Value per Square Foot of Commercial Taxlots, November 2000

Using the value per square foot of commercial taxlots, Beaverton, Hillsboro, and Washington Square emerge as regional centers. All three of them are also designated as regional centers by Metro. The fourth regional center designated by Metro, Tanasbourne, was not considered a regional center at the time - and also does not appear in this map. 


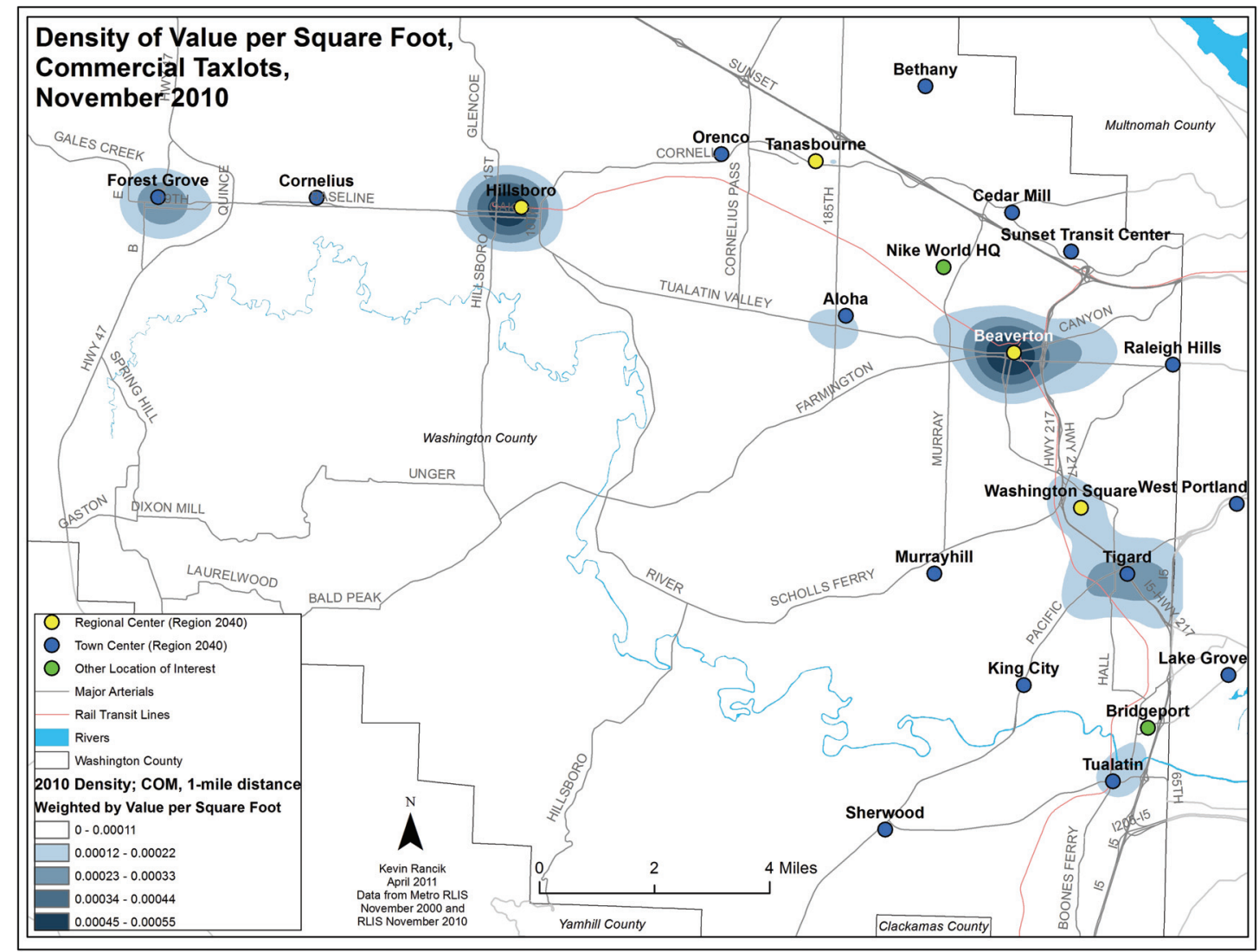

Figure 22

Density of Value per Square Foot of Commercial Taxlots, November 2010

For 2010, Beaverton and Hillsboro have the highest density of commercial taxlots weighted based on their value per square foot. No locations are in the second-highest density category, including Washington Square, which is considered a regional center using this criteria for the year 2000. 


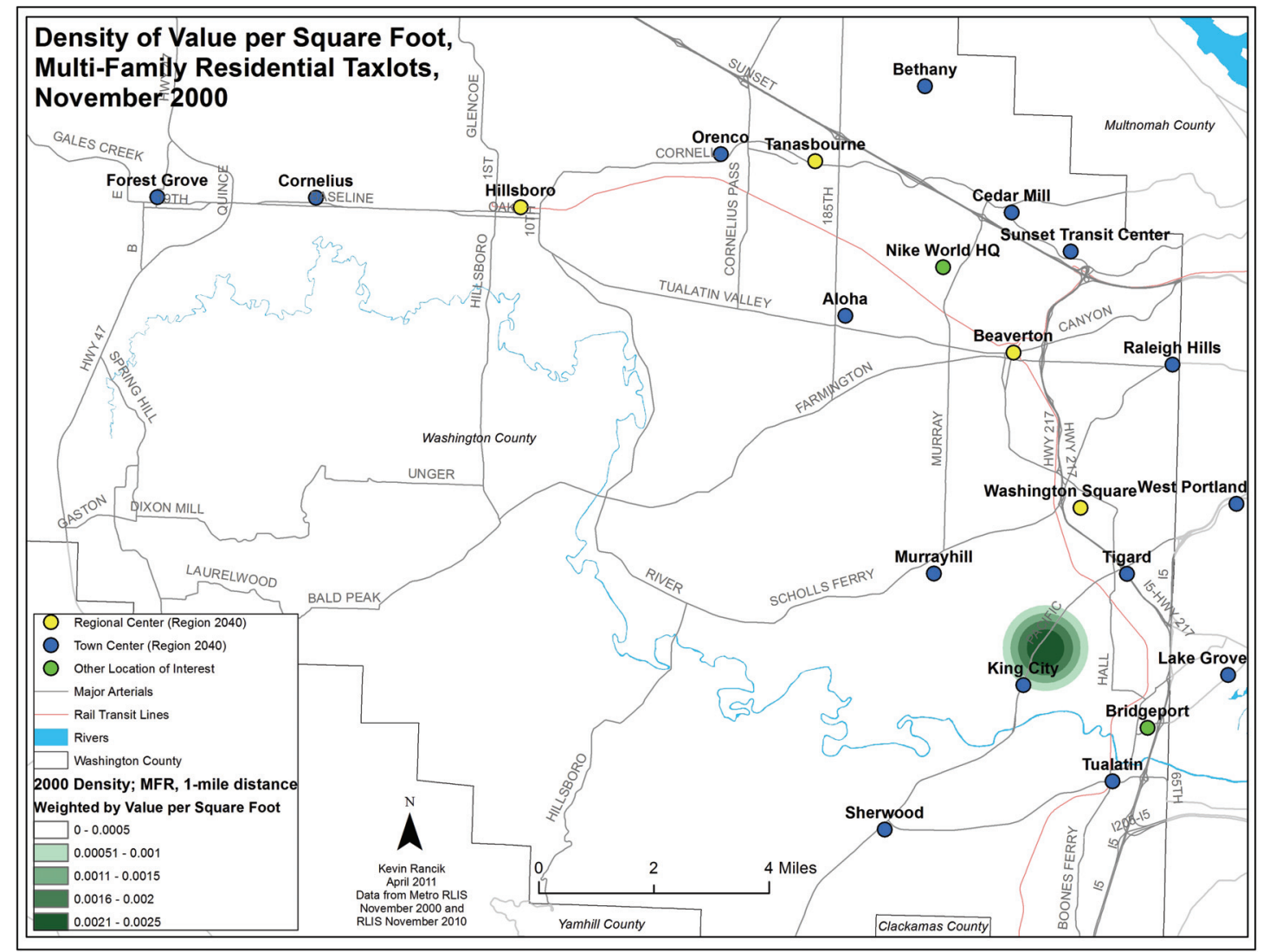

Figure 23

Density of Value per Square Foot of Multi-Family Residential Taxlots, November 2000

Using the value per square foot of multi-family residential taxlots, only King City shows up as a potential regional center. No other location in the county shows up in any of the density categories. 


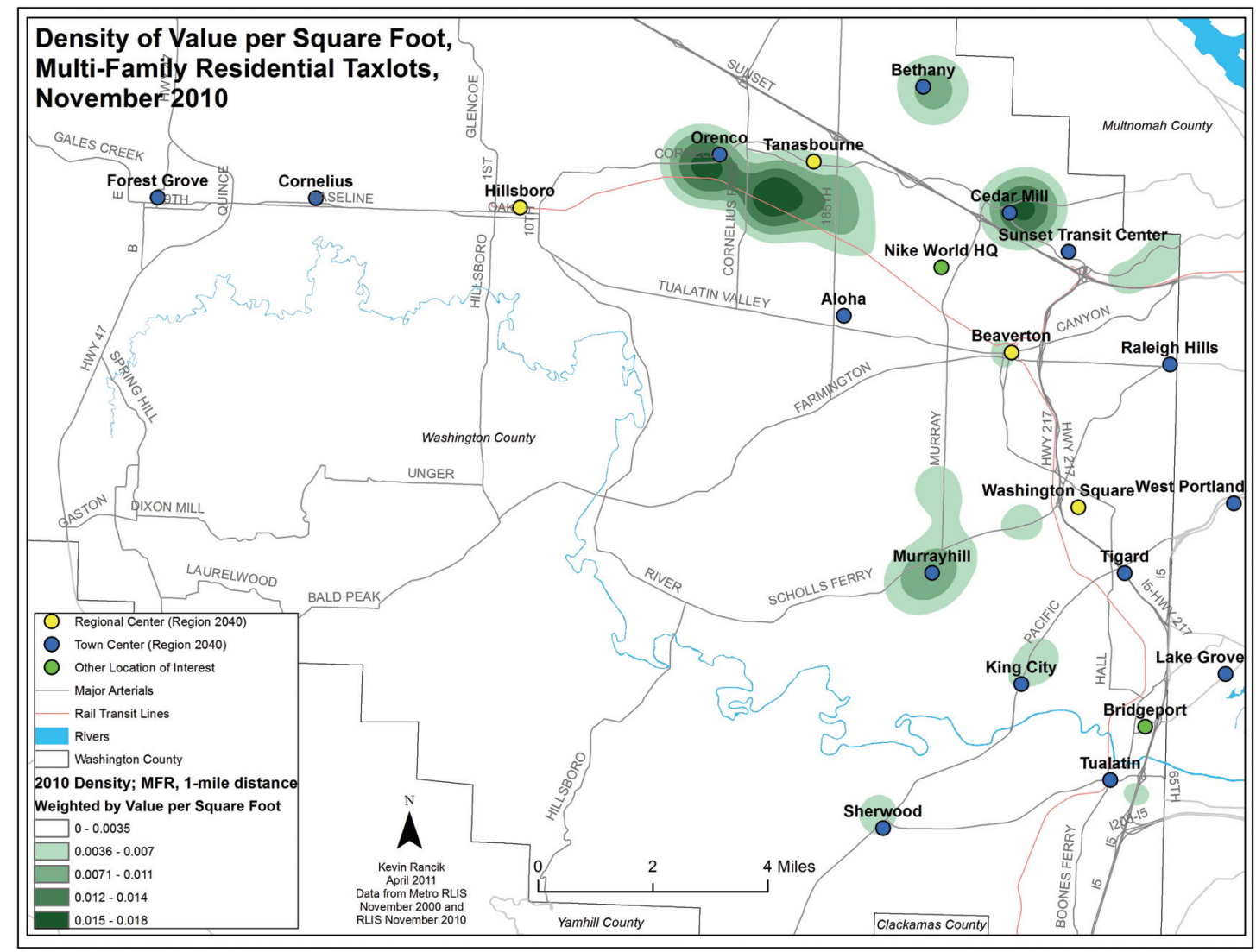

Figure 24

Density of Value per Square Foot of Multi-Family Residential Taxlots, November 2010

For 2010, the map of multi-family residential taxlots weighted on their value per square foot shows Cedar Mill, Quatama, and Orenco as potential regional centers.

Quatama is officially a part of the Tanasbourne center. The proximity of Orenco and Tanasbourne creates a large blob on the map where their densities bleed into one another. 
Appendix $\mathrm{C}$ includes tallies of location appearances in the previous maps. For each location that exhibited density in the highest category, a score of " 2 " was given for that category. For example, if downtown Portland appeared on a map at the highest possible public transportation density, then for the public transportation category downtown Portland would receive a score of "2." Its scores for each category would be added together to generate its final composite score.

For the year-2000 maps Beaverton and Hillsboro were the only two locations to achieve an appearance score greater than " 2 ." In other words, those were the only two locations to appear in more than one map which makes them the most likely candidates for regional centers. As stated before field visits for the year 2000 cannot be conducted. Because of this the initial GIS analysis is the only one which can be performed for that date, making Beaverton and Hillsboro the de facto regional centers in existence at that time. Other locations which reached a score of " 2 " may have been emerging regional centers or more closely matched Metro's town center rather than regional center designation.

Some change in the appearance scores is observed for the year 2010. Both Beaverton and Hillsboro remain regional centers based on their scores here, but they are joined by Washington Square, Murrayhill, and Orenco. As a result each of these five locations was selected for a field visit.

Three other locations were selected for field visits. Tanasbourne was chosen because Metro now considers it a regional center. Bridgeport, located in the southern urbanized portion of the county, is an area undergoing extensive redevelopment. It includes a newly constructed outdoor shopping mall with revenue per square foot among 
the top five percent of all national shopping malls (Culverwell 2007), and signs on Interstate 5 mention the location by name, so Bridgeport was also chosen for a field visit despite not appearing in any of the GIS maps. Bethany appeared in only a single map but was chosen for a visit as well. It has experienced rapid growth in a previously undeveloped area and has been a center of controversy surrounding local road expansions and possible extensions of the UGB (Parks 2011c, Tims 2011). Most of the urbanized area north of Highway 26 and Cornell Road consists exclusively of single-family residential development, whereas Bethany includes other land uses. Its status as a Metro designated town center also supports including it in the potential regional center list.

Furthermore, each of these three locations (Tanasbourne, Bridgeport, and Bethany) include development following the tenets of New Urbanism and smart growth. The terms, often used interchangeably despite their somewhat different origins, are both used to describe compact and dense development with a mix of uses, easy access to public transportation, and walkability. These goals are intended to improve neighborhood design in an effort to reduce the environmental impact and other negative consequences of sprawl (Hanlon et al, 2010; Song 2005). The Streets of Tanasbourne and Bridgeport Village shopping malls, as well as the Bethany center, are each attempts at constructing new commercial centers based on smart growth principles. Including these locations in the field visits allows the results of these efforts to be examined in the context of Metro's Region 2040 plan.

A few locations appeared on the maps but had their scores added into those for other places. For example, the Intel plant west of Cornelius Pass Road in Hillsboro had its scores added to Orenco's because the plant lies across the street from Orenco Station. 
There were four locations which had their scores added in this manner. The charts in Appendix C include details of which locations' scores were added to others.

After visiting the sites identified in the GIS research, the scores from the field visits were organized into the "Field observation scores" table shown in Table 2. Higher scores indicate a better performance; for example, the safety category would include a " 1 " if a location felt very unsafe and a " 5 " if it felt safe. Using this data, Bethany and Hillsboro are those most likely to be a center. Murrayhill, Tanasbourne, and Washington Square - the latter two of which are designated as regional centers by Metro - performed poorly using this criteria.

\begin{tabular}{|c|c|c|c|c|c|c|c|c|c|}
\hline $\begin{array}{r}\text { Field observation } \\
\text { scores }\end{array}$ & 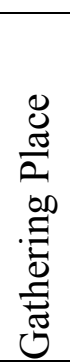 & 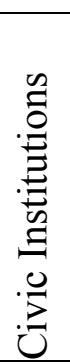 & 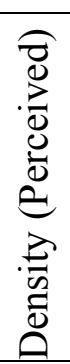 & 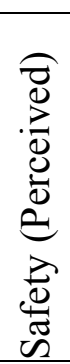 & 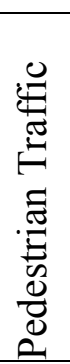 & 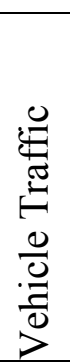 & 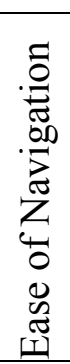 & 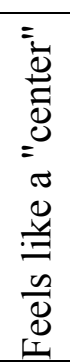 & $\frac{\sqrt{3}}{\tilde{3}}$ \\
\hline Beaverton & 3 & 5 & 3 & 3 & 3 & 5 & 2 & 3 & 27 \\
\hline Bethany & 3 & 3 & 4 & 5 & 3 & 4 & 5 & 4 & 31 \\
\hline Bridgeport & 3 & 0 & 2 & 5 & 3 & 4 & 5 & 2 & 24 \\
\hline Hillsboro & 3 & 5 & 3 & 3 & 3 & 4 & 5 & 4 & 30 \\
\hline Murrayhill & 2 & 1 & 2 & 5 & 2 & 4 & 3 & 1 & 20 \\
\hline Orenco & 2 & 0 & 3 & 5 & 2 & 4 & 4 & 4 & 24 \\
\hline & 2 & 1 & 3 & 5 & 2 & 3 & 3 & 2 & 21 \\
\hline $\begin{array}{r}\text { Washington } \\
\text { Square }\end{array}$ & 1 & 1 & 3 & 4 & 2 & 5 & 2 & 3 & 21 \\
\hline Average & 2 & 2 & 3 & 4 & 3 & 4 & 4 & 3 & 25 \\
\hline
\end{tabular}

$$
\text { Table } 2
$$

Scores from the field observations are shown in this table. Murrayhill's score of 20 makes it least indicative of a regional center, while Bethany's score of 31 makes it most likely to be a regional center based on these numbers.

Because the observation ratings in the may not be the best for comparison purposes, each center visited was also ranked by category. For example, the location 
with the most civic institutions was given a rank of "1" while the location with the fewest was given a rank of " 8 " as there were eight centers studied. Arranging the scores in this fashion resulted in the "Ranked scores" table (Table 3). In this case, lower scores are more indicative of being a regional center. Hillsboro and Beaverton had the best scores, while Bridgeport and Murrayhill the worst.

\begin{tabular}{|c|c|c|c|c|c|c|c|c|c|}
\hline Ranked scores & 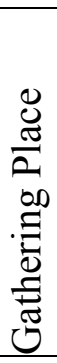 & 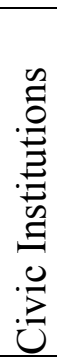 & 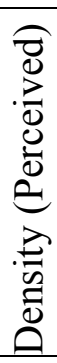 & 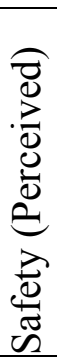 & 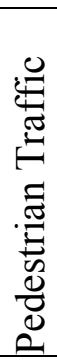 & 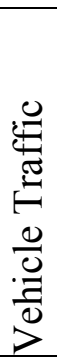 & 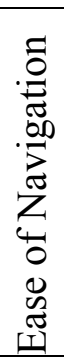 & 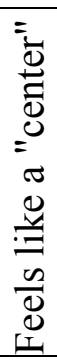 & $\underset{\tilde{\sigma}}{\tilde{\sigma}}$ \\
\hline Beaverton & 1 & 2 & 5 & 8 & 1 & 2 & 6 & 3 & 28 \\
\hline Bethany & 7 & 3 & 2 & 1 & 3 & 8 & 3 & 4 & 31 \\
\hline Bridgeport & 4 & 8 & 8 & 2 & 6 & 7 & 4 & 7 & 46 \\
\hline Hillsboro & 2 & 1 & 4 & 7 & 2 & 4 & 1 & 2 & 23 \\
\hline Murrayhill & 6 & 7 & 6 & 4 & 5 & 5 & 5 & 8 & 46 \\
\hline Orenco & 3 & 5 & 3 & 3 & 7 & 6 & 2 & 6 & 35 \\
\hline Tanasbourne & 5 & 4 & 7 & 5 & 4 & 3 & 7 & 5 & 40 \\
\hline $\begin{array}{r}\text { Washington } \\
\text { Square }\end{array}$ & 8 & 6 & 1 & 6 & 8 & 1 & 8 & 1 & 39 \\
\hline Average & & & & & & & & & 36 \\
\hline
\end{tabular}

Table 3

Each location visited was ranked relative to one another, as shown in this table. Murrayhill and Bridgeport share a score of 46, make them least indicative of regional centers. Hillsboro's score of 23 makes it most likely to be a regional center based on these numbers.

The case of civic institutions illustrates the higher subjectivity of the original field observation scores; both Bridgeport and Orenco scored a rare "0" for that metric. However, Orenco scores a "5" when compared against the other locations. When ranked, Orenco makes a greater impression due to the presence of multiple public parks which stand out more than Washington Square's fire station or Murrayhill's artificial pond. It should be noted however that the scores are quite subjective for both methods, and that 
visiting the locations at different times or by having multiple people perform the research may yield different results. Perceived safety scores in particular would benefit from having multiple people perform the field work; the author's perspective as a young male likely differs considerably from that of an elderly female.

Table 4 includes the final list of regional centers, compiled based on the GIS results for the year 2000 and on both the GIS results and field visits for the year 2010. The results are shown in a map in Figure 25. Of particular note is the case of Bethany. While it performs quite highly in the field visit criteria, it is not considered a regional center in this study. It is believed Metro's designation as a town center is adequate; Bethany proved to be a vibrant and pleasant location, but its small size (it is boxed in by single-family subdivisions and has no direction in which to grow), relative lack of access, and prevalence of moderate as opposed to high density construction prevent it from being a regional as opposed to a localized town center. Because of the newness of Bethany, it is unlikely to be targeted for high-density redevelopment in the near future. 


\begin{tabular}{|c|c|c|c|c|}
\hline $\begin{array}{c}\text { Metro- } \\
\text { Designated }\end{array}$ & $\begin{array}{c}\text { GIS Analysis } \\
\text { and } \\
\text { Appearance } \\
\text { Scores (2000) }\end{array}$ & $\begin{array}{c}\text { GIS Analysis } \\
\text { and } \\
\text { Appearance } \\
\text { Scores (2010) }\end{array}$ & $\begin{array}{c}\text { Field Visit } \\
\text { Scores }\end{array}$ & Study Results \\
\hline Beaverton & Beaverton & Beaverton & Beaverton & Beaverton \\
Hillsboro & Hillsboro & Hillsboro & Bethany & Hillsboro \\
Tanasbourne & & Murrayhill & Hillsboro & Wash. Square \\
Wash. Square & & Orenco & Orenco & \\
& & Wash. Square & & \\
& & & & \\
\hline
\end{tabular}

\section{Table 4}

Metro-designated centers and results from each portion of the analysis. Metro-designated locations are considered regional centers in the Region 2040 plan. The GIS analysis scores for 2000 include any location with a score of 4 or more in the 2000 chart shown in Appendix C. The scores for 2010 show the same thing using the 2010 chart in the same appendix. Field visit scores include any location with betterthan-average numbers. Study results show the final determination of regional centers.

Conversely, Washington Square performed relatively poorly in the field visit criteria but is included in the 2010 list. Washington Square, with a major shopping mall, employment area, convergence of highways, availability of public transportation, multitude of large and visible buildings, and highway signage advertising its presence make the location a clear center for its respective region. This is not to say Washington Square fits all of Metro's criteria. Navigation is fairly difficult as the center is bisected by a freeway with only two overpasses, traffic volumes are high, and there are multiple massive parking lots, making connectivity within the center poor. Residential development is lacking, though present. Despite these deficiencies, the area is wellknown throughout the county and metropolitan region as a whole. The golf course, mall and other shopping, and large employment areas bring people to the center.

Among the more difficult locations to classify are Orenco and Tanasbourne. Both are large in area. Both are in close proximity; their official boundaries are only about a half-mile apart from each other. Both have plentiful shopping, employment, residential, 
and gathering areas. The overall atmosphere in both is very similar. However, connectivity and navigation are poor within both; moving directly from one section of the center to another is often impossible. Pedestrian traffic is low in both. The gathering spaces, particularly in Orenco, are not widely used. Taken in their entirety, both have low building intensity despite pockets of density (Orenco Station at Orenco and the Streets of Tanasbourne in Tanasbourne). Activity at both is focused on the large local strip malls. Currently the Orenco Station and Streets of Tanasbourne areas within the centers are more on the scale of town rather than regional centers. With Hillsboro's plans to develop Tanasbourne into something of a downtown for the county, this may change. The small industrial operations sitting between the two centers may go out of business, be zoned out of the area, or be purchased by those wishing to develop something else on the land. It is conceivable that given Hillsboro's goals for the two centers and their unusually close proximity to one another, Orenco and Tanasbourne might merge into a large regional center with small districts within it. In the future the area could even rival downtown Portland in size and density. Today however, wide expanses of single-story development, few attractions, and large vacant lots seemingly scattered about the landscape at random characterize the area and are difficult to label a regional center. 


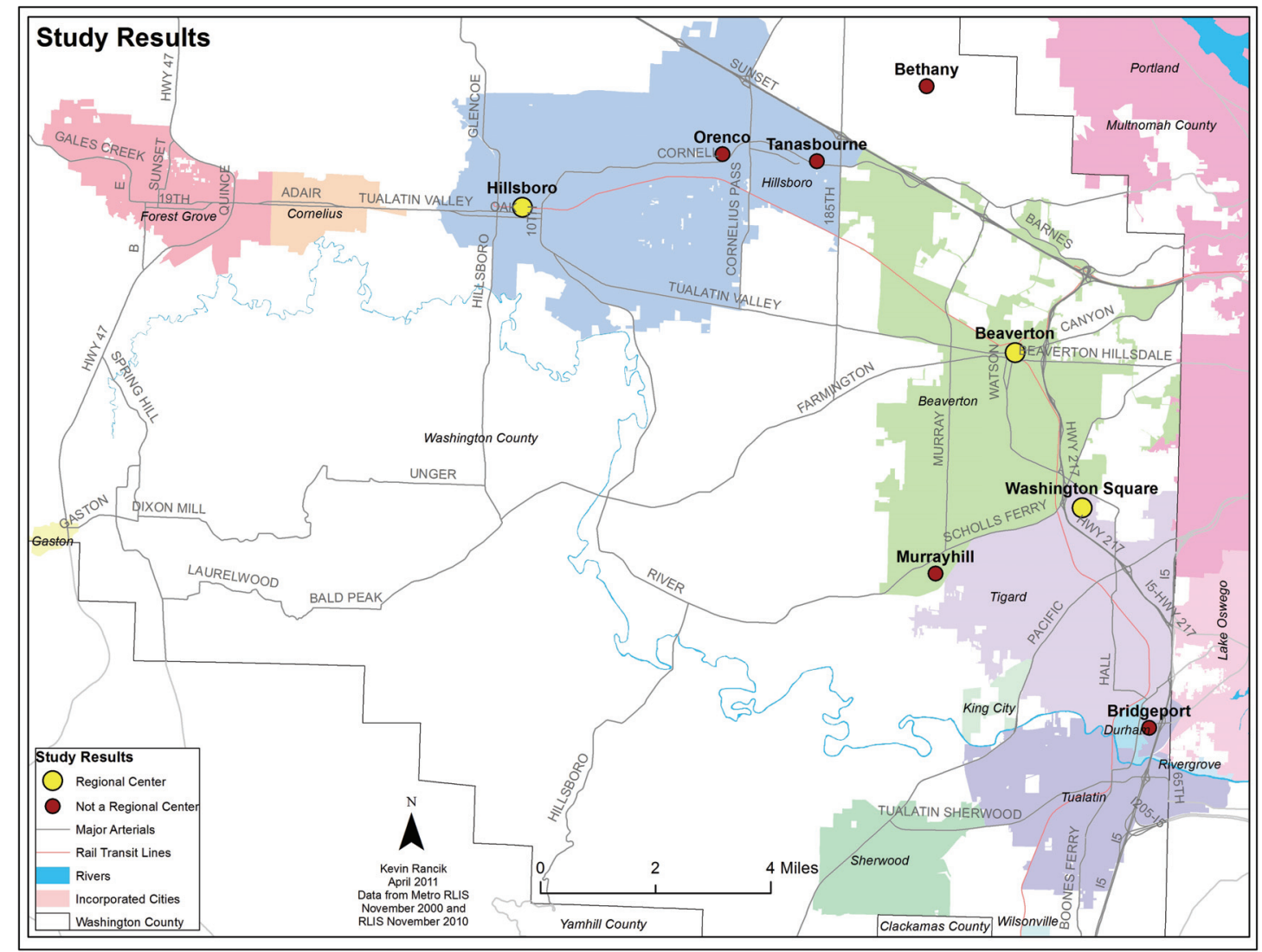

Figure 25

Study Results: This map shows the results of the study; locations labeled in yellow (Beaverton, Hillsboro, and Washington Square) are those determined to be regional centers. The other five locations, shown in red, are not considered regional centers in this study.

One question is whether or not the change in densities from 2000 to 2010 matches the change in centers during that time. In the case of this study Beaverton and Hillsboro are considered regional centers, with Washington Square added for 2010. The variables chosen for study should be anchored by the three regional centers in the change maps to verify that they either contribute to or indicate the presence of a regional center. The following pages include the results of the second portion of the GIS analysis: the maps showing change over time. 


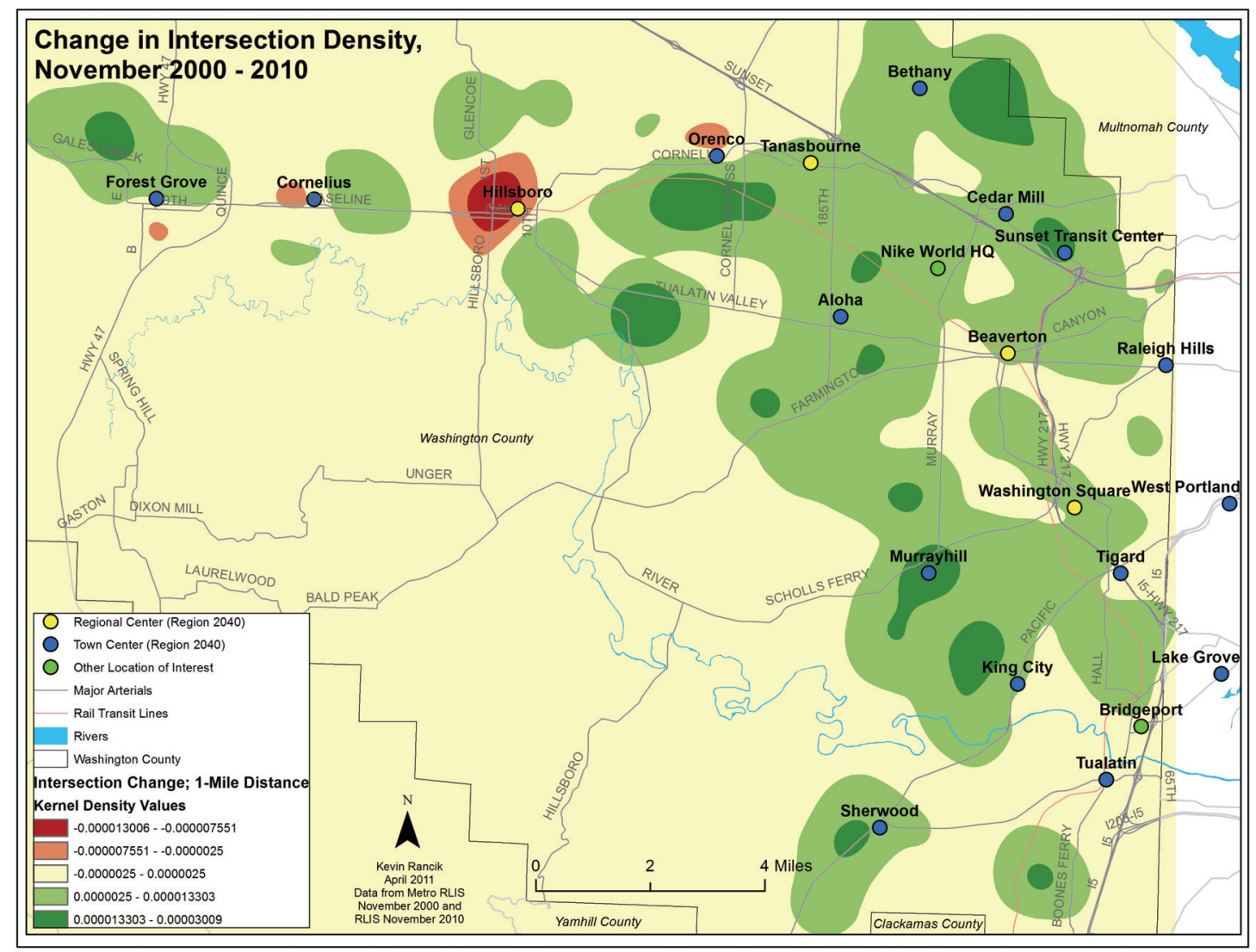

Figure 26

Change in Intersection Density, November 2000 - 2010

Between the years 2000 and 2010 intersection density strongly decreased in downtown Hillsboro. The removal of streets from the Hillsboro road network is, however, highly unlikely, suggesting a problem with the data. In other areas numerous locations showed strong growth in intersection density, and most of the urbanized portion of the county showed at least some notable increase. Murrayhill and Sunset Transit Center, two locations designated as town centers by Metro, anchored some of the strong growth in intersection density. 


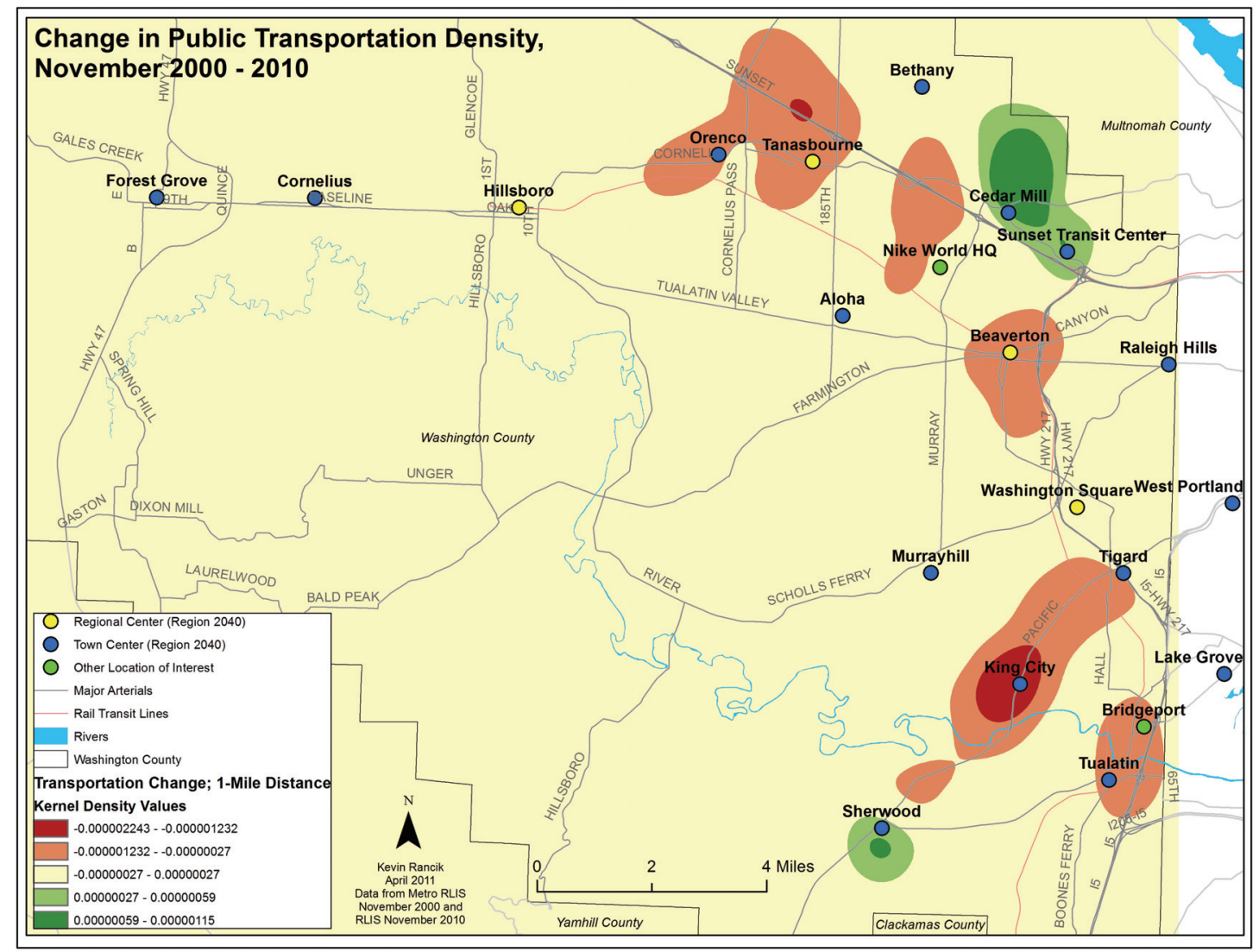

Figure 27

Change in Public Transportation Density, November 2000 - 2010

Public transportation density changed in surprising ways during this time period, suggesting TriMet dramatically altered its transportation coverage. Beaverton and Tanasbourne, both designated as regional centers by Metro (and Beaverton by this study), exhibited relative decreases. Orenco, deemed a town center by Metro and widely regarded as a prime example of smart growth and transit-oriented-development, also exhibited a decrease. King City, a small city with a minimum age requirement for residents, showed a marked decrease. The area north of Cedar Mill, and to a lesser extent Sherwood, are the only locations that exhibited an increase in public transportation density. 


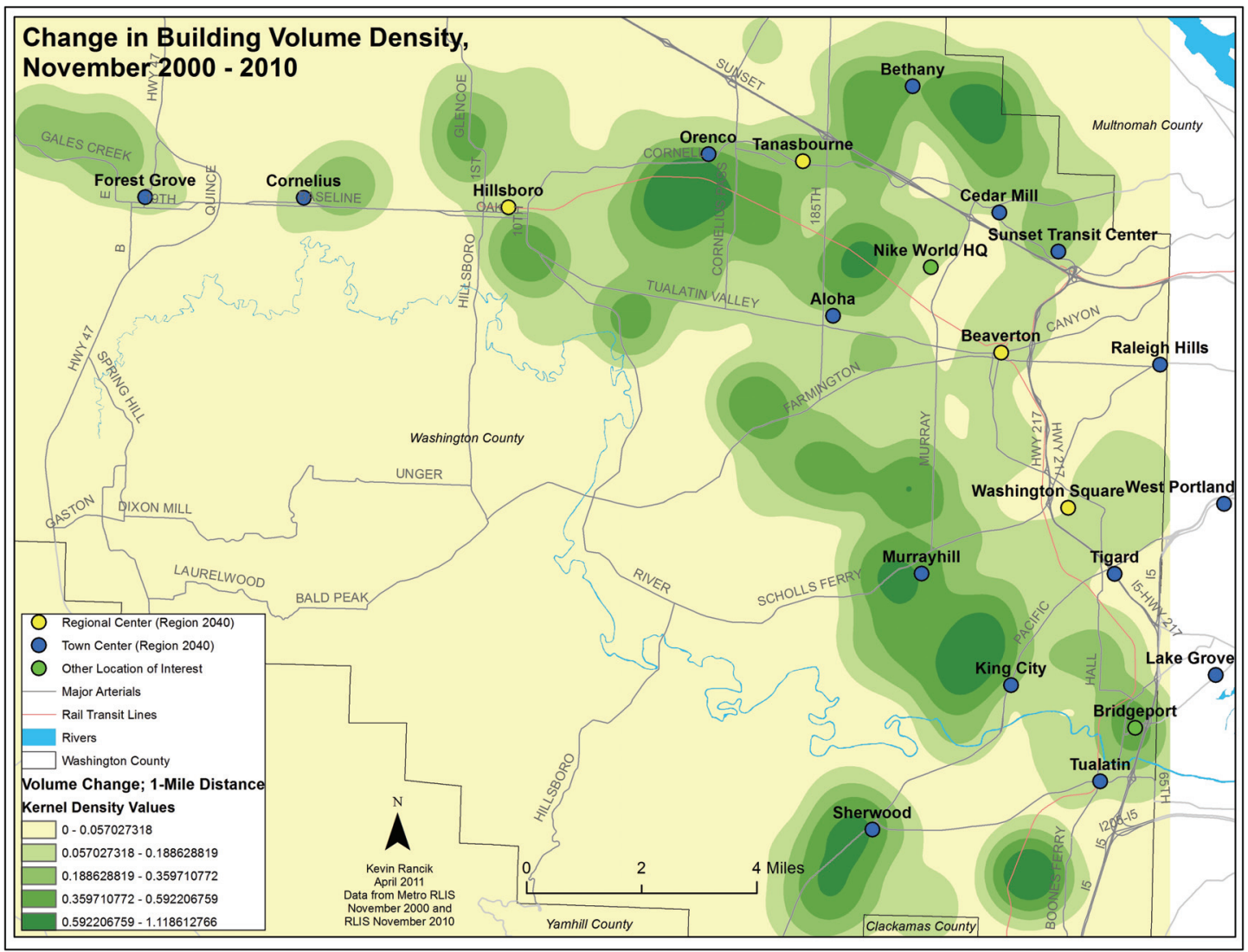

Figure 28

Change in Building Volume Density, November 2000 - 2010

During this time frame no locations exhibited a decrease in the density of building volume. Increases were spread throughout most of the urbanized area of the county. The strongest increases appeared at Orenco, east of Bethany, Sherwood, areas west of Murrayhill, west of King City, west of Nike World Headquarters, and an unnamed area south of Tualatin. Metro's designated regional centers did not anchor the strongest increases here; they tend to be in relatively built up areas, so the construction of new subdivisions on undeveloped land may have overshadowed them here. 


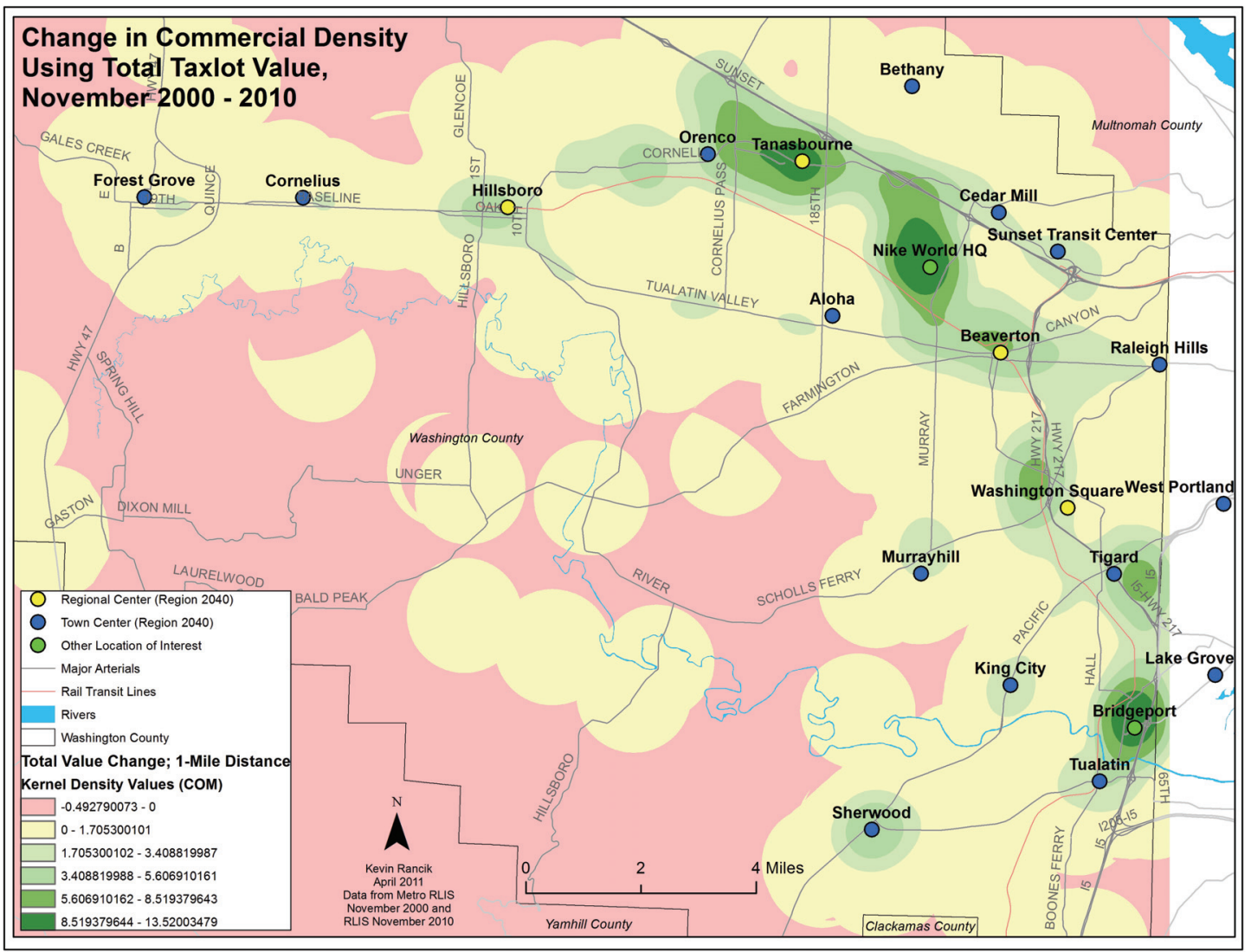

Figure 29

Change in Commercial Density Using Total Taxlot Value, November 2000 - 2010

Most rural areas outside of the urbanized area showed a slight decrease in commercial density using the taxlots' total value as a weight. Nike World Headquarters showed perhaps the greatest increase, with Bridgeport and Tanasbourne anchoring two other locations of prominent increases. Washington Square, despite being home to a major regional shopping mall and office complex, exhibited only modest growth in the portion west of Highway 217. Office complexes appeared to anchor the largest increases, while Bridgeport was a new shopping mall built atop a former rock quarry. 


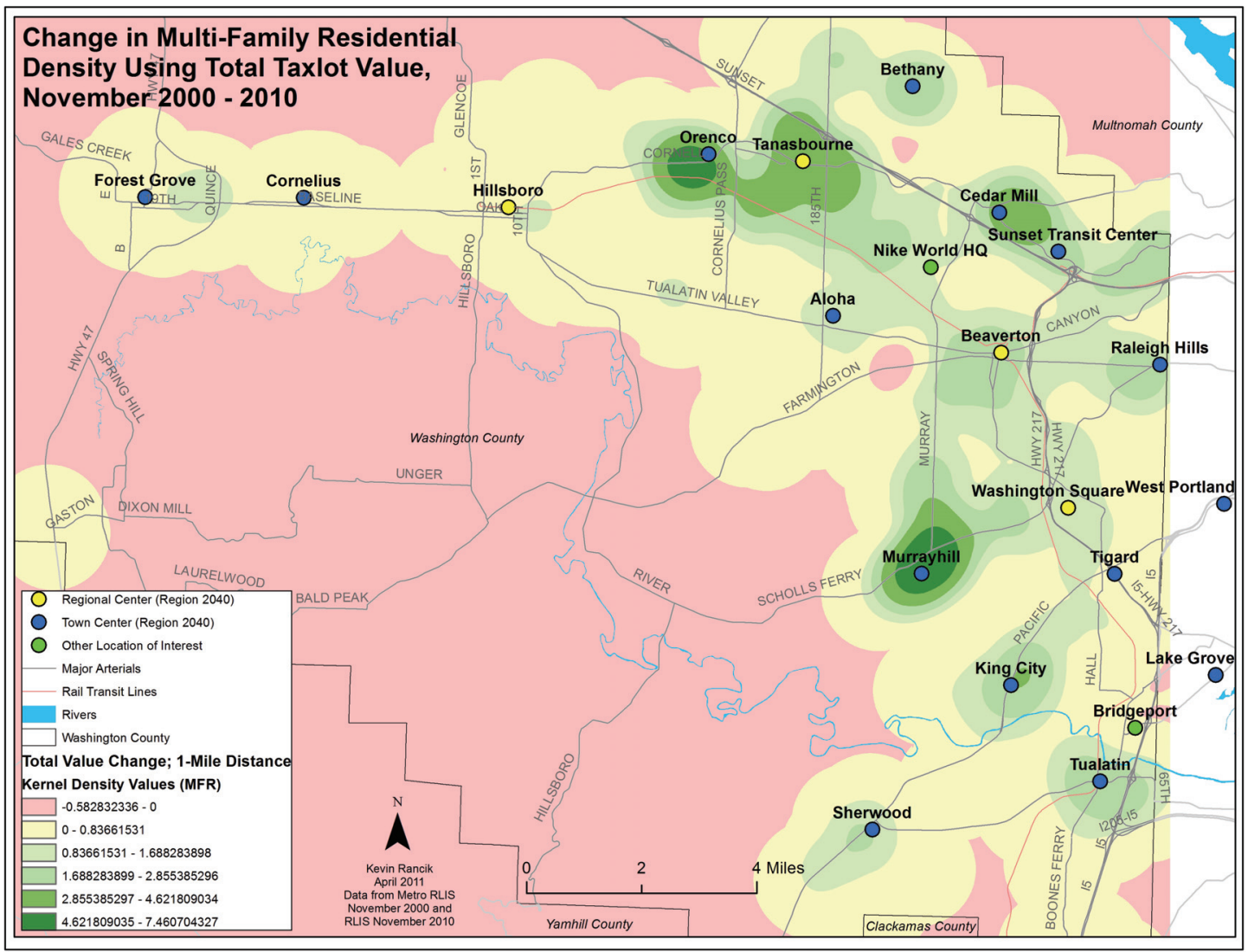

Figure 30

Change in Multi-Family Residential Density Using Total Taxlot Value, November 2000 - 2010

Using total taxlot value as a weight, multi-family residential density decreased in all rural areas in this time period (the unlabeled location just above the legend is the small town of Gaston). It is possible that locations outside the UGB lost value during the decade's housing boom as they could not be developed in the same way as locations within the UGB. Orenco and Murrayhill show the greatest increases using this metric, with Cedar Mill and Tanasbourne close behind. Other locations sported only modest increases, Beaverton among them. 


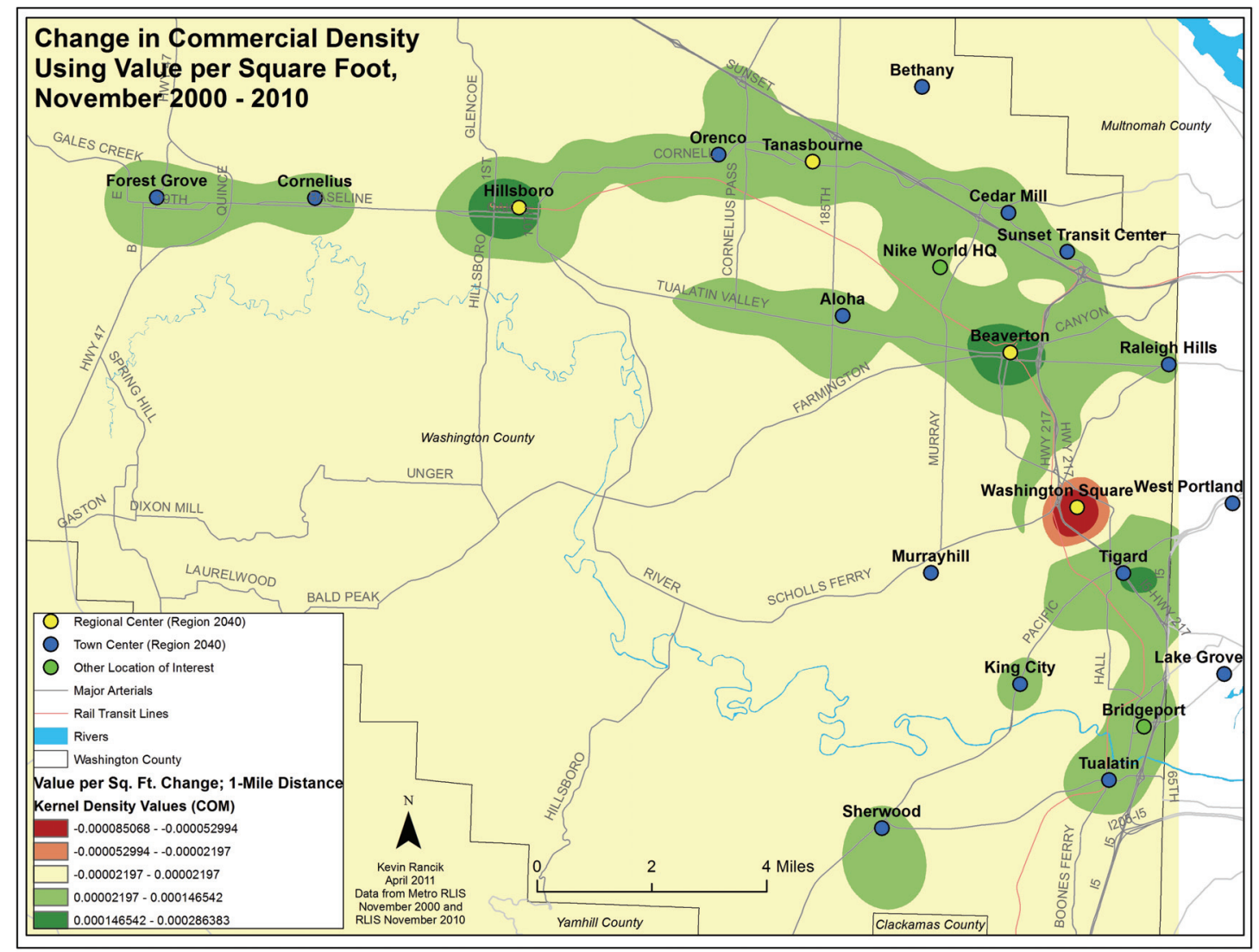

Figure 31

Change in Commercial Density Using Value per Square Foot, November 2000 - 2010

When examining the change in commercial density using the value per square foot as the weight instead of total taxlot value, rural areas held their ground. The regional centers of Beaverton and Hillsboro, designated as such by both Metro and this study, showed decidedly strong increases. Tigard, designated a town center by Metro, also showed a strong increase but over a smaller area. Washington Square, also considered a regional center by both Metro and this study, exhibited modest growth in density using the total taxlot value. Here, however, it showed the only decrease in the study area, and this decrease was particularly strong and localized. The economic downturn and Washington Square's status as an older shopping mall might have contributed to this. 


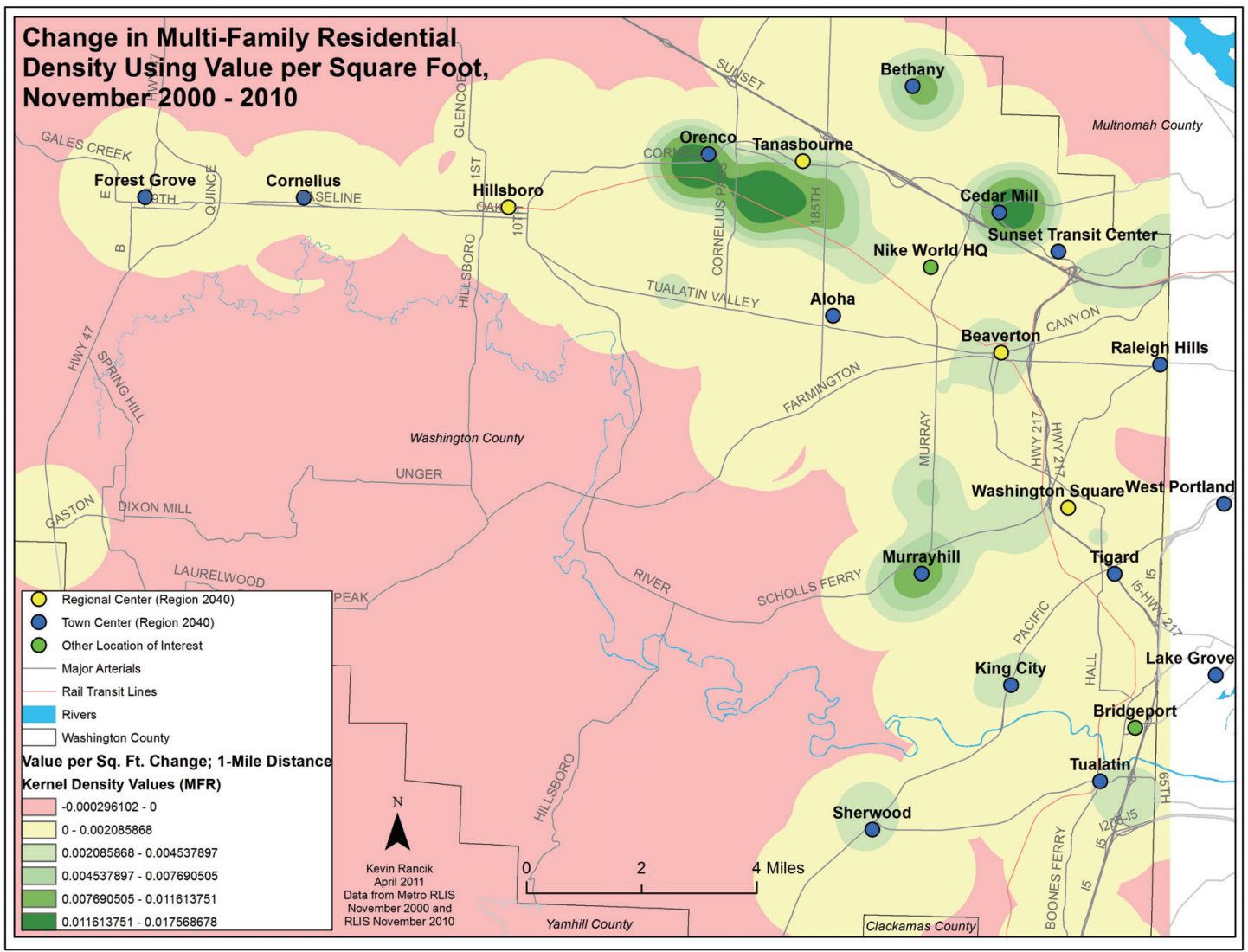

Figure 32

Change in Multi-Family Residential Density Using Value per Square Foot, November 2000 - 2010

As with multi-family residential density using total taxlot value, the results using the lots' value per square foot also showed all rural areas decreasing in density. Increases were generally in the same locations. The strong increase exhibited in Orenco using total taxlot value was shown as extending into Tanasbourne using the value per square foot metric. Both Orenco and Tanasbourne featured extensive new apartment and condominium construction which may explain this. Cedar Mill also showed a strong increase here, and Bethany and Murrayhill showed relative increases as well.

Table 5 shows the results of the analysis of change from 2000 to 2010, with the maps referenced preceding it. Results in the extreme categories were rated as strong; for 
instance, the map of street intersection change shows Hillsboro in the extreme negative category. Thus it was rated as "strong negative" for this variable. Results in middle categories were rated as "negligible." This is not to say the variable has no effect on the development of that particular center but instead that the effect is weak compared to other locations. Categories between negligible and strong were rated as "weak"; the change in commercial value weighted on the total value of the lot showed weak positive results for each of the three centers. The centers exhibited results in the second highest category, hence their weak rating.

\begin{tabular}{|r|c|c|c|}
\hline Change Results & Beaverton & Hillsboro & $\begin{array}{c}\text { Washington } \\
\text { Square }\end{array}$ \\
\hline Intersection & Negligible & $\begin{array}{c}\text { Strong } \\
\text { Negative }\end{array}$ & Weak Positive \\
\hline TriMet Transportation & Weak Negative & Negligible & Negligible \\
\hline Building Volume & Negligible & Weak Positive & Negligible \\
\hline Total Value, Commercial & Weak Positive & Weak Positive & Weak Positive \\
\hline Residential & Weak Positive & Negligible & Negligible \\
\hline Value/fte ${ }^{2}$, Commercial & Strong Positive & Strong Positive & $\begin{array}{c}\text { Strong } \\
\text { Negative }\end{array}$ \\
\hline Value $/ \mathrm{ft}^{2}$, Multi-Family Residential & Negligible & Negligible & Negligible \\
\hline
\end{tabular}

Table 5

Table 5 includes the results derived from analysis of the change maps on the previous pages. Commercial taxlot value is most consistently associated with the location of a center. Public transportation, building volume, and multi-family residential values produced negligible results, while intersection density results were mixed.

What these results show is that out of the variables chosen for study, only commercial land value reliably indicates the presence of centers. In the case of values weighted on the total value of the lot, each center exhibited a weak positive result. This means that in Beaverton, Hillsboro, and in Washington Square, commercial value a shows modest increase over the ten-year period. Using the values weighted by value per 
square foot yields different results. Both Beaverton and Hillsboro show the same trend but stronger; both show large increases in value over the ten-year period. Washington Square showed a strong decrease unmatched by any other location in the county.

Understanding the reason for this requires further study, particularly given that Washington Square is home to a major regional shopping mall, a major office complex including a twelve-story tower, and office parks. Nevertheless, because Beaverton and Hillsboro both exhibited strong increases here, and because all three showed at least some increase using the total taxlot value metric, it can be concluded that commercial value is an indicator of centeredness on a regional scale.

The remaining variables are less conclusive. Using the value of multi-family residential land use yields negligible results. Though very slight increases are observed in some portions of the centers, they are negligible overall in comparison with the rest of the county. Building volume also captures only negligible results. Some locations show significant increases in volume density, but none of them overlap with the centers.

Public transportation change generally shows similar results, with Washington Square and Hillsboro exhibiting negligible change. Hillsboro had the light-rail line in its downtown prior to 2000, and no major transportation projects have been undertaken there since. Washington Square recently had the Westside Express (WES) commuter rail line constructed through it, but this one stop did not significantly increase the availability of transit according to the results. Beaverton, surprisingly, shows a decrease in transit density. Beaverton has two light-rail stops in its downtown, a transit center with multiple bus routes converging on it, and the northern terminus of the new WES line. A more thorough investigation of this change is required, as it seems unlikely that transit service 
decreased overall in Beaverton. Results showing transit has not aided much in the way of regional center development seem to defy conventional wisdom, though it may be explained by the fact these locations already had high transit service in 2000. Expansions of the service in the centers may not show up on maps comparing those locations to the rest of the county, which may have previously had underserved locations receiving new service since 2000 .

Street intersection density, like public transit availability, seems to be a major factor in the vibrancy of urban centers. However, these particular results do not necessarily confirm this. Beaverton shows no significant change in the number of street intersections, which indicates that roads were neither constructed nor removed. Washington Square shows a slight increase, indicating a small change in the street network occurred there. However, just as Beaverton unexpectedly shows a decrease in public transit availability, Hillsboro unexpectedly shows a marked decrease in its street intersection density. Hillsboro's grid pattern has remained largely unchanged for decades and did not receive adjustment during the time frame examined. Why its intersection density would go down over time without major street removals in the area requires further investigation.

Of the three centers only Washington Square was a new addition for the year 2010. This means that if the selected variables are significantly indicative of a regional center, then Washington Square should logically show increases in these variables over the ten-year time frame. It does not, however. Intersection density went up but only slightly. Commercial value generally went up, but using the value per square foot measure also included a massive decrease in its northern section. Beaverton and 
Hillsboro show strong positive results only on the commercial value per square foot, indicating these centers continue to grow and hold on to the relative importance they had in 2000. However, it is difficult to conclude this is a major factor in regional center development when Washington Square included the only strong decrease in the county for this variable. 


\section{Conclusions}

So then why are the three centers where they are? What makes them regional centers? Metro, prior to its recent addition of Tanasbourne as a regional center, designated Beaverton, Hillsboro, and Washington Square as the three regional centers in Washington County. These are also the three determined to be regional centers in this study. Thus, Metro's designations were confirmed despite the hypothesis that centers would appear in other locations. All three of them were picked up in the initial GIS analysis, indicating the variables used here can indeed be used in combination to detect these locations. It is certainly safe to say though that no single variable among those chosen detects a center. Beaverton and Hillsboro both appear on the street intersection density maps but Washington Square forms a hole in them. Beaverton dominates the county in the availability of public transportation, while in 2010 Washington Square emerges as a center of building volume. Hillsboro barely shows up in either of those categories. All three show up on the maps of commercial value, but then the question becomes which kind of value to use. Beaverton and Hillsboro have high commercial values per square foot, but Washington Square shows up more strongly using the total value of the entire commercial lot. Then there is the matter of multi-family residential use, which while a major portion of Metro's growth plans, had only negligible results in these three centers both in the mapping of values and mapping of change.

These results point to the need for more detailed analysis or a change in methodology, as well as the fact that defining a regional center is a demanding effort at best. It could be helpful in the future to use statistical methods to determine just how 
significant each of these variables is. It may be possible to generate a regression equation with these variables to determine their significance and how much each contributes to the center's formation or existence. Each variable would require normalization since they are not directly comparable. For instance, one multi-family residential lot and one commercial lot may be the same size and have the same type of buildings built at the same time, but are they really worth the same amount? Commercial and residential markets are geared toward different buyers with different purposes. Direct comparisons do not reflect these differences.

In some cases the underlying data may have led to unreliable results. For example, the building volume data include a field for the year of construction for anything on a particular taxlot. However, that field may be incomplete. Since the results for the year 2000 are based on that field, they do not include buildings with the date of construction missing. It is quite possible different results would be achieved with more complete information. Since Metro is continuously updating its RLIS data a more thorough investigation may be possible soon. Land value data may also be flawed due to inflation and fluctuation in economic conditions. Inflation is likely less of an issue than economic conditions; in theory all land values should be increasing at the same rate, meaning that any notable changes over time would indicate a change of significance such as a major construction project increasing value or a problem with local services that causes a local decrease in value. However, economic conditions may skew some results. Residential and commercial markets, as stated before, differ in their clientele and use. If market trends favor one over the other, and one location has an abundance of one and not the other, this may cause that location to stand out more than it otherwise would. A large 
commercial district with no housing would obviously benefit more in the results during a commercial building boom, while a mixed-use center might not.

Additionally, visiting each location multiple times and having multiple people make field observations would enhance this research. Pedestrian traffic may change on a daily basis. Sunny weather likely yields greater pedestrian activity than stormy weather. No field visits were conducted during a storm, but nevertheless, controlling for variables such as precipitation and temperature would generate more consistent results. Future research should compare weekday and weekend activity as well; the number and type of people in a public park or office complex are likely to vary considerably from a Wednesday to a Saturday. Including multiple people in the field observation portion of the research would add a greater perspective. The perception of safety is perhaps most notable in this regard; a young male indubitably sees this differently than an elderly woman. A rural farmer likely sees traffic levels differently than someone who grew up in Manhattan. Asking various people to conduct the field observations and then averaging their scores could yield results different from those provided here.

There is, of course, the overarching theme of what makes a regional center. Perhaps Metro's definitions accurately describe a center, though their definitions are in flux and overly broad. Perhaps Garreau's more specific criteria for an edge city, complete with over a half-million square feet of retail space and millions of square feet in office space, makes more sense. Maybe the urban models are most useful because they use land value and economic criteria in determining the locations of centers. Ultimately there is no single, widespread, accepted definition that applies to this concept. Even with such a definition there would arguably be exceptions; a location in a declining industrial 
small town in the Northeast could arguably be a center for its respective region, while a resort destination in metropolitan Miami, Florida could also be a center. Beyond the fact they are centers, commonalities might be few and far between. Defining a center's boundaries introduces another level of complexity this study cannot address. Though a generalized area can be considered a regional center, at what point is the boundary drawn? In the case of Bethany, this may be as simple as drawing a line down a road. One side has the activity area and mixed-use multi-story development while the other side has single-family homes blocked from view and from access by a retaining wall. Other locations such as Beaverton and Washington Square, however, are nowhere near as cut and dry. Land use patterns in older neighborhoods such as those rarely conform to an obvious standard.

In this study three of Metro's four designated regional centers in Washington County do indeed appear to be regional centers, with Tanasbourne showing strong signs of becoming a regional center in the future. As a result the criteria used here is consistent with their goals. Commercial land value appears to indicate center development most significantly, but that does not discount the importance of the other variables. Further field work and the introduction of statistical methodology would add a greater understanding of the regional centers, but this work provides a starting point for future research of these and other Region 2040 plans.

It is worth noting that Metro's Region 2040 map has changed over the years. Appendix A includes three maps from Region 2040 at different time periods. The first map is an early version. Clark County is not included in the plans, and Damascus has not yet become an incorporated city nor a part of the region's urban growth boundary. 
Milwaukie is designated a regional center (Calthorpe Associates, Date Unknown). A 2005 update includes Clark County and Damascus in the context of the growth concept, but Milwaukie is downgraded to a town from a regional center (Metro 2005). The most current edition released in 2011 (Metro 2011b) adds Tanasbourne and Mill Plain as regional centers. Every center within Metro's jurisdiction, including downtown Portland, appears with defined boundaries and a name. The Happy Valley town center was moved about two miles to the southeast.

This study originally began as an attempt to create an urban model for the Portland area. Region 2040 attempts to plan out Portland's urban form, so the study moved on to determine how "correct” the Region 2040 map was. Does Metro's map match reality on the ground? In the case of Washington County it appears the map does indeed match on the ground conditions; regional centers are where Metro says they are. Of Metro's regional centers in the county, only Tanasbourne is not considered one by this study - but Hillsboro's plans for the Amberglen business park and existing construction in the vicinity of the Streets of Tanasbourne suggest a very strong possibility it soon will become one. A major hospital is already under construction there. New multi-story, denser residential buildings have been built. Extensive retail brings people to the area. Connections to the local freeway and light rail line exist. Due to Tanasbourne's size, location, and future plans, and due to Orenco's size, construction pattern, and proximity to Tanasbourne, the two may someday merge and even rival downtown Portland in many regards. In other words, Metro's designation of Tanasbourne as a regional center does not accurately describe it today but is not a mistaken designation. Tanasbourne has strong signs of being an emerging regional center. 
This does not, however, mean Metro's map will always pan out. The recent movement of the Happy Valley town center in Clackamas County two miles to the southeast is a radical change. West Linn's town center, also in Clackamas County, has also moved - in this case to the southwest. Its previous position is now connected to the Oregon City regional center. Mill Plain's recent addition as a regional center in Clark County comes as a surprise; in previous iterations of the concept map it did not exist as anything. It was not a town center, it was not a corridor, and it was not a Main Street. It seemingly comes out of nowhere.

In light of Metro's own changes, an obvious avenue for further research is to simply study the entire metropolitan region. Clackamas County, with its numerous changes in the maps over the years, seems it would provide results different from those in this study. Perhaps Milwaukie should have remained a designated regional center. Why was Happy Valley's original center where it was? Would the use of taxlots' commercial value, seen to be an indicator of centers in Washington County, also locate centers in other parts of the metropolitan area - or would the other variables used here prove to be more effective in locating them? Would Clark County, outside of Metro's jurisdiction, not bound to Oregon's land use laws, with a different history of development, show different results than what was achieved here? Or, perhaps, Washington County itself would provide somewhat different results with the use of different variables.

Washington County, with its rapid development over the past few decades, may seem to be more stable in the maps' designations because it had more open space to develop than other counties. As such, its blank canvas and marginal historic development may have made it easier to develop as Metro intended, making revisions to 
the Region 2040 concept map less necessary. Does Washington County match Metro's map? Generally yes, when it comes to regional centers. This study even revealed that some town centers, such as Bethany and Orenco, are properly designated by Metro. Do the selected variables explain the centers' locations? Not all of them do, but commercial taxlot values are the strongest indicator among them.

Any number of questions arise from the study of urban areas. The questions asked here are answered for one county. Geography is the study of space and place, and using this study's methodology to answer these questions at other locations would enhance understanding of Portland's urban geography. Issues related to increasing populations and urban development affect not only Portland however, but cities and metropolitan areas throughout the United States. The research presented here helps citizens, urban planners, and policy makers make informed decisions regarding their neighborhoods' futures and how best to achieve their goals for future development. 


\section{References Cited}

Abbott, C. 2006. Urban history for planners. Journal of Planning History. 5:4 301-313.

Adler, S. and J. Dill. 2004. The evolution of transportation planning in the Portland metropolitan area. In The Portland edge: challenges and successes in growing communities, ed. C. Ozawa, 230-256. Washington: Island Press.

Alig, R. and J. Kline, M. Lichtenstein. Urbanization on the US landscape: looking ahead in the 21st century. Landscape and Urban Planning. 69 219-234.

Allen, J. and T. Potiowsky. 2008. Portland's green building cluster: economic trends and impacts. Economic Development Quarterly. 22:4 303-315.

Aurand, A. 2010. Density, housing types and mixed land use: smart tools for affordable housing? Urban studies. 47:5 1015-1036.

Brail, R., ed. 2008. Planning support systems for cities and regions. USA: Lincoln Institute of Land Policy.

Burgess, E. 1925. The growth of a city: introduction to a research project. In The urban geography reader, ed. N. Fyfe and J. Kenny, 19-27. New York: Routledge.

Calthorpe Associates. Date Unknown. Regional plan, showing growth boundary and transit corridors. Retrieved May 14, 2011 from http://www.calthorpe.com/lutraq.

Census 2010. 2011. American FactFinder. Retrieved May 1, 2011 from http://factfinder2.census.gov/faces/nav/jsf/pages/index.xhtml.

Chapman, N. and H. Lund. 2004. Housing density and livability in Portland. In The Portland edge: challenges and successes in growing communities, ed. C. Ozawa, 206229. Washington: Island Press.

Christensen, N. 2010. Centers discussion centers in on substance. Retrieved May 1, 2011 from http://news.oregonmetro.gov/1/post.cfm/centers-discussion-centers-in-onsubstance. 
City of Vancouver, Washington. 2004. Vancouver comprehensive plan: 2003-2023. Retrieved July 11, 2010 from http://www.cityofvancouver.us/compplan.asp?menuid=10463\&submenuid=10485.

City of Vancouver, Washington. 2007. City of Vancouver comprehensive plan implementation: 2007 monitoring report. Retrieved July 11, 2010 from http://www.cityofvancouver.us/compplan.asp?menuid=10463\&submenuid=10485.

Columbia River Crossing (CRC). 2010. Project overview. Retrieved May 1, 2011 from http://www.columbiarivercrossing.org/Background/ProjectOverview.aspx.

Crowe, J. 2011. Rural perceptions of growth management legislation on rural economic development: welcoming comrade or hostile foe? Society and Natural Resources. 24:3 $221-241$.

Culverwell, W. 2007. Bridgeport spurs retailing revival: returns are in top 5 percent in nation. Portland Business Journal. Retrieved May 12, 2011 from http://www.bizjournals.com/portland/stories/2007/07/23/story2.html

Dieleman, F. and M. Wegener. 2004. Compact city and urban sprawl. Built Environment. 30:4 308-323.

Dill, J. 2008. Transit use at transit-oriented developments in Portland, Oregon, area. Transportation Research Record. 2063: 159-167.

ESRI (Environmental Systems Resource Institute). 2010. Kernel density (spatial analyst). ArcMap 10. Redlands: ESRI.

Fong, D. 2011. Beaverton to offer discounted solar program for a second year. The Oregonian. Retrieved May 1, 2011 from http://www.oregonlive.com/beaverton/index.ssf/2011/02/beaverton_to_expand_solar_pro gram_at_a_discount_to_residents.html

Fong, D. 2011b. Lack of performing arts space leaves Beaverton groups struggling to find places to sing, dance and act. The Oregonian. Retrieved May 1, 2011 from http://www.oregonlive.com/beaverton/index.ssf/2011/01/lack_of_performing_arts_space _leaves_beaverton_groups_struggling_to_find_places_to_sing_dance_and_ac.html.

Fyfe, N. and J. Kenny, ed. 2005. The urban geography reader. New York: Routledge. 
Garreau, J. 1992. Edge city: life on the new frontier. New York: Anchor Books.

Gibson, K. and C. Abbott. 2002. City profile: Portland, Oregon. Cities. 19: 6 425-436.

Godfrey, B. 1995. Restructuring and decentralization in a world city. Geographical Review. 85:4 436-457.

Hagerman, C. 2007. Shaping neighborhoods and nature: urban political ecologies of urban waterfront transformations in Portland, Oregon. Cities. 24:4 285-297.

Hamilton, I. 1987. Silicon forest. In Portland's changing landscape, ed. L. Price, 174190. Portland: Portland State University.

Hanlon, B., Short, J., and T. Vicino. 2010. Cities and suburbs: new metropolitan realities in the US. New York: Routledge.

Hannah-Jones, N. 2011. 2010 Census: small area in Washington County is home to area's highest concentration of Asians. The Oregonian. Retrieved March 21, 2011 from http://www.oregonlive.com/washingtoncounty/index.ssf/2011/02/2010_census_small_are a_in_wash.html

Harris, C. and E. Ullman. 1945. The nature of cities. In The urban geography reader, ed. N. Fyfe and J. Kenny, 46-55. New York: Routledge.

Hillsboro Oregon. 2010. AmberGlen Community Plan. Prepared by the City of Hillsboro with Cardno WRG, David Evans and Associates, Inc., and Johnson Reid Land Use Economics. Retrieved June 1, 2010 from http://www.ci.hillsboro.or.us/Planning/OHSUAmberGlen.aspx\#Adopted.

Hoyt, H. 1939. The pattern of movement of residential rental neighborhoods. In The urban geography reader, ed. N. Fyfe and J. Kenny, 28-36. New York: Routledge.

Institute of Portland Metropolitan Studies. 2009. Policy report: achieving sustainable, compact development in the Portland metropolitan area: new tools and approaches for developing centers and corridors. Retrieved July 13, 2010 from http:/www.oregonmetro.gov/index.cfm/go/by.web/id=31931/level=4. 
Johnson-Gardner. 2007. An assessment of the marginal impact of urban amenities on residential pricing. Received from Dennis Yee, Metro Research Manager in June 17, 2010 e-mail.

Jun, M. 2008. Are Portland's smart growth policies related to reduced automobile dependence? Journal of Planning Education and Research. 28 100-107.

Kane, K. 2010. Metro council approves grants for regional planning projects.

Retrieved May 1, 2011 from

http://www.oregonmetro.gov/index.cfm/go/by.web/id=33437

Kline, J. 2005. Forest and farmland conservation effects of Oregon's (USA) land-use planning program. Environmental Management. 35:4 368-380.

Knox, P. and L. McCarthy. 2005. Urbanization: an introduction to urban geography. New Jersey: Pearson Education, Inc.

Kost, R. 2010. Beaverton tries to take the mantle of Oregon's most diverse city. PolitiFact Oregon. Retrieved March 21, 2011 from

http://politifact.com/oregon/statements/2010/dec/14/city-beaverton/beaverton-tries-takemantle-oregons-most-diverse-c/

Lang, R. 2003. Edgeless cities: exploring the elusive metropolis. Washington DC: Brookings Institution Press.

Lang R. and J. LeFurgy. 2007. Boomburbs: the rise of America's accidental cities. Washington DC: Brookings Institution Press.

Lee, B. 2007. "Edge" or "edgeless" cities? Urban spatial structure in U.S. metropolitan areas, 1980 to 2000. Journal of Regional Science. 47:3 479-513.

Lewis, P. 1996. Shaping suburbia: how political institutions organize urban development. Pittsburgh: University of Pittsburg Press.

Marshall, A. 2000. How cities work: suburbs, sprawl, and the roads not taken. Austin: University of Texas Press. 
Mayer, H. and J. Provo. 2004. The Portland edge in context. In The Portland edge: challenges and successes in growing communities, ed. C. Ozawa, 9-34. Washington: Island Press.

McHarg, I. 1992. Design with nature: $25^{\text {th }}$ anniversary edition. USA: John Wiley \& Sons, Inc.

Metro. 2000. The nature of 2040: the region's 50-year plan for managing growth. Retrieved July 12, 2010 from http://www.oregonmetro.gov/index.cfm/go/by.web/id=29882.

Metro. 2004. 2004 performance measures report: an evaluation of 2040 growth management policies and implementation. Retrieved July 11, 2010 from http:/www.oregonmetro.gov/index.cfm/go/by.web/id=13104/level=4.

Metro. 2005. 2040 Growth Concept. Retrieved July 11, 2010 from http://www.oregonmetro.gov/index.cfm/go/by.web/id=29882.

Metro. 2009. State of the centers: investing in our communities. Retrieved July 12, 2010 from http://www.oregonmetro.gov/index.cfm/go/by.web/id=30760/level=4.

Metro. 2010. Urban revitalization: centers and corridors. Retrieved May 19, 2010 from http://www.oregonmetro.gov/index.cfm/go/by.web/id=6555.

Metro. 2010b. Capacity ordinance explained: just what is the Metro council considering? Retrieved April 21, 2011 from http://news.oregonmetro.gov/1/post.cfm/capacity-ordinance-explained-just-what-is-themetro-council-considering.

Metro. 2011. Regional vision: the 2040 growth concept. Retrieved April 21, 2011 from http://www.oregonmetro.gov/index.cfm/go/by.web/id=29882.

Metro. 2011b. 2040 growth concept map. Retrieved April 11, 2011 from http://library.oregonmetro.gov/files//concept_011411.pdf.

Metro. 2011c. RLIS Live, Geographic Information System data. Retrieved May 1, 2011 from http://www.oregonmetro.gov/index.cfm/go/by.web/id=593. 
Moore, T. 2008. Planning support systems: what are practicing planners looking for? In Planning support systems for cities and regions, ed. R. Brail, 231-256. USA: Lincoln Institute of Land Policy.

Mumford, L. 1961. The city in history: its origins, its transformations, and its prospects. USA: Harcourt, Inc.

Nelson, A. 1993. Disamenity influences of edge cities on exurban land values: a theory with empirical evidence and policy implications. Urban Studies. 30:10 1683-1690.

Nicolaides, B. and A. Wiese, ed. 2006. The suburb reader. New York: Routledge.

Ozawa, C, ed. 2004. The Portland edge: challenges and successes in growing communities. Washington: Island Press.

Pacione, M. 2005. Urban geography: second edition. New York: Routledge.

Parks, C. 2010. Hillsboro makes art part of the city landscape. The Oregonian. Retrieved May 1, 2011 from http://www.oregonlive.com/hillsboro/index.ssf/2010/10/hillsboro_hillsboro_city_council _public_art_dancing_chairs_james_schmidt_sean_morgan_hillsboro_arts.html.

Parks, C. 2011a. Forest Grove will consider Orenco Station style project in hopes of bringing light rail to town. The Oregonian. Retrieved March 21, 2011 from http://www.oregonlive.com/forestgrove/index.ssf/2011/01/forest_grove_will_consider_orenco_station_style_project_in_ho pes_of_bringing_light_rail_to_town.html

Parks, C. 2011b. Hillsboro City Council will consider organic grocery store downtown. The Oregonian. Retrieved March 21, 2011 from

http://www.oregonlive.com/hillsboro/index.ssf/2011/01/hillsboro_city_council_will_cons ider_moving_forward_on_proposal_to_bring_organic_grocery_store_to_do.html

Parks, C. 2011c. Bethany's burgeoning growth makes its main road the one more traveled. The Oregonian. Retrieved May 1, 2011 from http://www.oregonlive.com/north-of26/index.ssf/2010/05/bethanys_burgeoning_growth_makes_its_main_road_the_one_mor e_traveled.html. 
Price, L, ed. 1987. Portland's changing landscape. Portland: Portland State University.

Redden, J. 2009. Metro's new look aims to head off growing pains. The Portland Tribune. Retrieved August 18, 2010 from http://www.portlandtribune.com/news/story.php?story_id=115258302205483300.

Schmidt, B. 2009. Beaverton stadium deal is $\$ 59$ million -- 60 percent from taxpayers. The Oregonian. Retrieved May 1, 2011 from http://www.oregonlive.com/washingtoncounty/index.ssf/2009/10/beaverton_stadium_dea 1_is_59_m.html.

Schmidt, B. 2009b. Beaverton leaders say the Round and Westgate projects need jumpstart. The Oregonian. Retrieved May 1, 2011 from

http://www.oregonlive.com/washingtoncounty/index.ssf/2009/03/beaverton_leaders_say_ the_roun.html.

Shandas, V. and W. Messer. 2008. Fostering green communities through civic engagement: community-based environmental stewardship in the Portland area. Journal of the American Planning Association. 74:4 408-418.

Simpson, D. and T. Kelly. 2008. The New Chicago School of urbanism and the New Daley Machine. Urban Affairs Review. 44:2 218-238.

Song, Y. and G-J. Knaap. 2004. Measuring urban form: is Portland winning the war on sprawl? Journal of the American Planning Association. 70:2 210-225.

Song, Y. 2005. Smart growth and urban development pattern: a comparative study. International Regional Science Review. 28:2 239-265.

Spolek, G. 2008. Performance monitoring of three ecoroofs in Portland, Oregon. Urban Ecosyst. 11 349-359.

Throop, V. 1948. The suburban zone of metropolitan Portland, Oregon. Chicago: University of Chicago.

Thurstain-Goodwin, M. and D. Unwin. 2000. Defining and delineating the central areas of towns for statistical monitoring using continuous surface representations.

Transactions in GIS. 4:4 305-317. 
Tims, D. 2011. Controversial Washington County road-widening project on Bethany Boulevard may be getting slimmer. The Oregonian. Retrieved May 1, 2011 from http://www.oregonlive.com/washingtoncounty/index.ssf/2011/02/controversial_washingt on_count.html.

UN (United Nations). 2002. World urbanization prospects: the 2001 revision: half the world will go urban in five years. UN Chronicle. 336

Vance, J. 1964. Geography and urban evolution in the San Francisco Bay area. Berkeley: University of California Institute of Governmental Studies.

Vance, J. 1990. The continuing city: urban morphology in Western civilization. Baltimore: Johns Hopkins University Press.

Vancouver. 2011. Fourth Plain plan. Retrieved May 1, 2011 from

http://www.cityofvancouver.us/PlanningProjects.asp?menuid=10463\&submenuid=18226 \&itemid $=18220$.

Wheeler, S. 2003. The evolution of urban form in Portland and Toronto: implications for sustainability planning. Local Environment. 8:3 317-336.

White, M. 1987. American neighborhoods and residential differentiation: for the National Committee for Research on the 1980 Census. New York: Russell Sage Foundation.

Wollner, C. 2011. Silicon Forest. The Oregon Encyclopedia. Retrieved March 21, 2011 from http://www.oregonencyclopedia.org/entry/view/silicon_forest/

Yang, Y. 2008. A tale of two cities: physical form and neighborhood satisfaction in metropolitan Portland and Charlotte. Journal of the American Planning Association. $74: 3$ 307-323. 
Appendix A: Region 2040 Growth Concept Maps

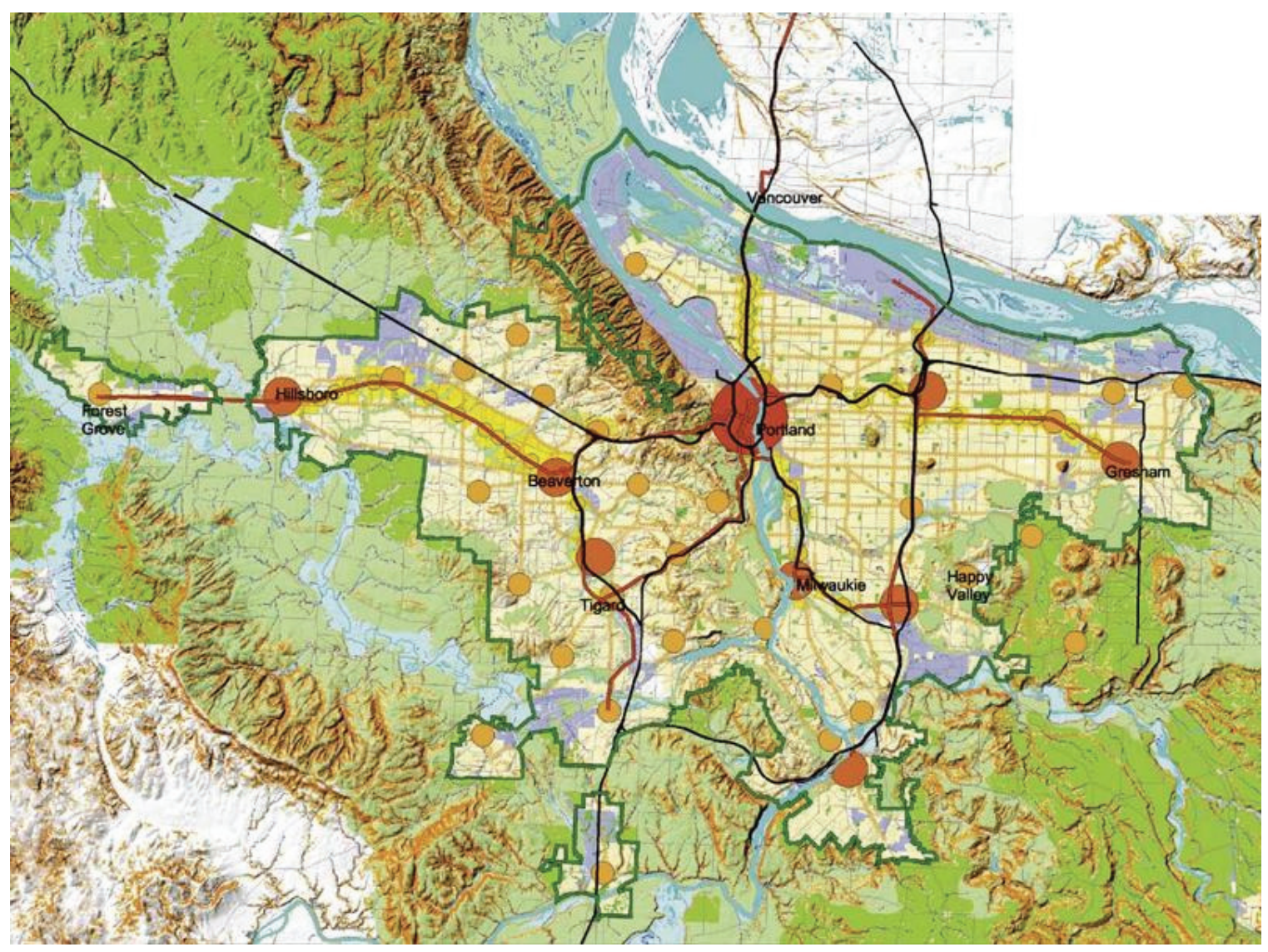

Figure 33

This is an undated, early version of the Region 2040 concept map (Calthorpe, Date Unknown). This map was developed by Calthorpe Associates prior to the inclusion of Damascus in the UGB. Milwaukie was designated a regional center in this map, though it loses this designation in later versions. Clark County is shown for reference purposes but not in the context of the Region 2040 plan. 


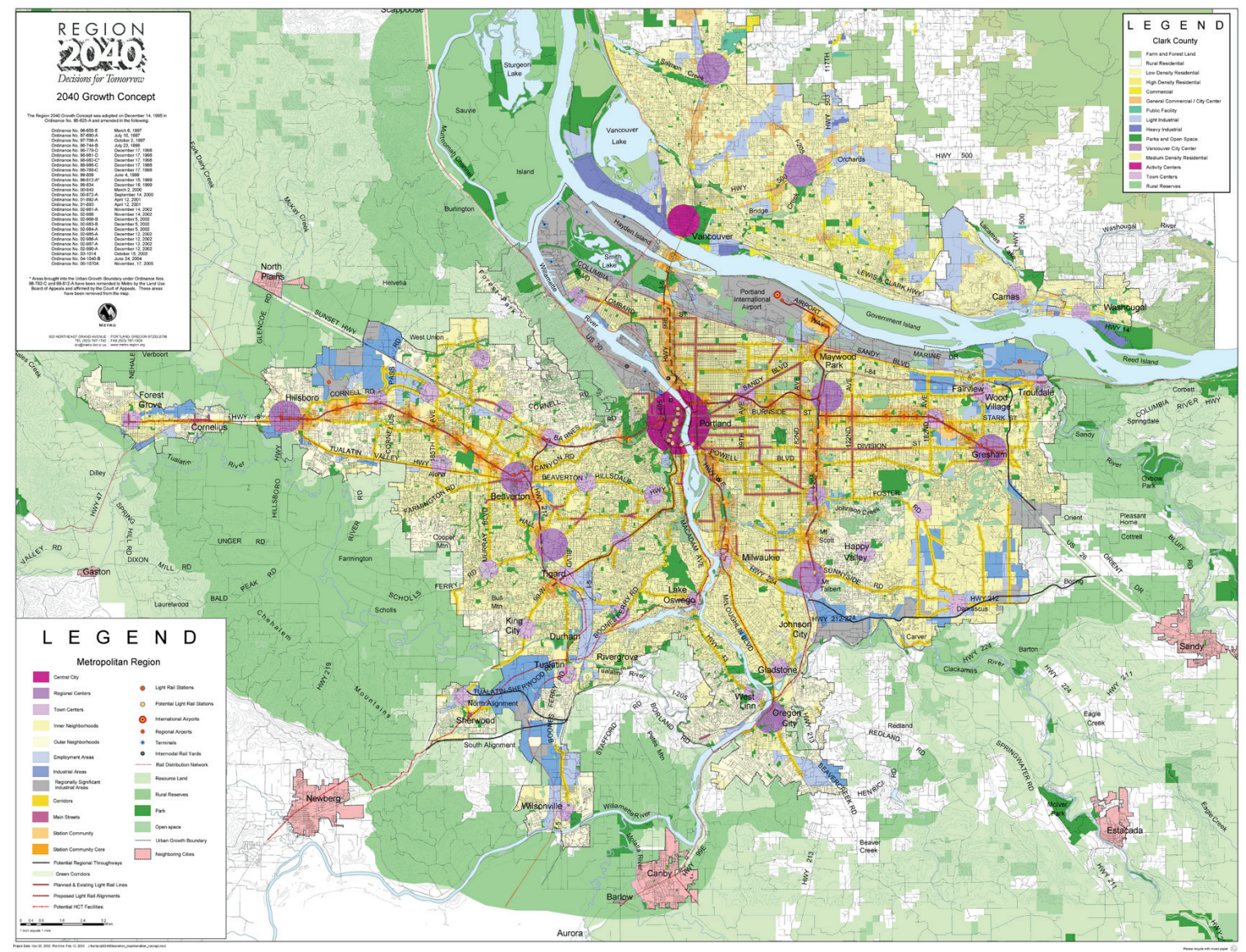

Figure 34

This intermediate map, a 2005 update of the Februrary 2003 edition, exhibits some notable differences from the earlier version (Metro 2005). The southern portion of Clark County now appears in the context of the growth concept, complete with town and regional centers, as well as downtown Vancouver being marked as an activity center. Milwaukie, instead of being a regional center as it was previously designated, is now downgraded to town center status. Cities outside of Metro's jurisdiction, such as Canby and Newberg, are now included in the map to generate a clearer picture of the entire region. Potential future regional transporatation routes are shown, such as the one extending from Clackamas east past Damascus. 


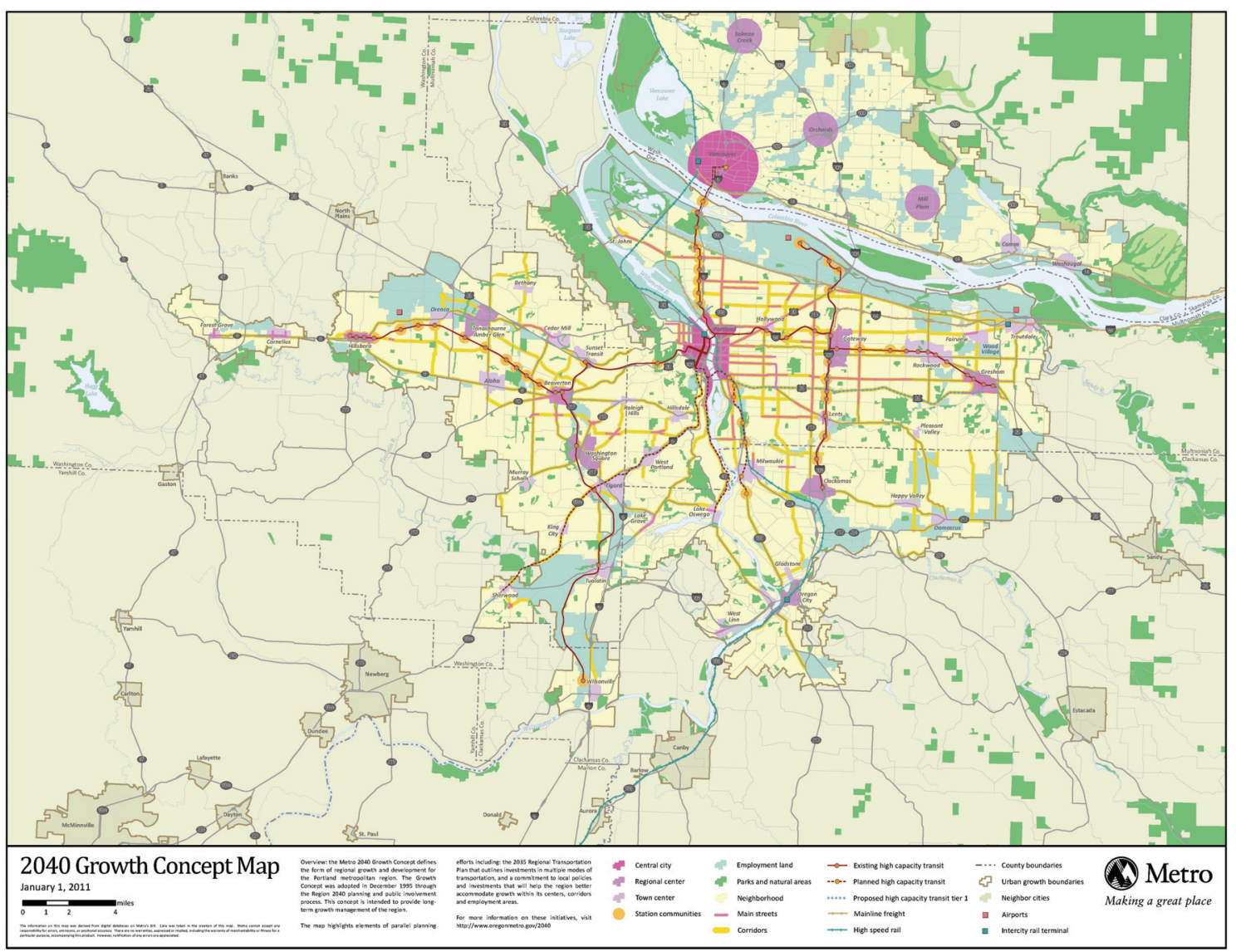

Figure 35

Region 2040 map as of January 1, 2011 (Metro 2011b). By this time Tanasbourne (Oregon) and Mill Pain (Washington) have been added as regional centers. Both town and regional centers within Metro's jurisdiction (Oregon side of the Columbia River only) have defined boundaries; they are no longer marked on the map using circles. Each center, including those in Clark County, Washington is named. Happy Valley, a town center in Clackamas, is now almost adjacent to the Damascus town center. Earlier versions of the concept placed it to the northwest, much closer to the Clackamas regional center. The size of downtown Vancouver's circle has grown tremendously and visually detracts from downtown Portland. Future transportation routes are limited to public transportation; the potential road routes displayed in Figure 34 have been removed. 


\section{Appendix B: Complete ArcGIS Analysis Model}

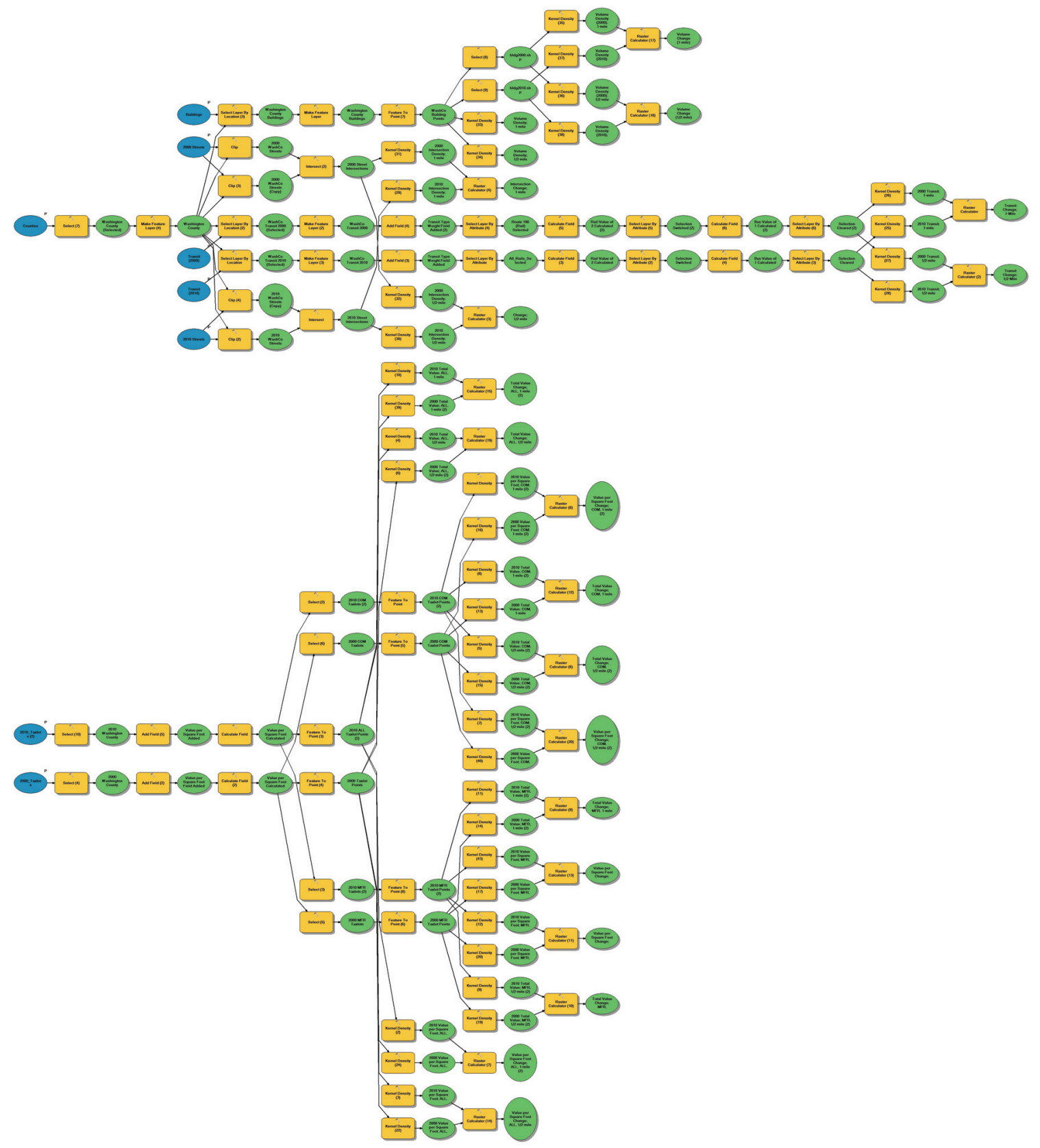




\section{Appendix C: Appearance Scores}

The tables included in this appendix show the results of the initial GIS analysis. Beaverton and Hillsboro are the only locations to appear in more than one map for the year 2000. Murrayhill, Orenco, and Washington Square joined them in the year 2010. The first numerical column sums the appearance results for intersection density, public transportation, building volume, and value per square foot of multi-family residential and commercial taxlots. The second column sums the same results but uses the total value of the multi-family residential taxlots instead of their values per square foot. The two methods yield slightly different results; Hillsboro only appears in multiple maps for the year 2000 using the value per square foot metric. 


\begin{tabular}{|c|c|c|c|c|c|c|c|c|c|c|}
\hline & $\begin{array}{c}\text { Appearance Scores, Year } \\
2000\end{array}$ & 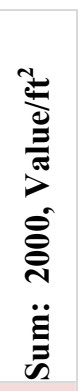 & 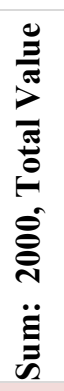 & 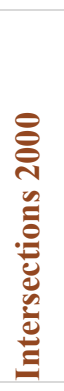 & 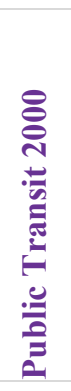 & 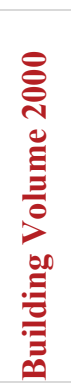 & 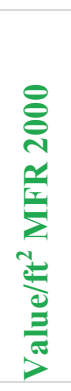 & 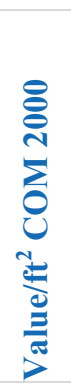 & 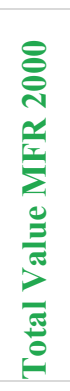 & 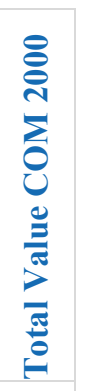 \\
\hline \multirow{4}{*}{$\begin{array}{c}\text { Metro- } \\
\text { Designated }\end{array}$} & Beaverton* & $\underline{6}$ & $\underline{6}$ & 2 & 2 & & & 2 & & \\
\hline & Hillsboro & $\underline{4}$ & 2 & 2 & & & & 2 & & \\
\hline & Tanasbourne* & 0 & 2 & & & & & & 2 & \\
\hline & Washington Square & 2 & 2 & & & & & 2 & & 2 \\
\hline \multirow{15}{*}{ GIS-Identified } & Bethany & 2 & 2 & & & 2 & & & & \\
\hline & Cedar Mill & 0 & 0 & & & & & & & \\
\hline & Cornelius & 2 & 2 & 2 & & & & & & \\
\hline & King City & 2 & 0 & & & & 2 & & & \\
\hline & Murrayhill* & 2 & 2 & & & & & & & \\
\hline & Orenco* & 0 & 0 & & & & & & & \\
\hline & Tualatin & 0 & 0 & & & & & & & \\
\hline & 185th/Baseline & 0 & 0 & & & & & & & \\
\hline & Jackson School Rd. & 2 & 2 & & & 2 & & & & \\
\hline & S. Cornelius Pass & 2 & 2 & & & 2 & & & & \\
\hline & SR8/SR10/Murray ${ }^{1}$ & 0 & 2 & & & & & & 2 & \\
\hline & SE of DT Beaverton ${ }^{1}$ & 0 & 0 & & & & & & & \\
\hline & Quatama $^{2}$ & 0 & 0 & & & & & & & \\
\hline & S. Murray Corridor ${ }^{3}$ & 2 & 2 & & & 2 & & & & \\
\hline & Intel at Corn. Pass ${ }^{4}$ & 0 & 0 & & & & & & & \\
\hline \multirow{2}{*}{$\begin{array}{l}\text { Other Places of } \\
\text { Interest }\end{array}$} & Bridgeport & 0 & 0 & & & & & & & \\
\hline & Nike Headquarters & 0 & 0 & & & & & & & \\
\hline & & \multicolumn{9}{|c|}{$\begin{array}{l}{ }^{1} \text { Added to Beaverton's score due to adjacency and/or } \\
\text { proximity } \\
{ }^{2} \text { Added to Tanasbourne's score; Metro includes } \\
\text { Quatama in the Tanasbourne center } \\
{ }_{3}^{3} \text { Added to Murrayhill's score due to the corridor's } \\
\text { location extending both north and south from } \\
\text { Murrayhill } \\
{ }^{4} \text { Added to Orenco's score due its location across the } \\
\text { street from Orenco Station }\end{array}$} \\
\hline
\end{tabular}

Table 6

Appearance Scores, Year 2000 


\begin{tabular}{|c|c|c|c|c|c|c|c|c|c|c|}
\hline & $\begin{array}{c}\text { Appearance Scores, Year } \\
2010\end{array}$ & 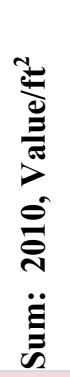 & 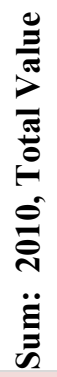 & 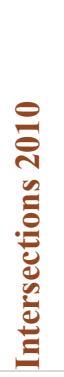 & 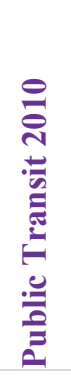 & 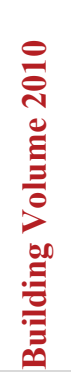 & 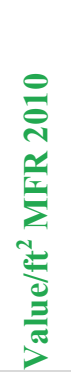 & 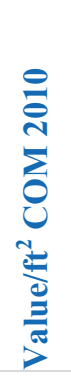 & 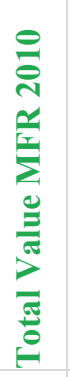 & 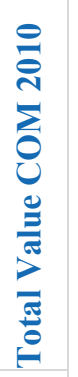 \\
\hline \multirow{4}{*}{$\begin{array}{c}\text { Metro- } \\
\text { Designated }\end{array}$} & Beaverton* & $\underline{8}$ & $\underline{6}$ & 2 & 2 & & & 2 & & \\
\hline & Hillsboro & $\underline{4}$ & 2 & 2 & & & & 2 & & \\
\hline & Tanasbourne* & 2 & 2 & & & & & & 2 & \\
\hline & Washington Square & 2 & $\underline{4}$ & & & 2 & & & & 2 \\
\hline \multirow{15}{*}{ GIS-Identified } & Bethany & 2 & 2 & 2 & & & & & & \\
\hline & Cedar Mill & 2 & 0 & & & & 2 & & & \\
\hline & Cornelius & 2 & 2 & 2 & & & & & & \\
\hline & King City & 2 & 2 & 2 & & & & & & \\
\hline & Murrayhill* & 2 & $\underline{4}$ & & & & & & 2 & \\
\hline & Orenco* & $\underline{6}$ & $\underline{4}$ & 2 & & & 2 & & & \\
\hline & Tualatin & 2 & 2 & & & 2 & & & & \\
\hline & 185th/Baseline & 2 & 2 & 2 & & & & & & \\
\hline & Jackson School Rd. & 0 & 0 & & & & & & & \\
\hline & S. Cornelius Pass & 0 & 0 & & & & & & & \\
\hline & SR8/SR10/Murray ${ }^{1}$ & 0 & 0 & & & & & & & \\
\hline & SE of DT Beaverton ${ }^{1}$ & 2 & 2 & & & 2 & & & & \\
\hline & Quatama $^{2}$ & 2 & 0 & & & & 2 & & & \\
\hline & S. Murray Corridor ${ }^{3}$ & 2 & 2 & 2 & & & & & & \\
\hline & Intel at Corn. Pass ${ }^{4}$ & 2 & 2 & & & 2 & & & & \\
\hline \multirow{2}{*}{$\begin{array}{l}\text { Other Places of } \\
\text { Interest }\end{array}$} & Bridgeport & 0 & 0 & & & & & & & \\
\hline & Nike Headquarters & 0 & 0 & & & & & & & \\
\hline & & \multicolumn{9}{|c|}{$\begin{array}{l}{ }^{1} \text { Added to Beaverton's score due to adjacency and/or } \\
\text { proximity } \\
{ }^{2} \text { Added to Tanasbourne's score; Metro includes } \\
\text { Quatama in the Tanasbourne center } \\
{ }^{3} \text { Added to Murrayhill's score due to the corridor's } \\
\text { location extending both north and south from } \\
\text { Murrayhill } \\
{ }^{4} \text { Added to Orenco's score due its location across the } \\
\text { street from Orenco Station }\end{array}$} \\
\hline
\end{tabular}

Table 7

Appearance Scores, Year 2010 
Appendix D: Selected Photographs

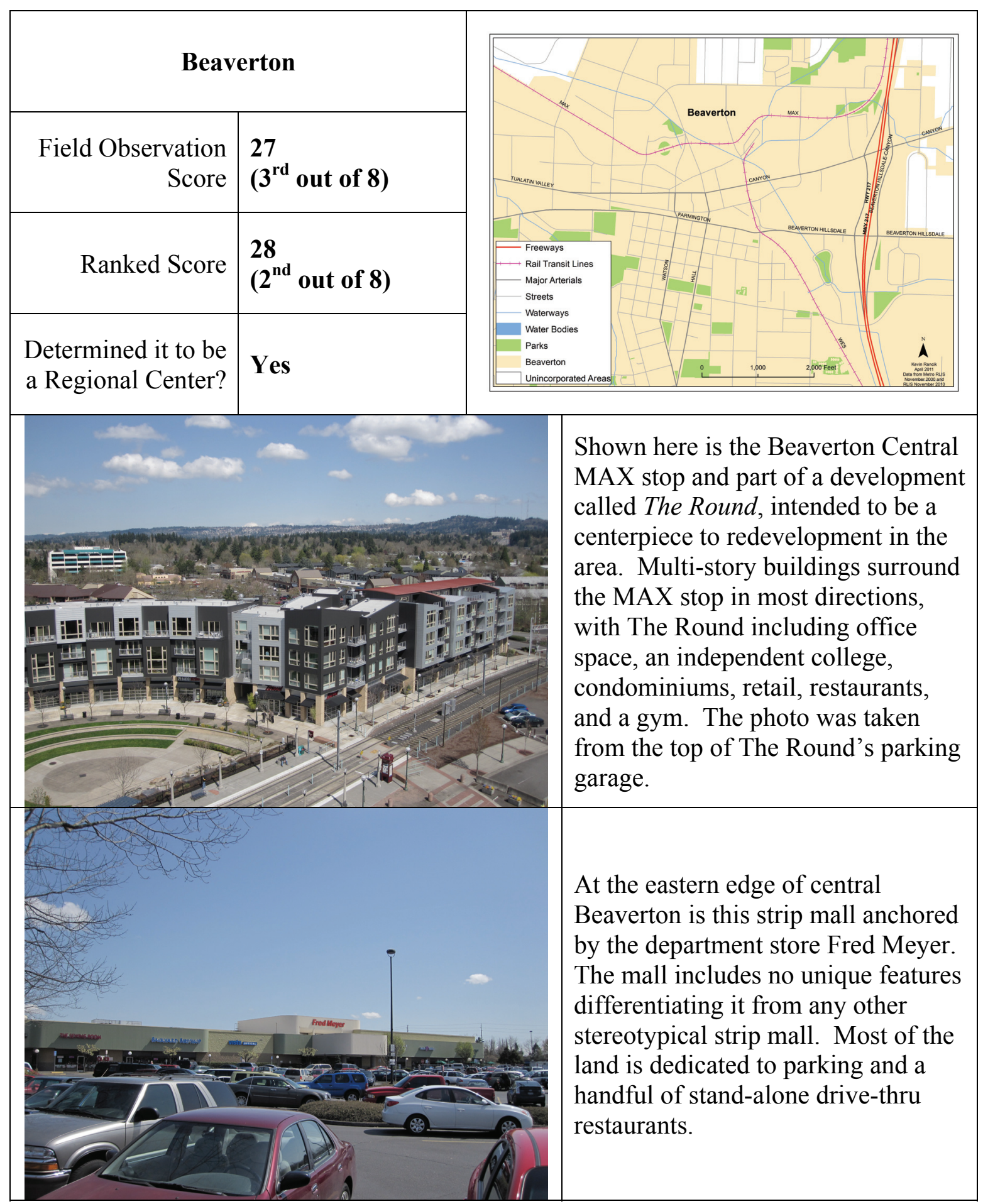




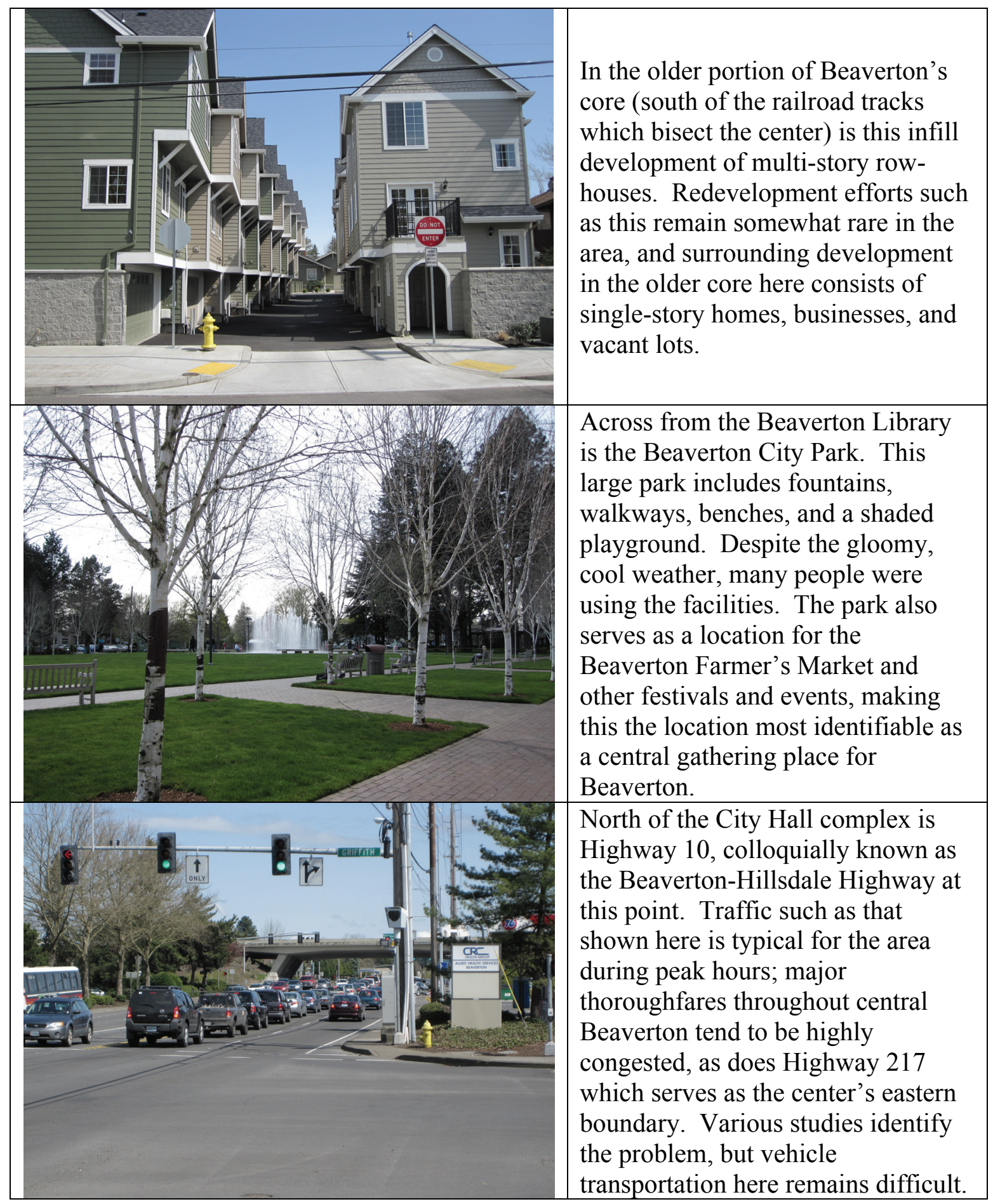




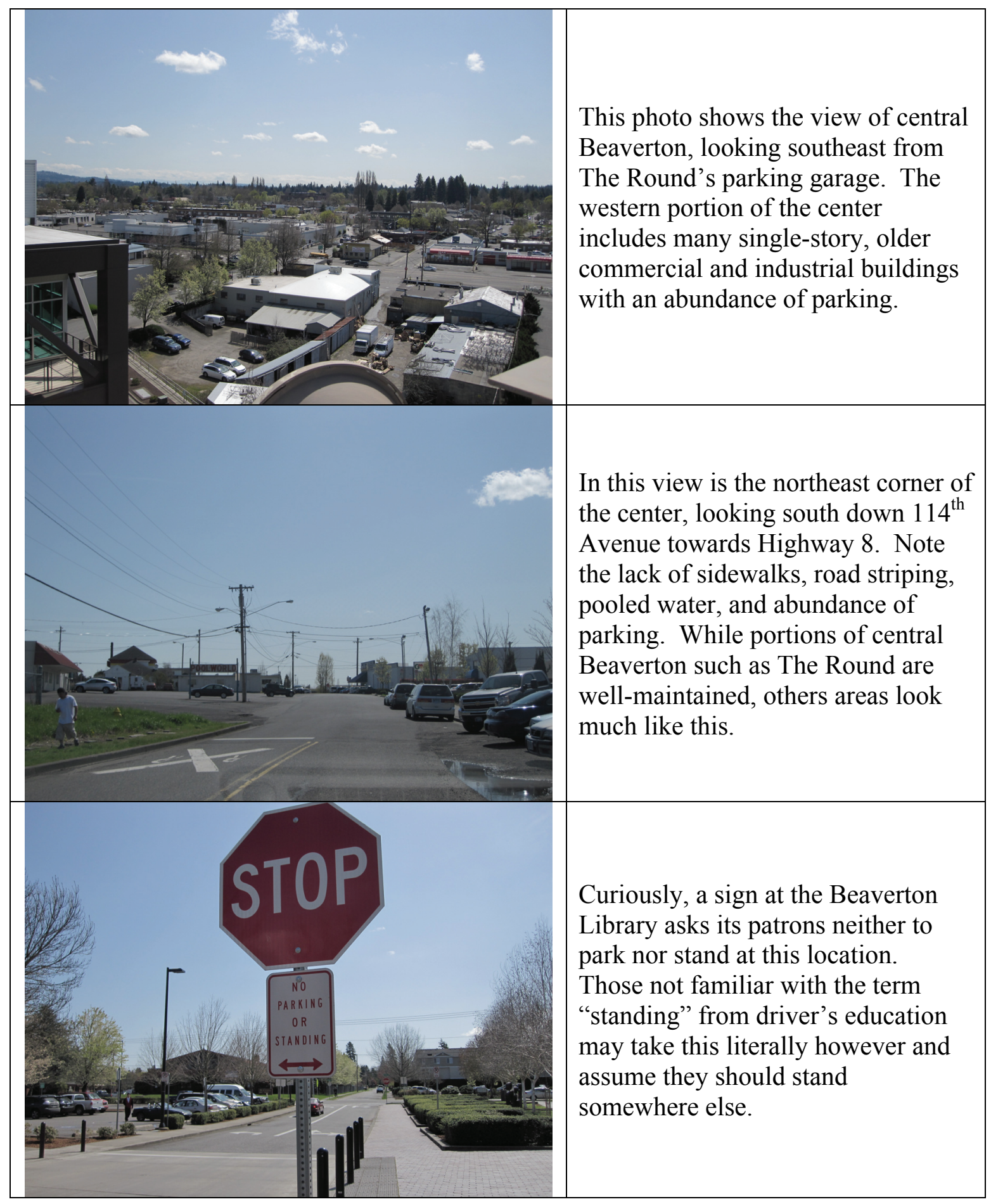




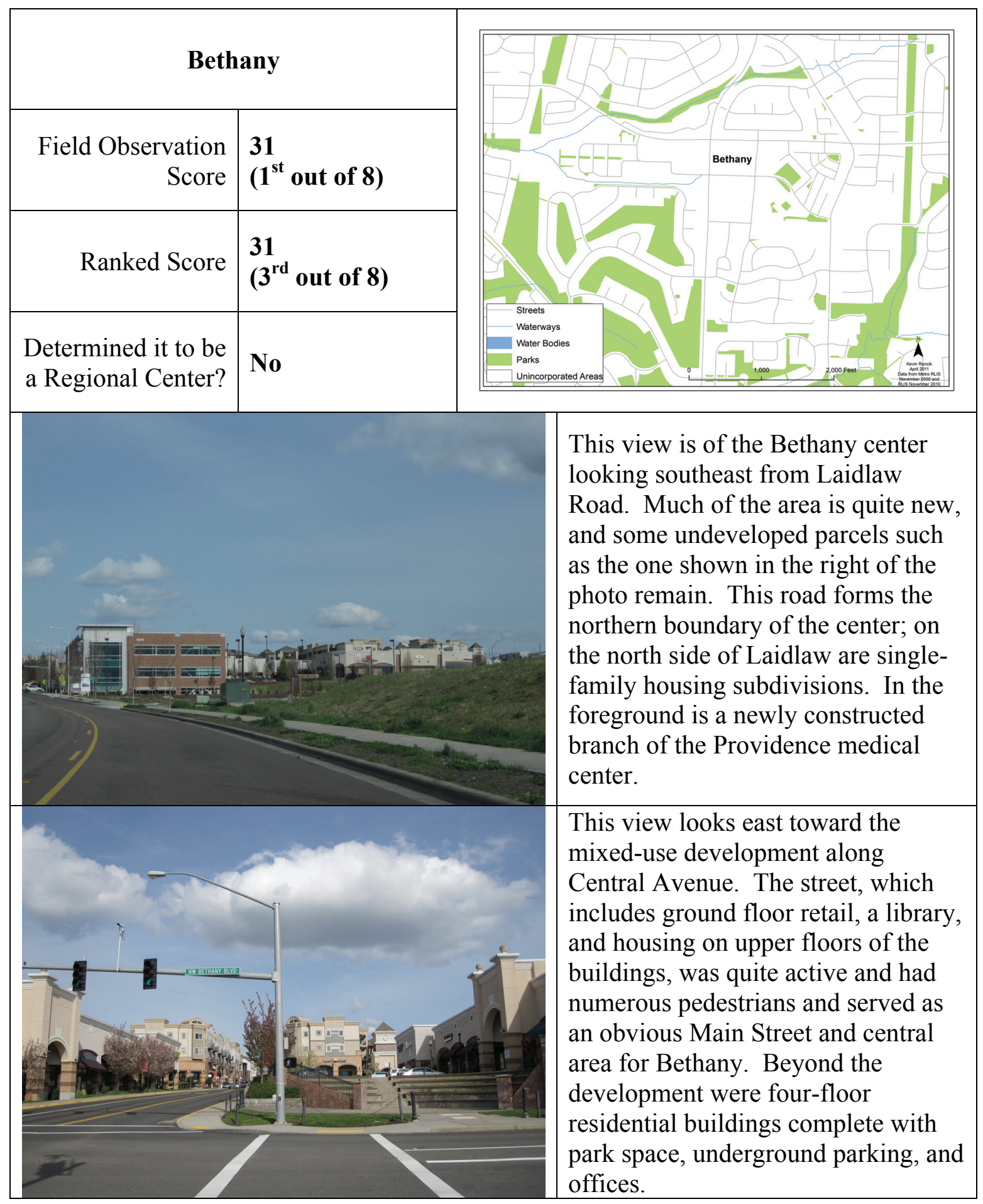




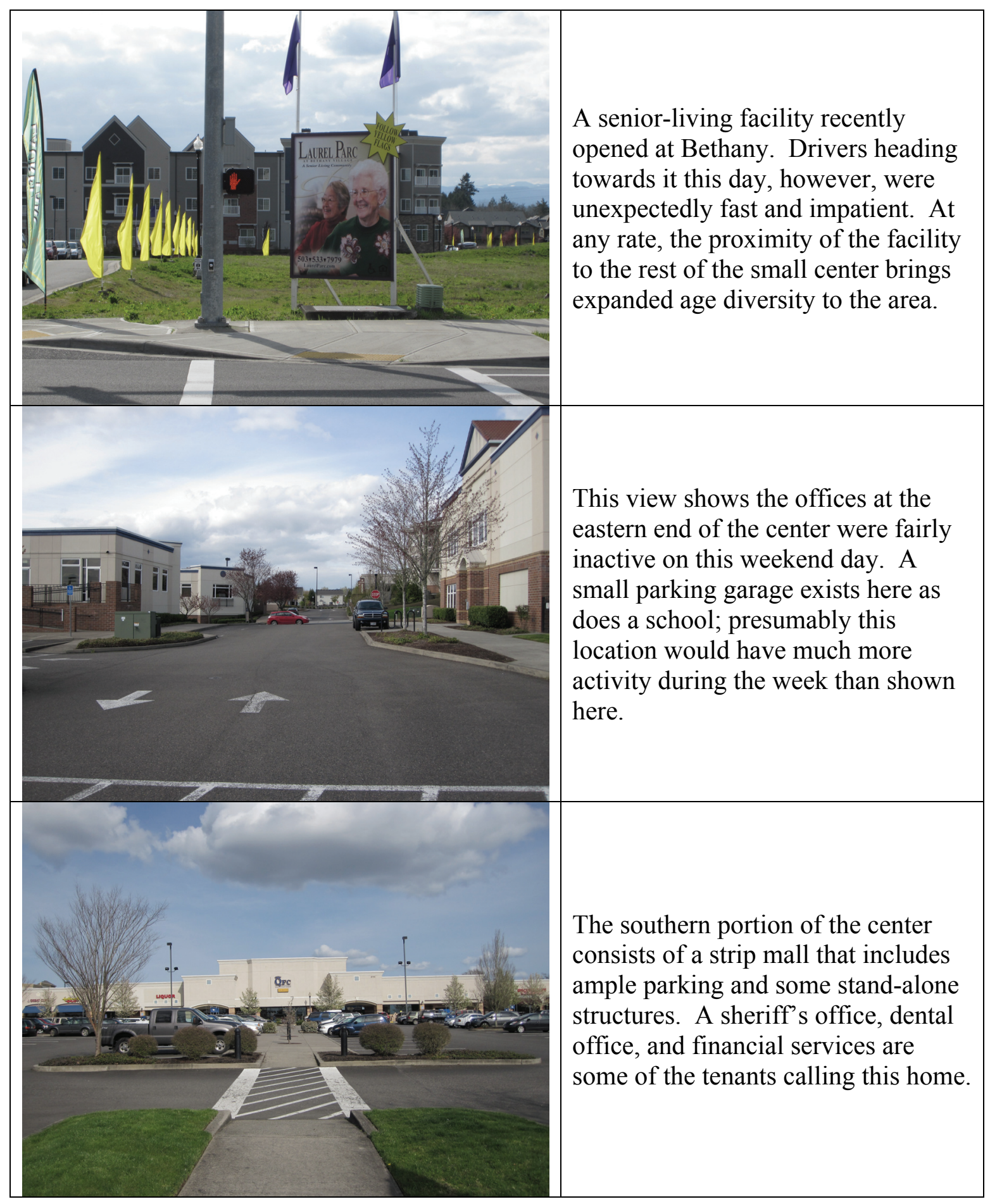




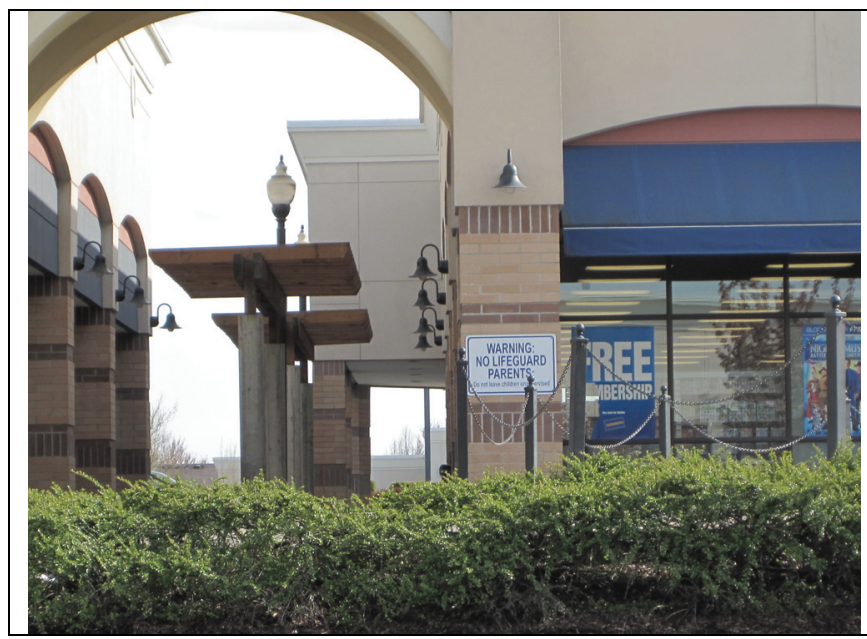

This unusual sign posted outside a Blockbuster Video warns parents there is no lifeguard in the area. This sign exists despite the lack of any water feature here. It is possible this sign is intentionally strange to draw attention to it and remind parents to watch their children. However, none of the children or other pedestrians in the area this day were anywhere near the sign.

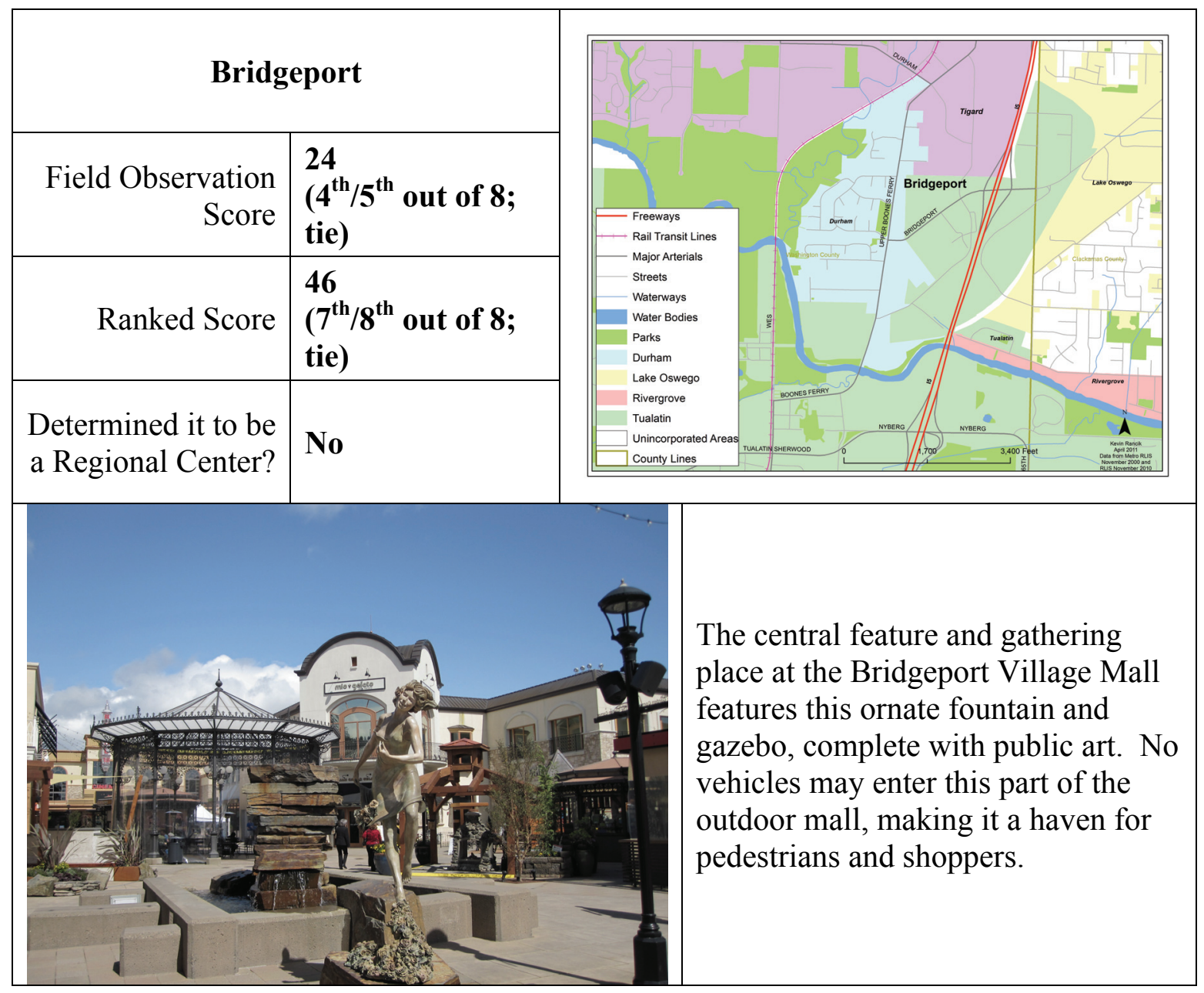




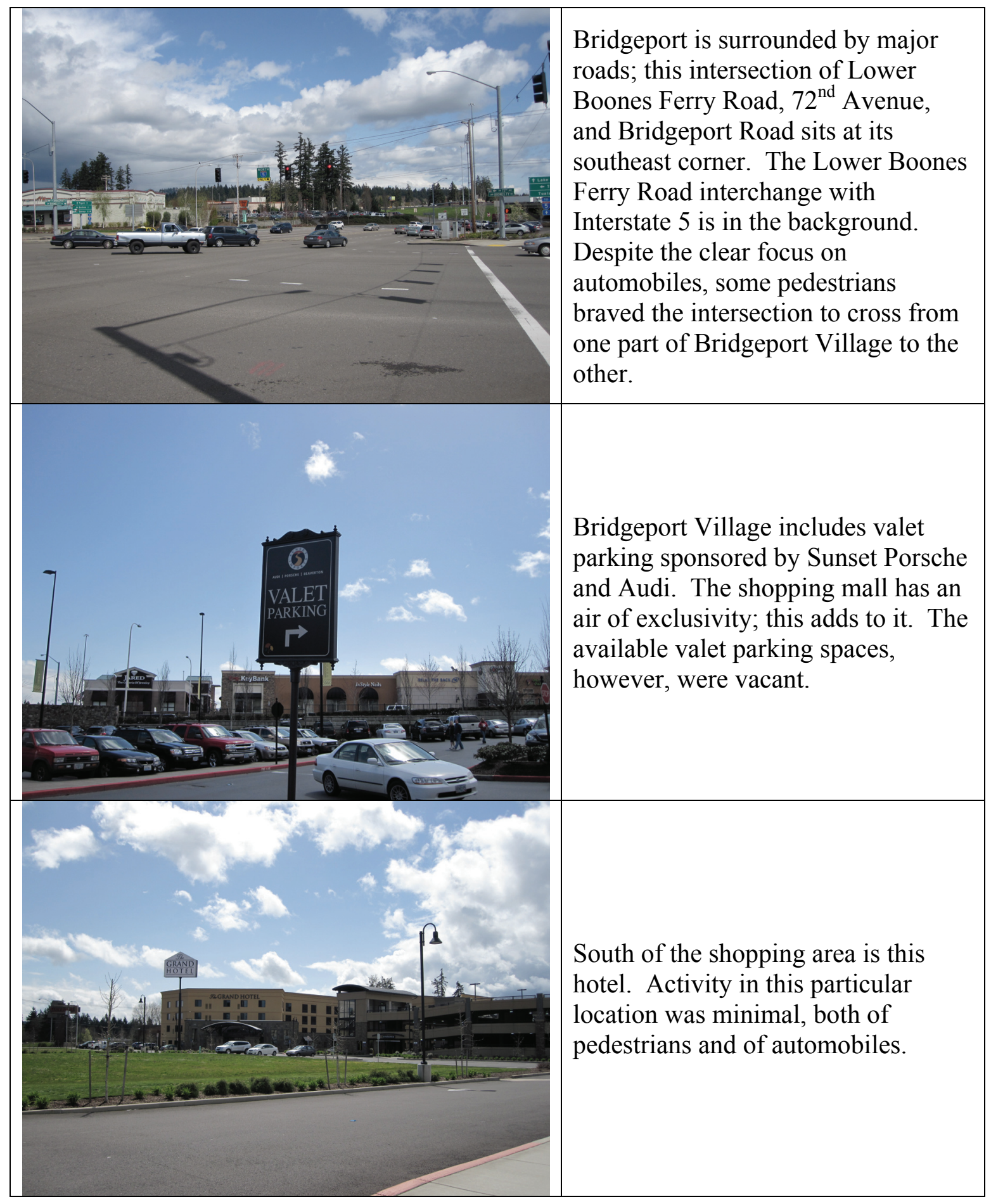




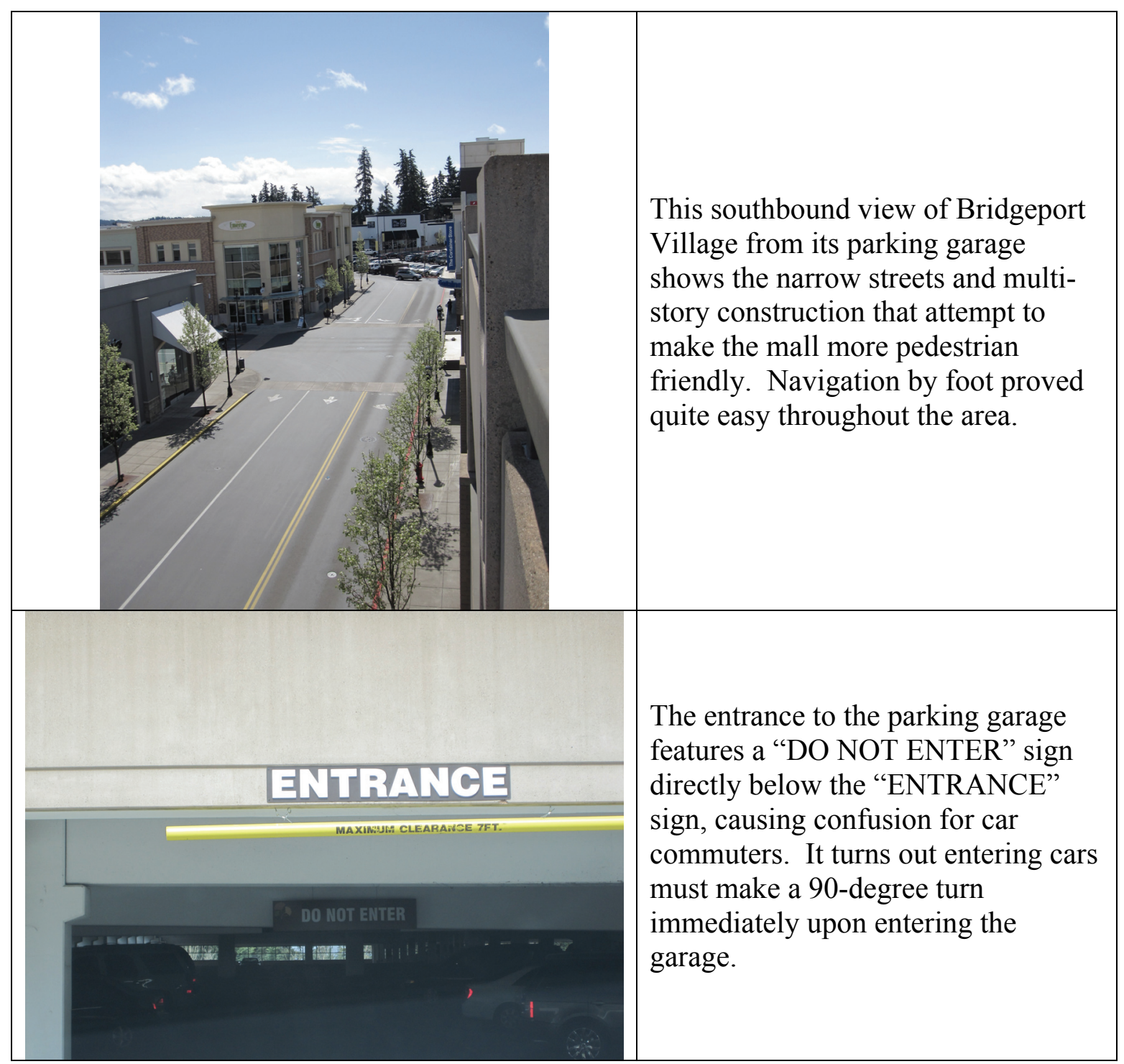




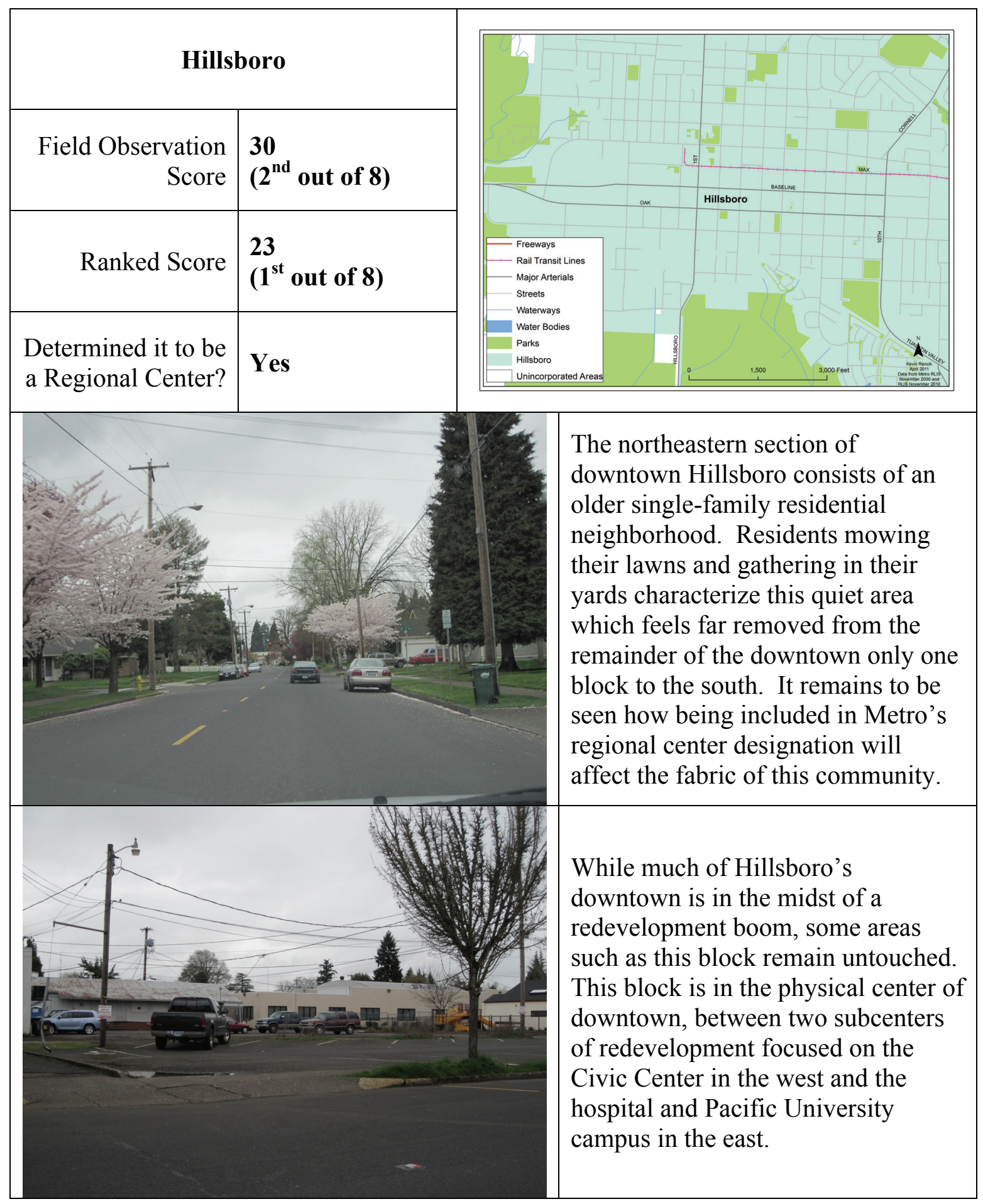




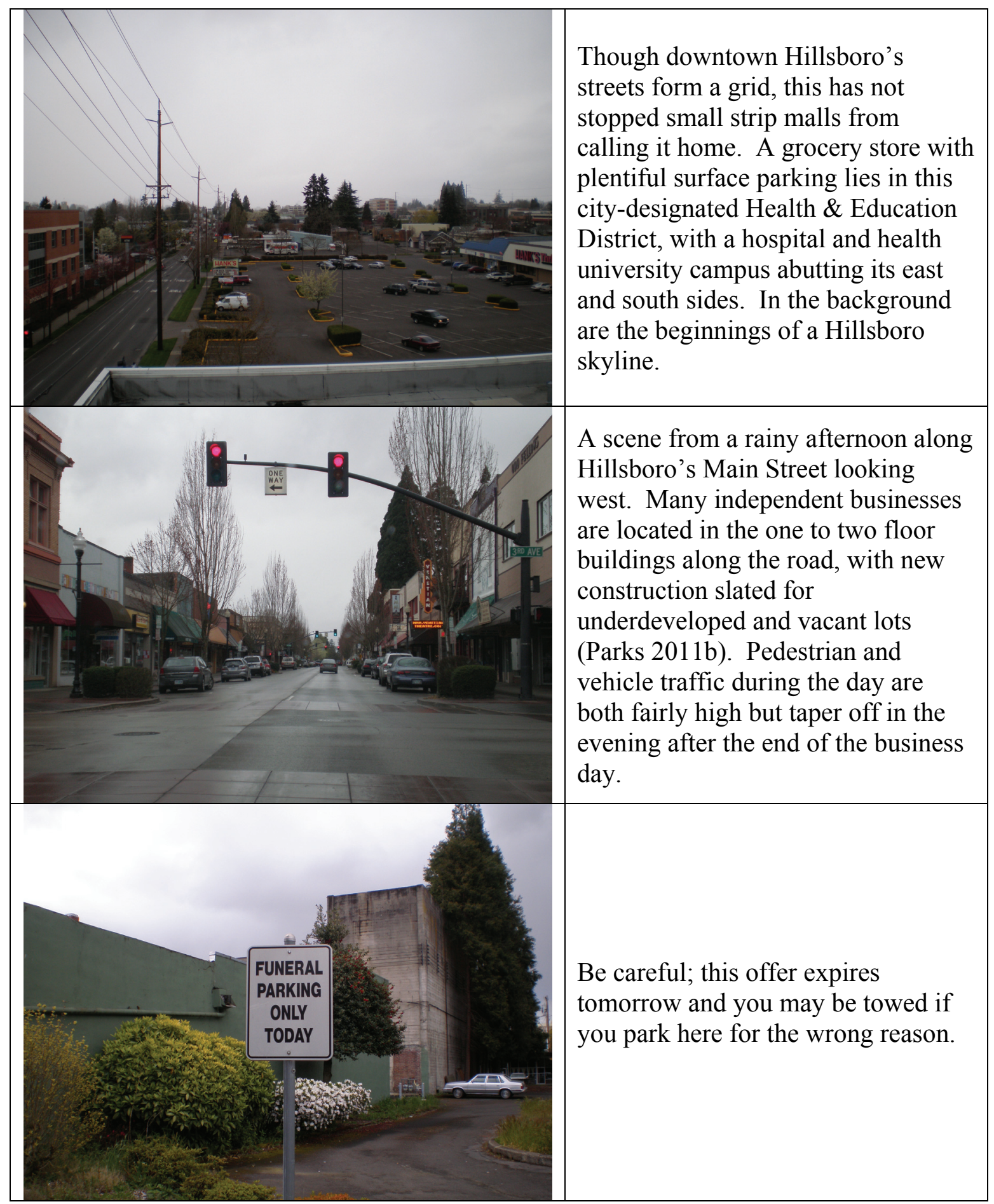




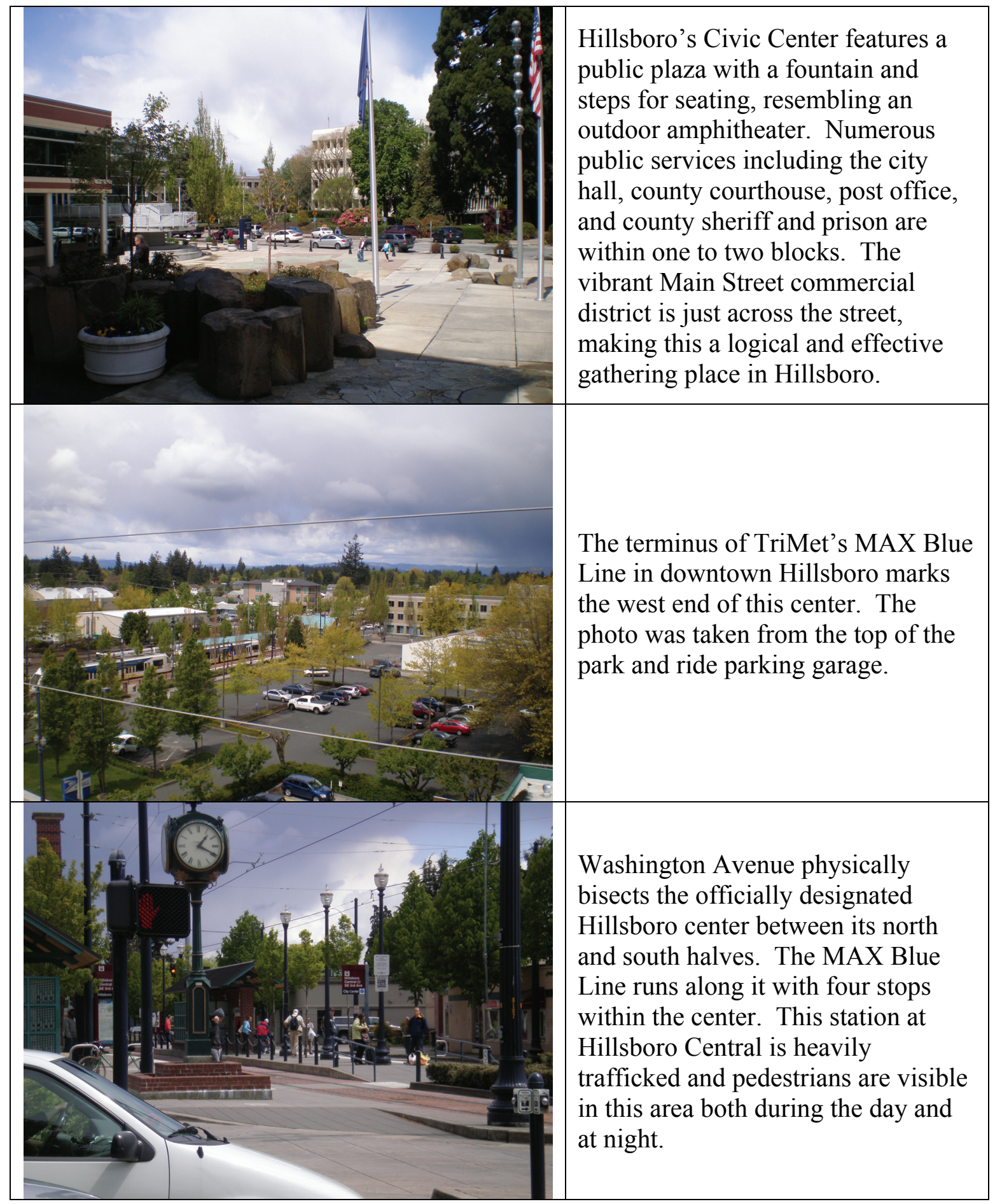




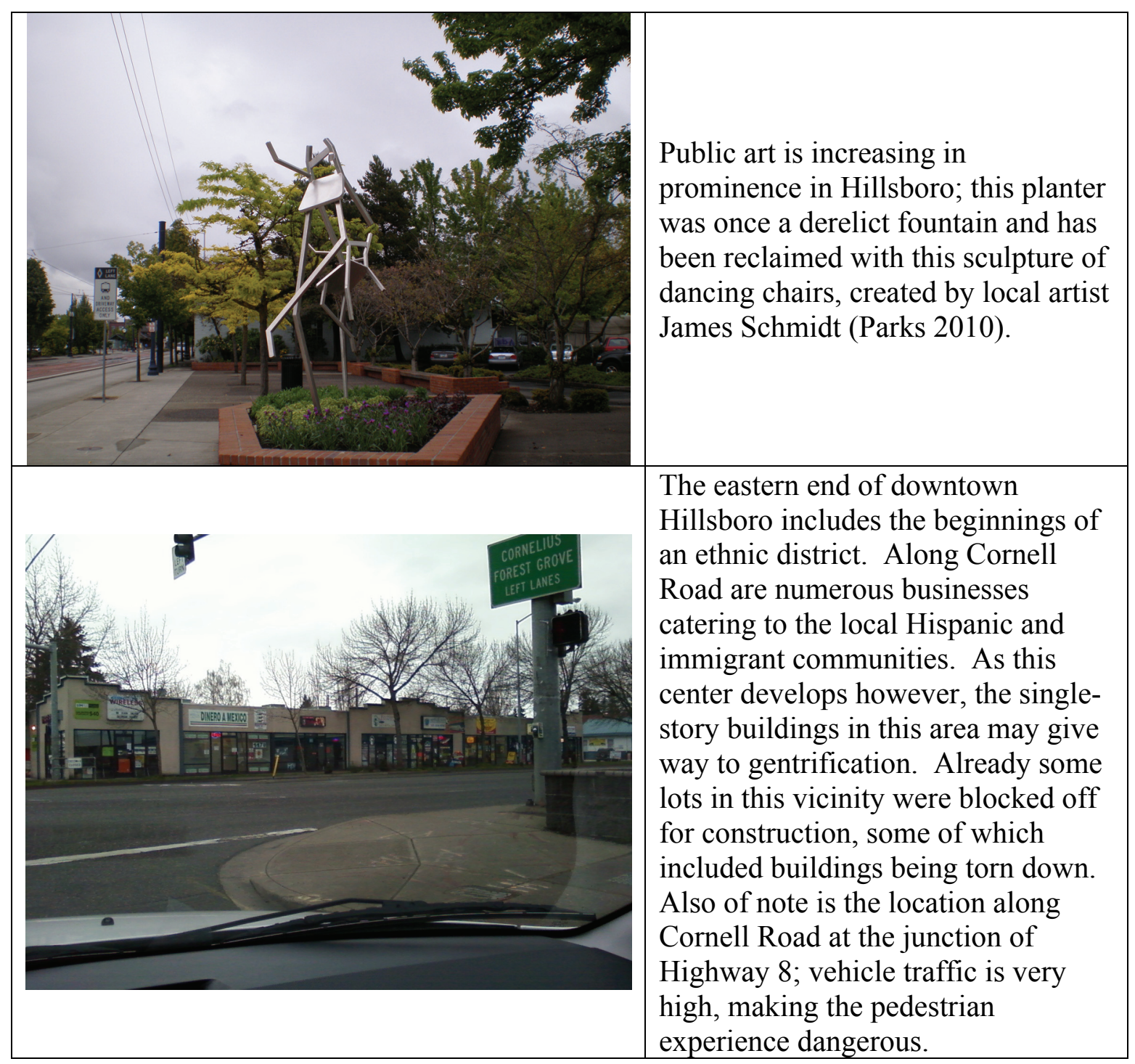




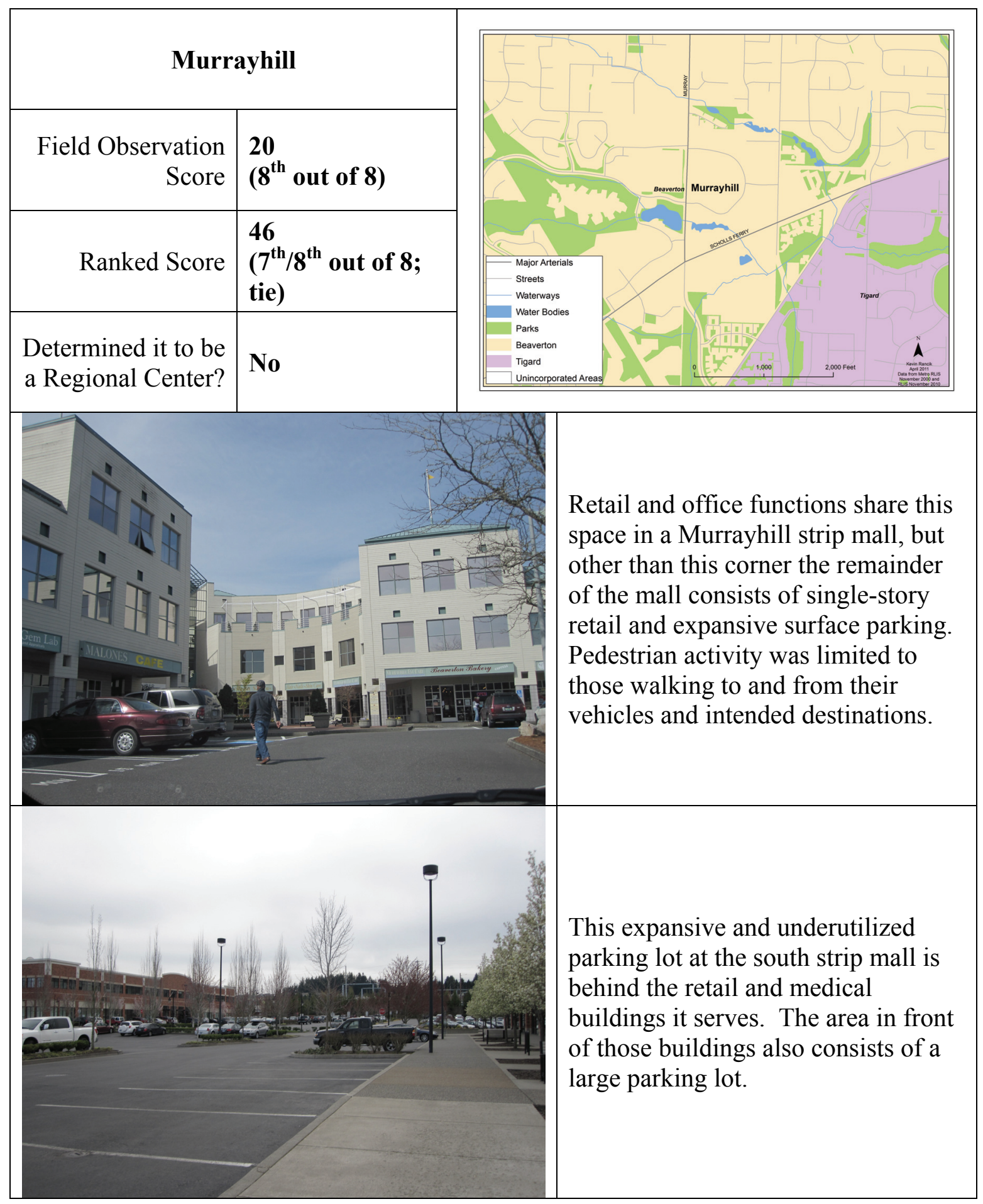




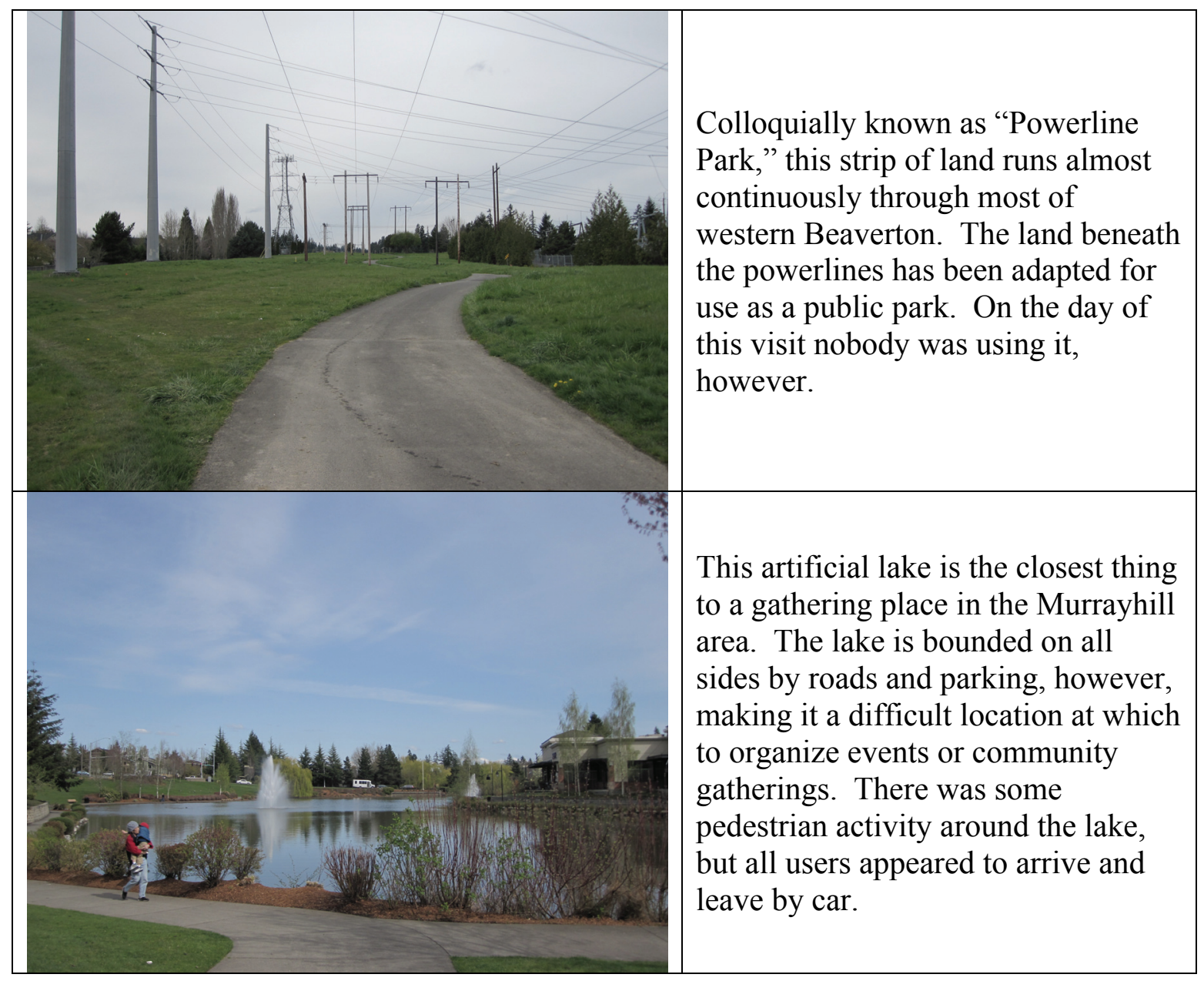




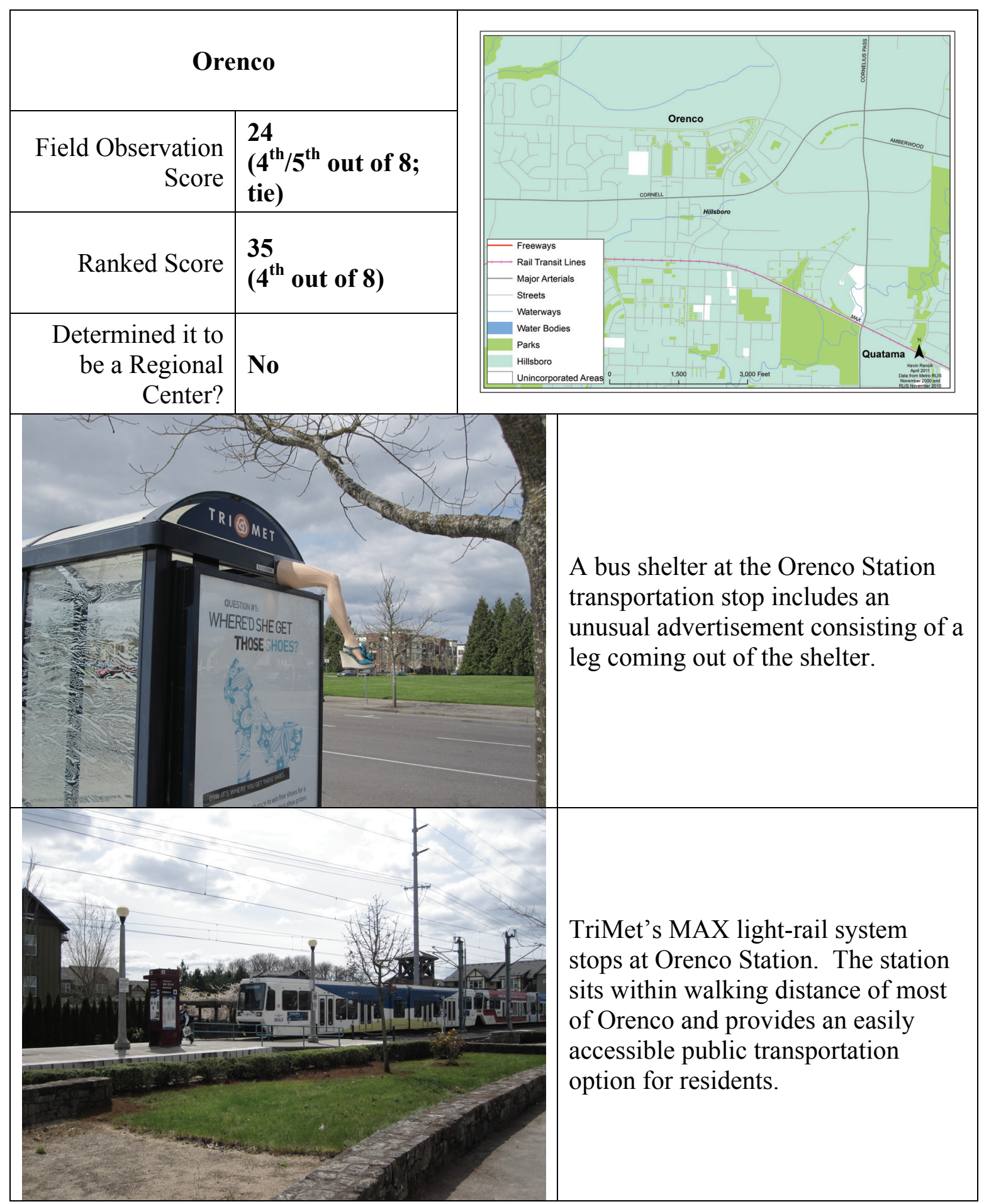




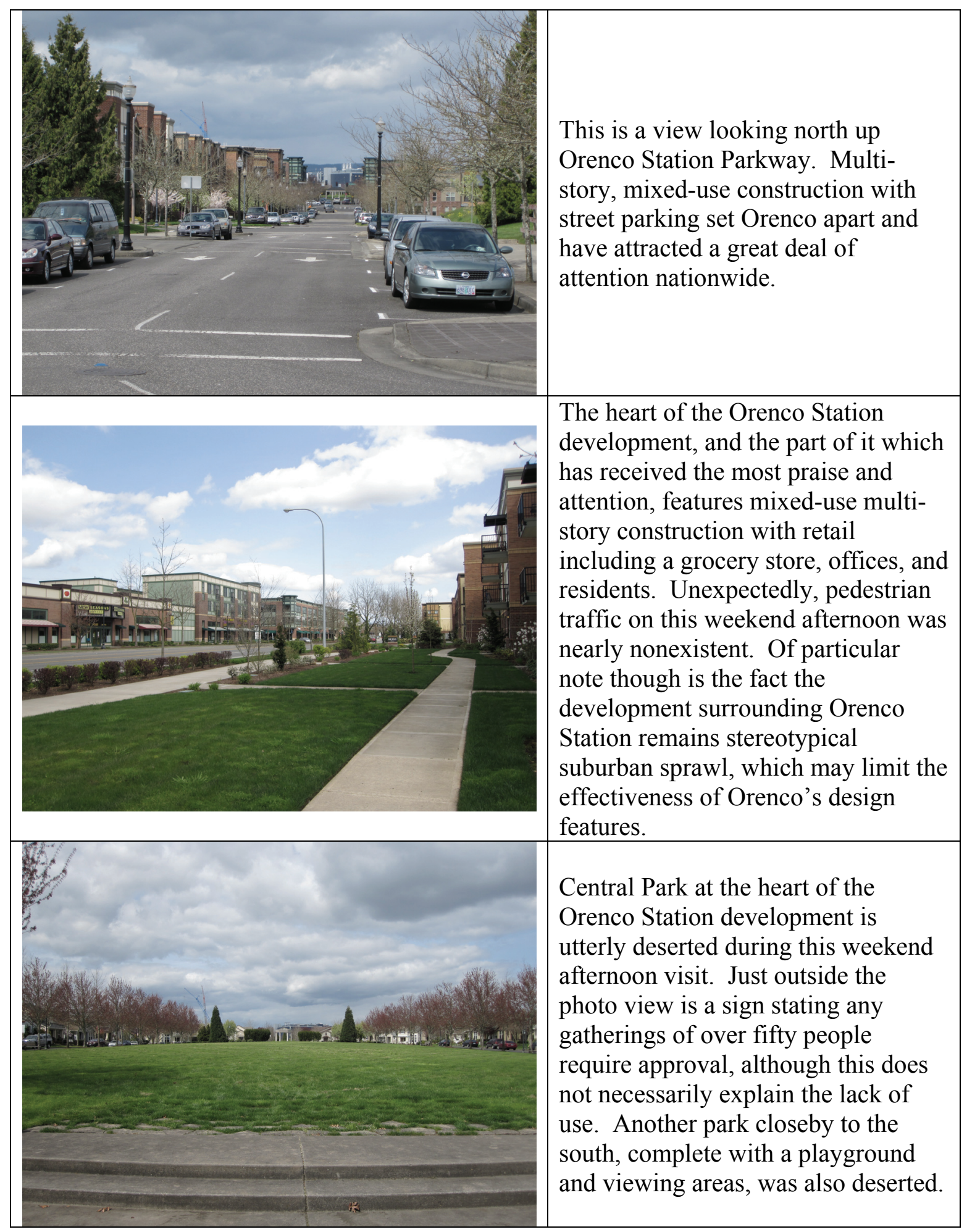




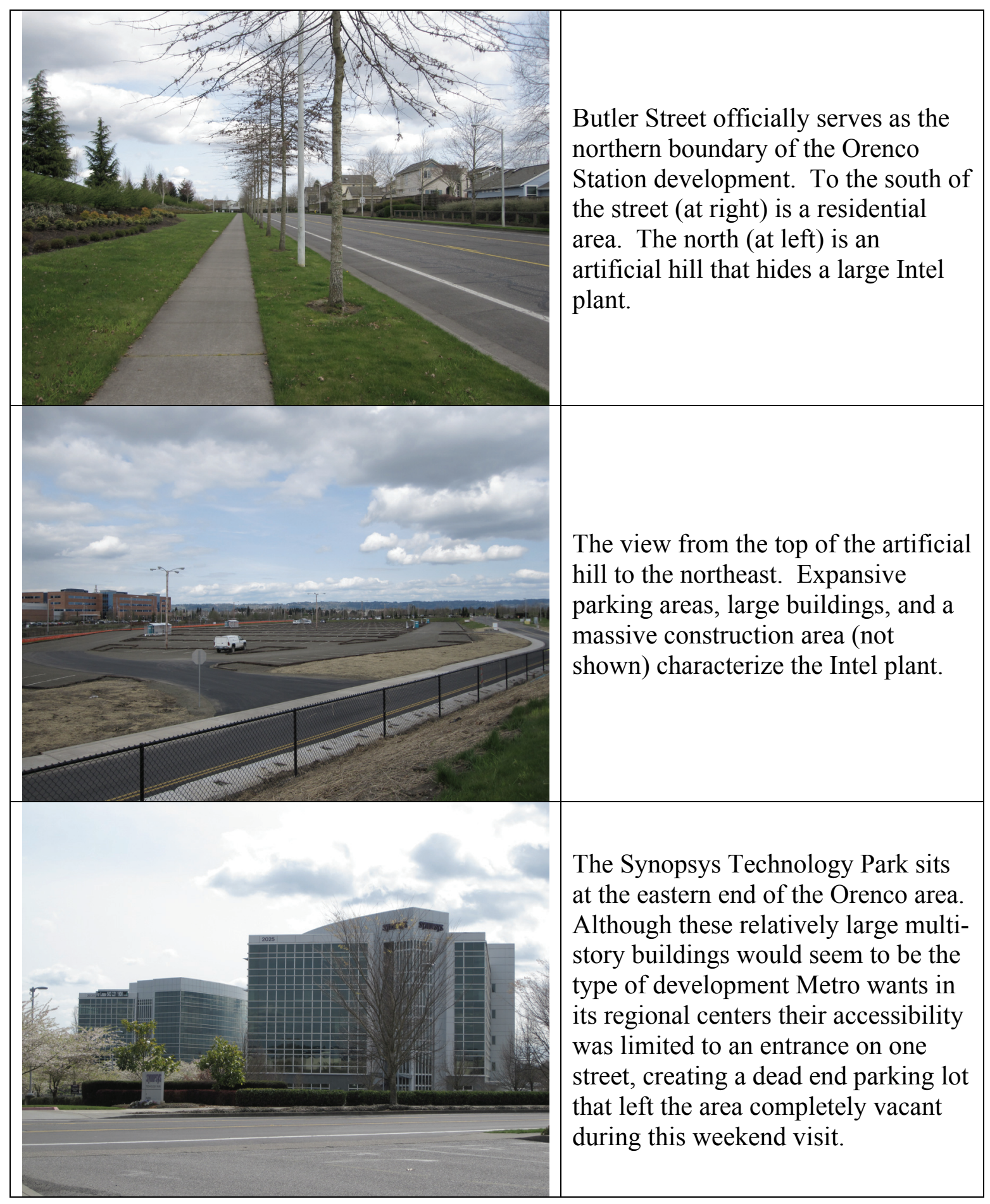




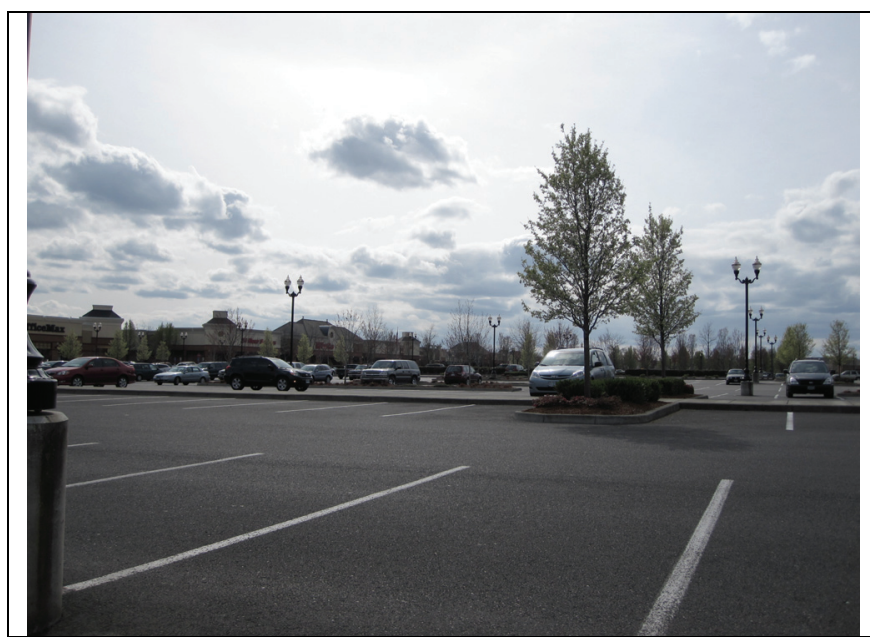

This strip mall sits just north of the Synopsys Technology Park at the intersection of Cornell and Cornelius Pass Roads, the two major thoroughfares through Orenco. This mall bears no resemblance to the New Urbanist style part of Orenco that has received so much attention and praise. Nevertheless, this strip mall featured the overwhelming majority of pedestrian and vehicle activity in Orenco.

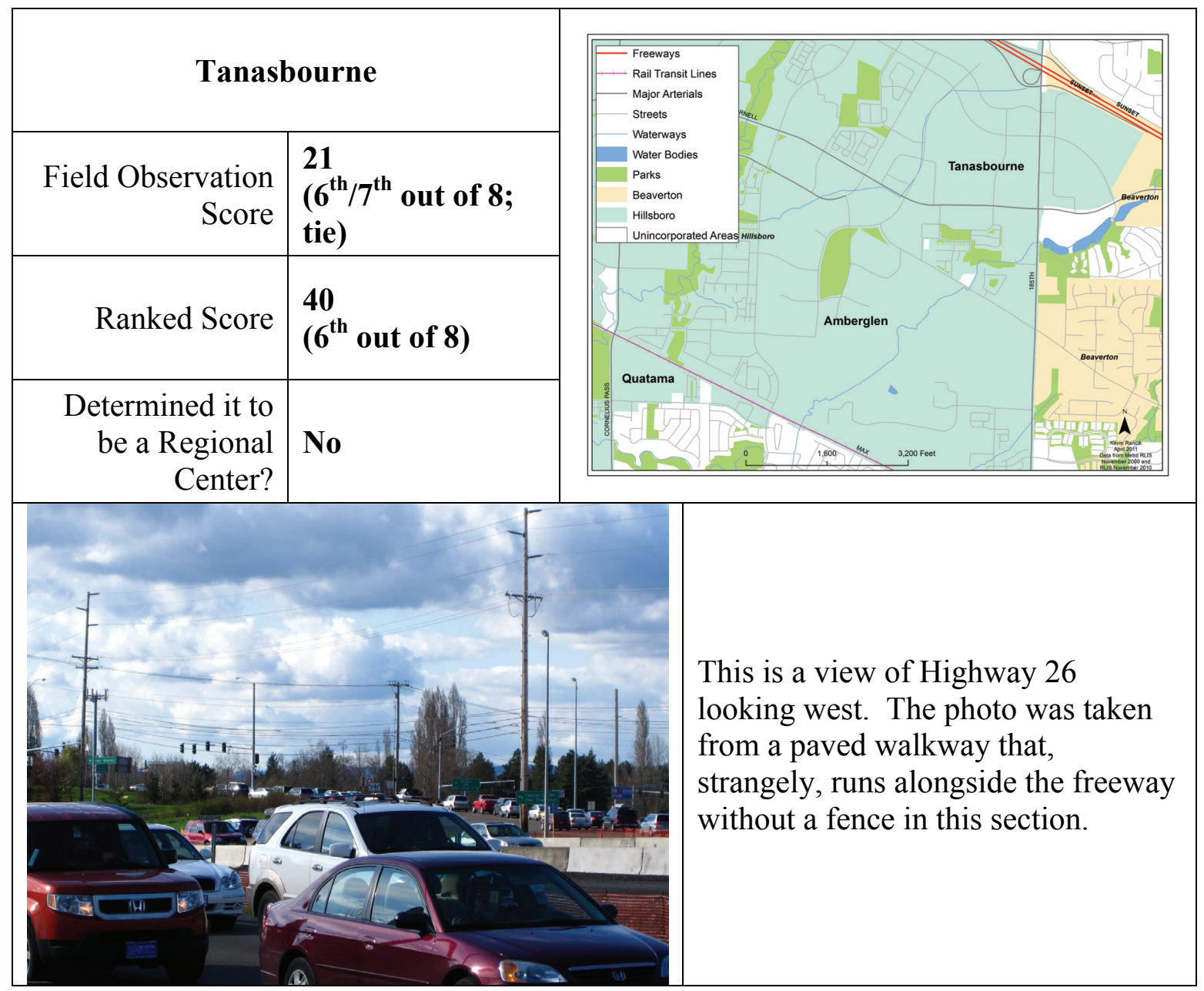




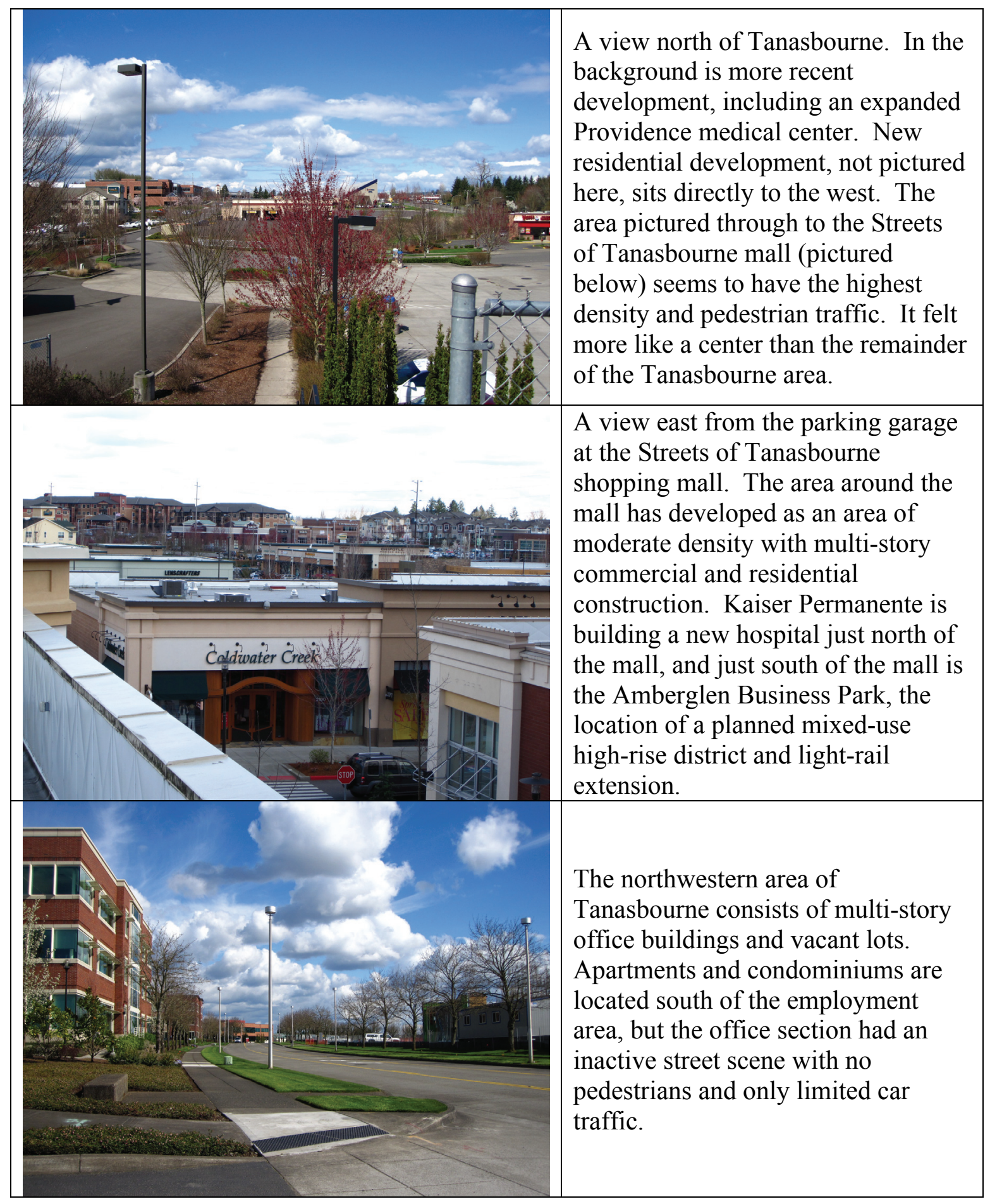




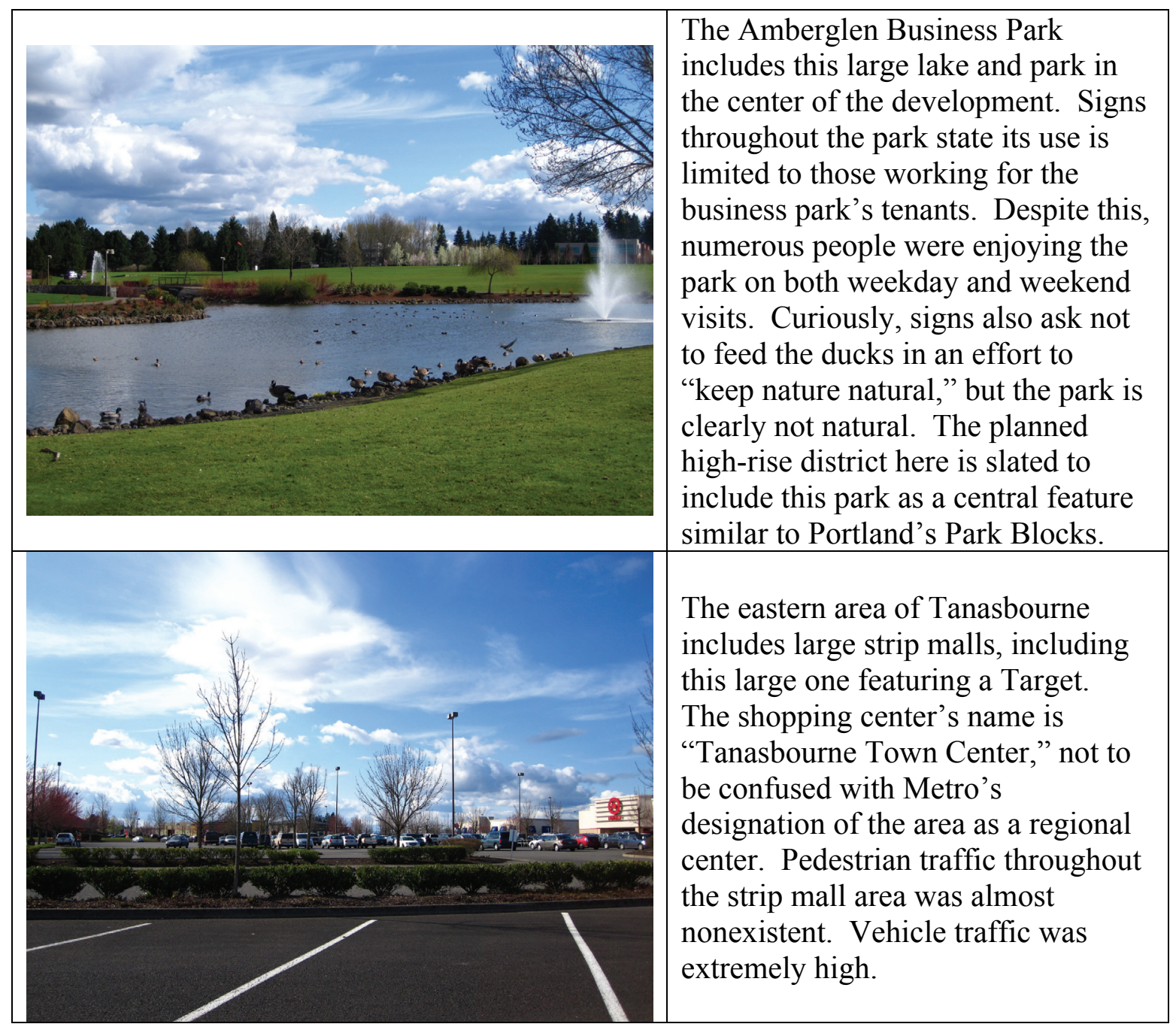




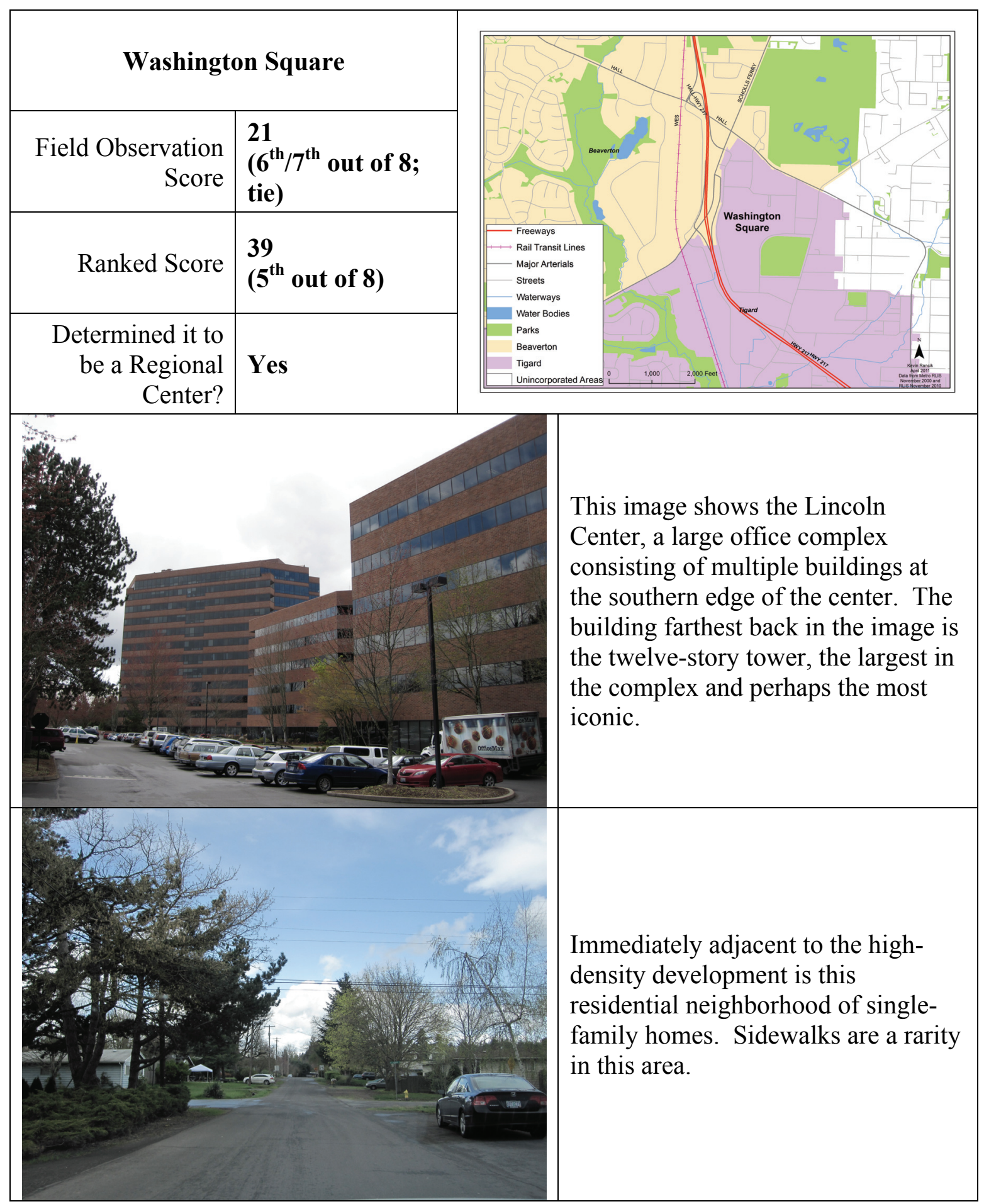




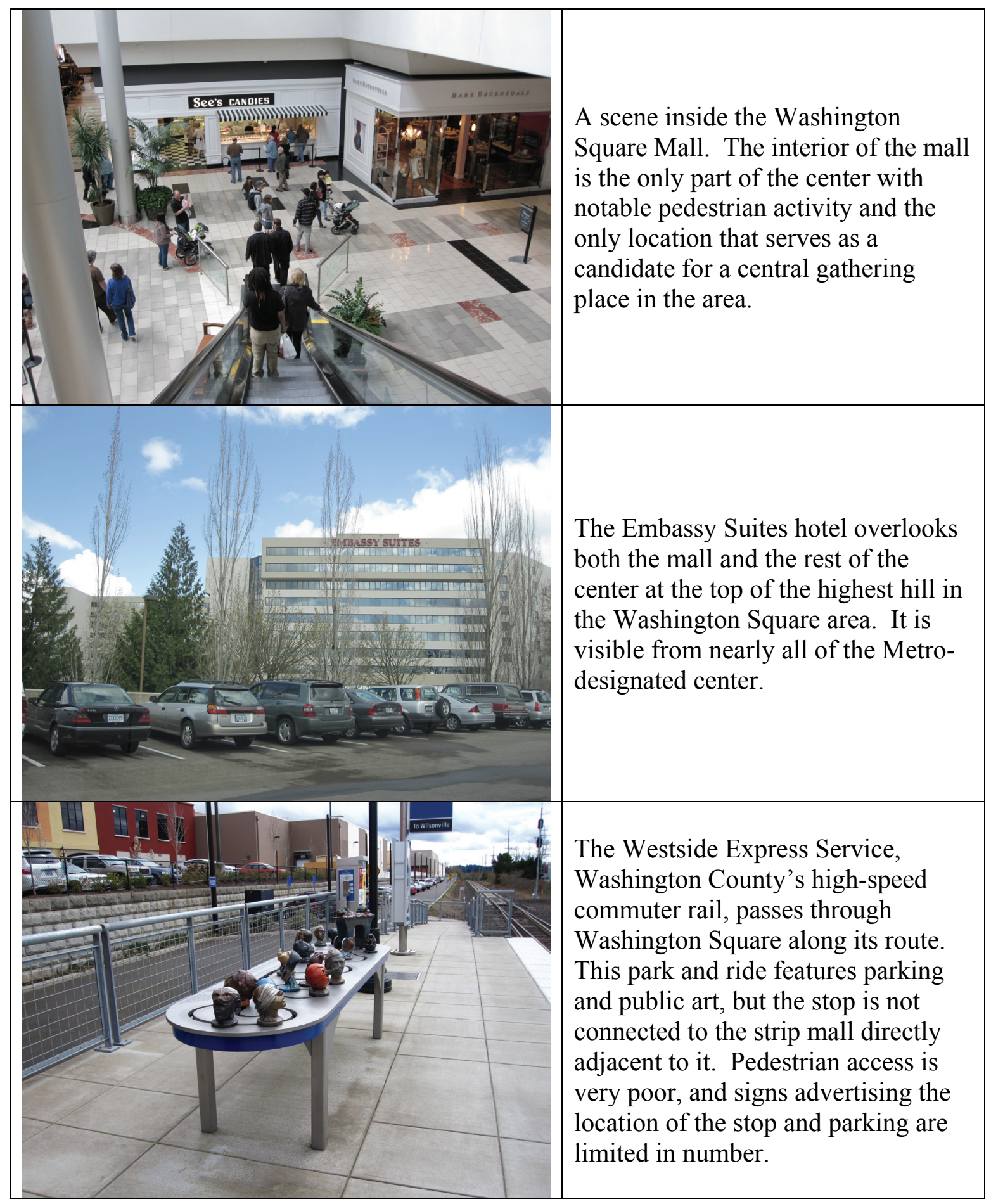




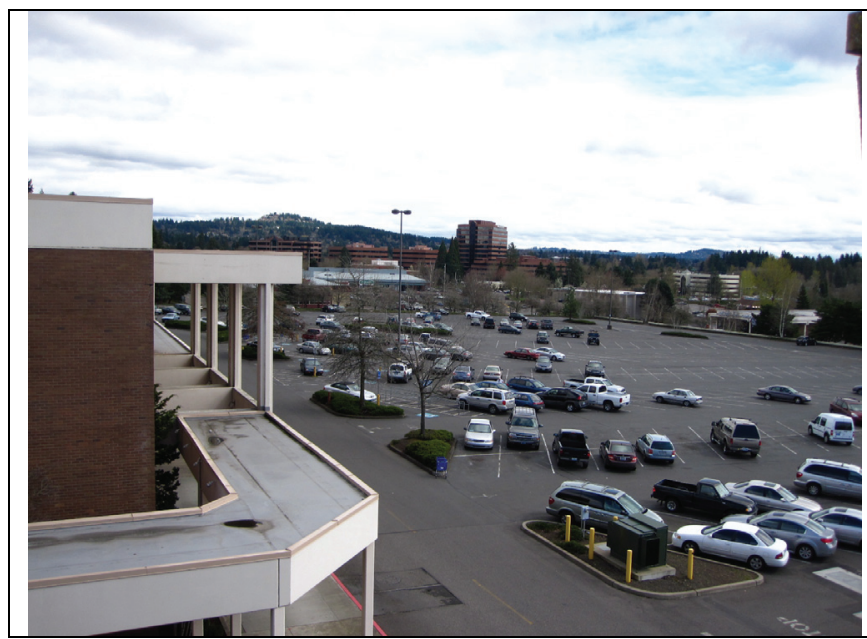

This expanse of parking outside of the Washington Square mall combined with the Lincoln Center office towers in the distance and the location at the junctions of state Highways 217 and 210 almost perfectly fit Joel Garreau's definition of an edge city. 